\title{
The causes and potential mitigating strategies of New Zealand residents' negative perceptions of self-drive tourism, a Theory of constraints (TOC) approach
}

BY

Wing Cho (Joe) Cheung

A thesis submitted to the Victoria University of Wellington in fulfilment of the requirements for the degree of Master of Tourism

Victoria University of Wellington 


\begin{abstract}
The purpose of this study is to first, explore the causes of New Zealand residents' negative perceptions of self-drive tourism, and second, create potential strategies to mitigate such negative perceptions.

To investigate the two main objectives of this study, the Theory of constraints (TOC) methodology is applied. The power of the TOC methodology is its ability to understand a complex phenomenon via presentations of logic trees. In this study, the TOC methodology is applied from the construction of interview guides through to drawing conclusions. Three essential questions namely "Why change?", "What to change?" and "What to change to?" from the change sequence of the TOC methodology are employed.
\end{abstract}

The findings of this study are based on the interview data from four main participant groups (Self-drive tourists, government experts, tourism academic, media, 16 participants in total) as well as surveys of residents' perceptions (Mood of the Nation and Views on Tourism). The results of the first TOC question "Why change?" examined the gap between the "perfect world" and the actual state of the self-drive tourism system, and all participant groups agreed that the current self-drive tourism system is not achieving the "perfect world".

Building on the results of the first TOC question, "What to change?" sought to discover the root causes and core problems via cause-and-effect logic. The causes of residents' negative perceptions are represented in three stages, with infrastructure, driving and self-drive tourism issues in stage 1 (fundamental issues); media issues in stage 2 magnify problems in stage 1 and eventually cause perception issues in stage 3. To address the root causes and core problems, potential mitigating strategies were developed by using the TOC methodology, followed by a logic tree to test the robustness of such proposed strategies, responding to the TOC's "What to change to?" question.

The discussions are mainly consistent with the literature in social psychology, tourism, selfdrive tourism, management, and media studies. This study also makes theoretical and practical contributions. At a theoretical level, this thesis bridges TOC methodology and tourism, to showcase how complex tourism problems can be tackled via such methodology. It also offers a holistic view to the causes of residents' negative perceptions, and mitigating strategies are designed to address the problems holistically, rather than a piecemeal approach dealing with a few symptoms at a time. At a practical level, this study offers stakeholders with logic maps depicting the causes of residents' negative perceptions as well as offering mitigating strategies. 


\section{Acknowledgments}

It has been a long but fruitful journey in the completion of this thesis, there is a number of people I would like to thank wholeheartedly.

My wife, Carol, you have supported me throughout this thesis journey and without you, it would not be the same. Thank you for your caring regardless of my ups and downs.

My first supervisor, Professor Vicky Mabin, you have taught me since the System Thinking paper back in 2017, and it was a great and memorable experience working with you as a student and a tutor. I can not express enough with my gratitude that you have not only guided me with the completion of this thesis, but also inspired me with wonderful ideas that I would not have thought of, and of course, your optimistic vibe has certainly influenced me!

My second supervisor, Associate Professor Ian Yeoman, you have also taught me since the beginning of tourism papers in 2017, and it was definitely an amazing experience working as a student and a tutor with you. Your professional knowledge in tourism was a torch leading my thesis to the correct direction. Without you, it would be challenging for me to know if I am writing tourism! Thank you, Ian!

My peers, Diana Kham, Ari Chen, Ao Zhou and Cindy Li. There are countless great memories with you all, from really stressful days to drinks at pub nights. You all are amazing!

Dr. Sarah Kimani, your PhD thesis have helped and inspired me greatly when I am stuck when writing my thesis. Thank you!

Last, a special thanks here to the team of Angus and Associates, especially Christopher Joyce. You all have supported me with updated tourism information and did not hesitate to provide me help when needed. I feel grateful to be a part of the team!

\section{Thank you!}




\section{Table of contents}

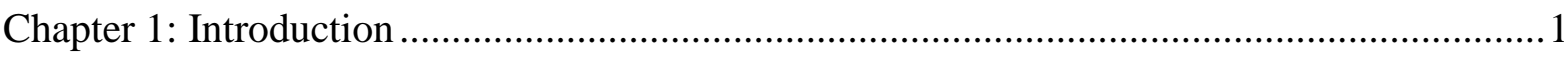

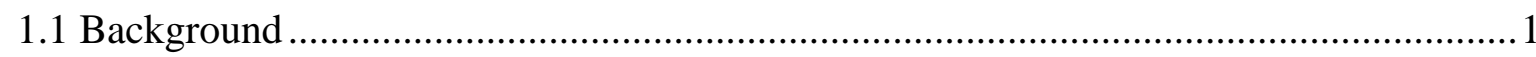

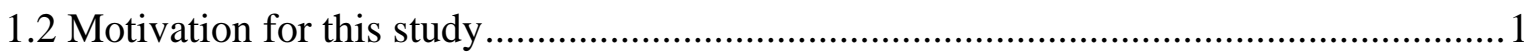

1.3 Self-drive tourism background in New Zealand .................................................... 1

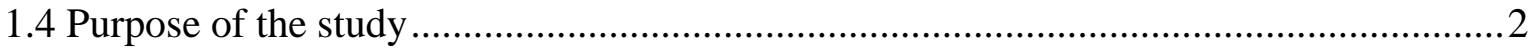

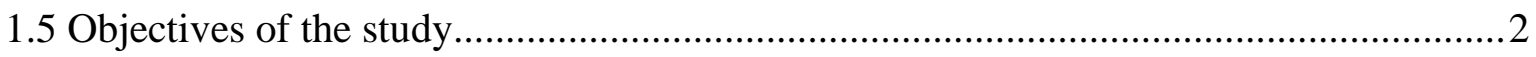

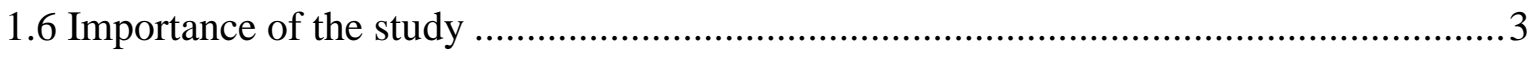

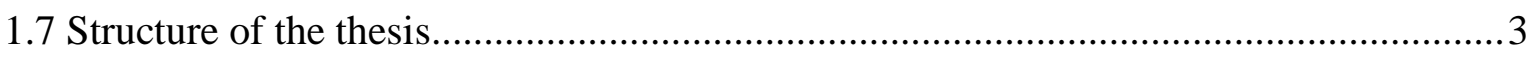

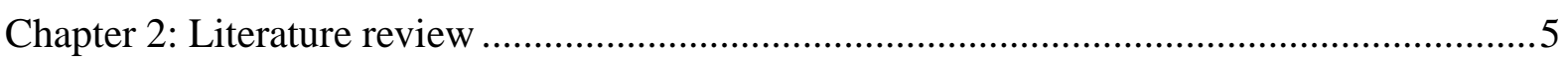

2.1 Perception studies in social psychology and tourism ......................................... 6

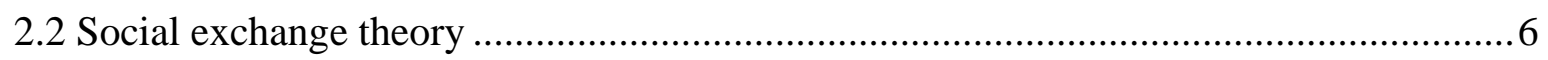

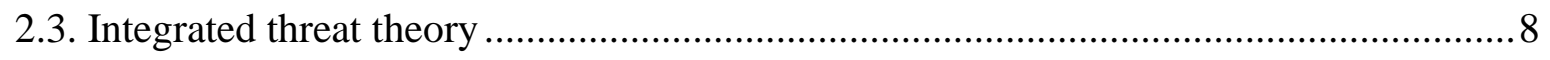

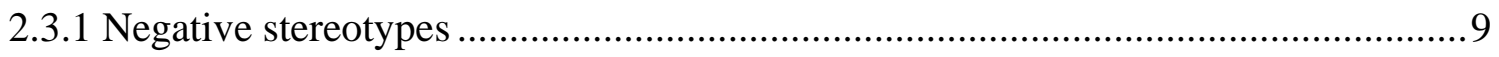

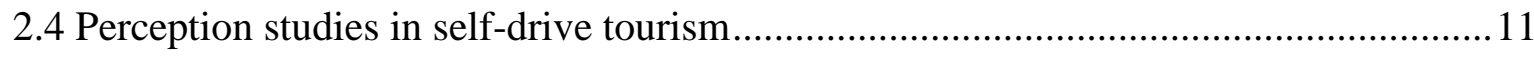

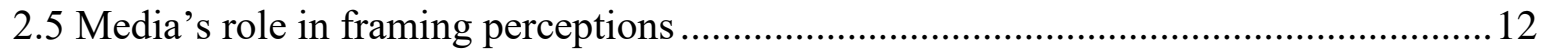

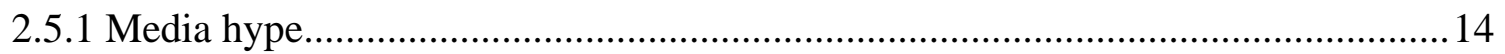

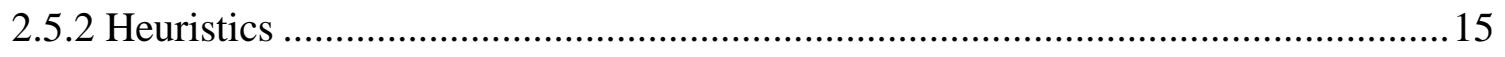

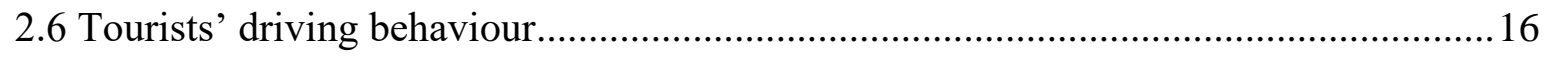

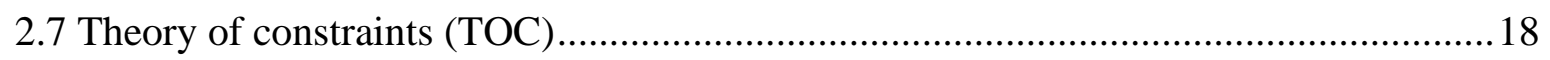

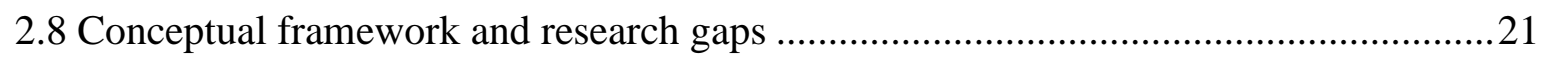

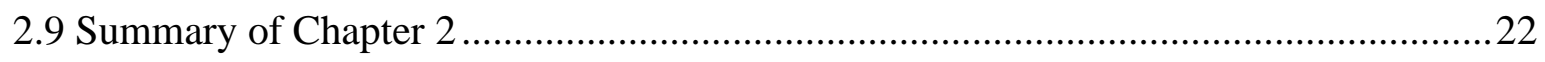

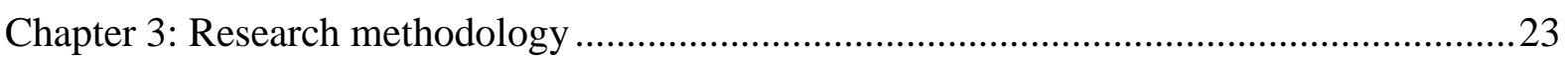

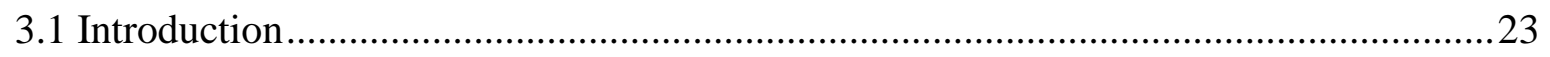

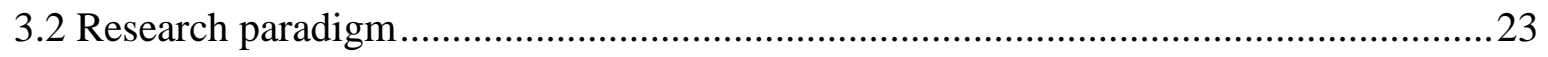

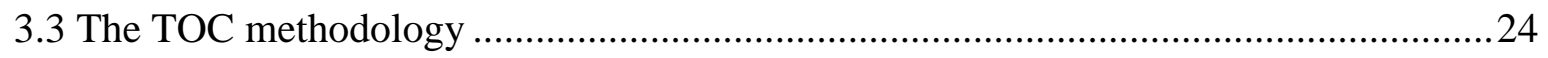

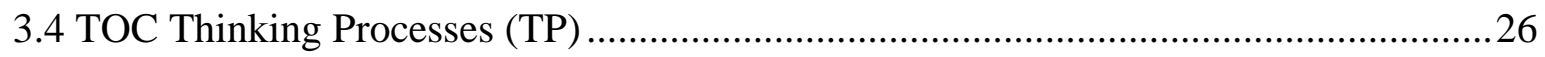


3.4.1 Why change?

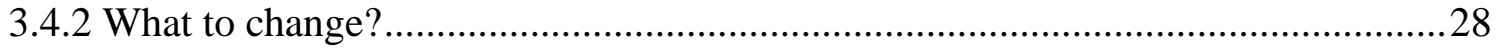

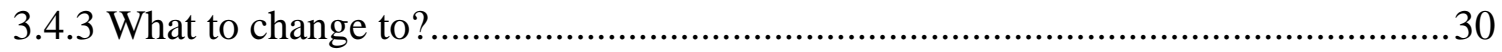

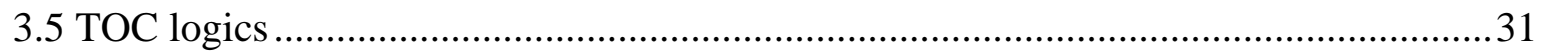

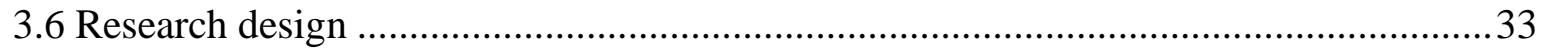

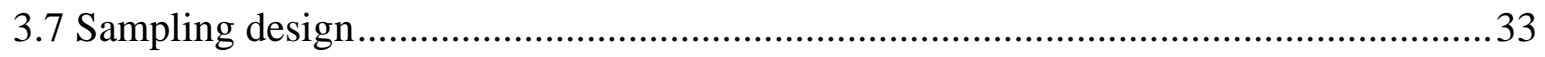

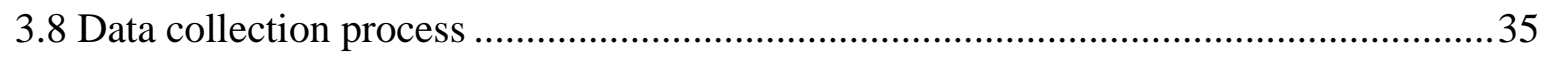

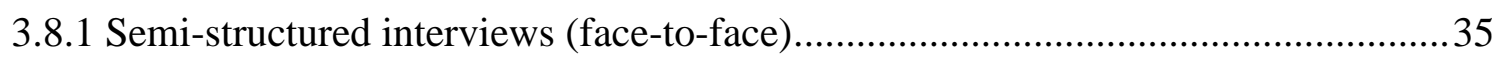

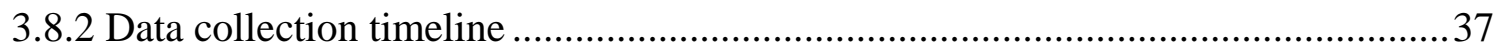

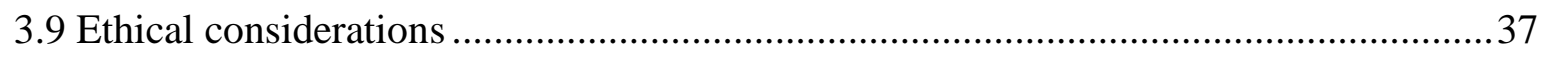

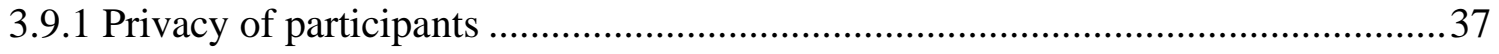

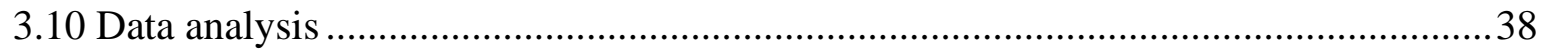

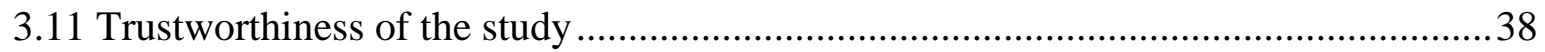

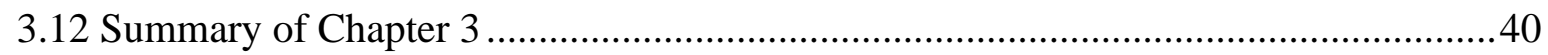

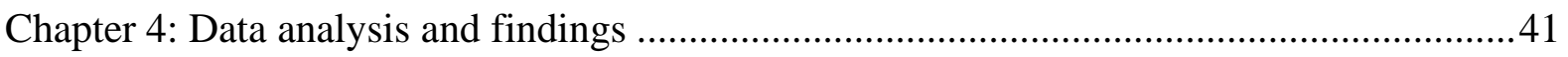

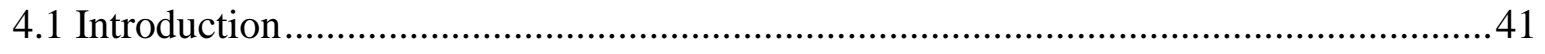

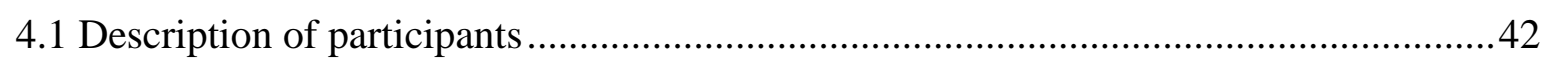

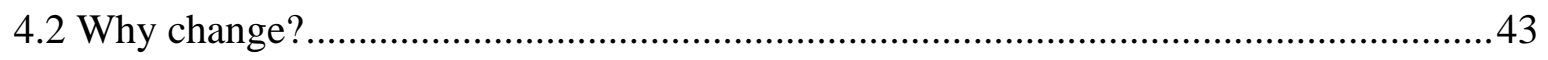

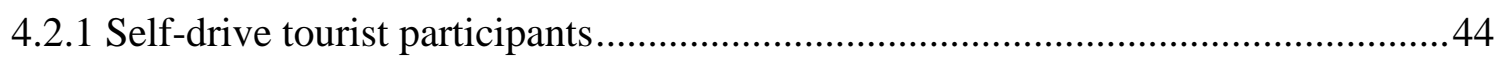

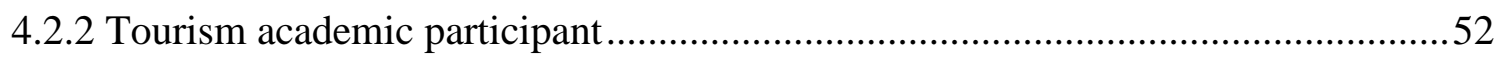

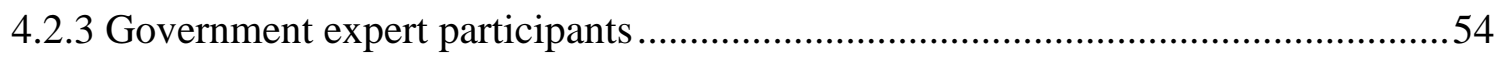

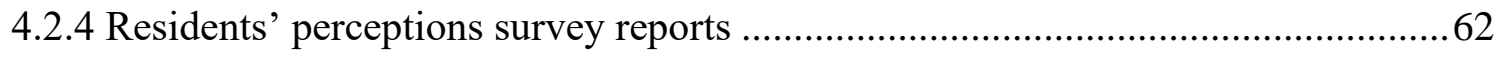

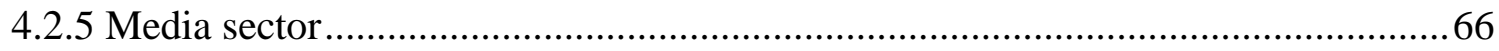

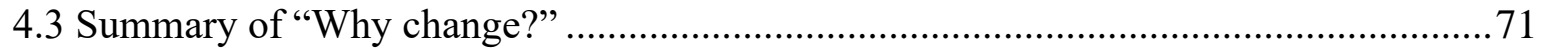

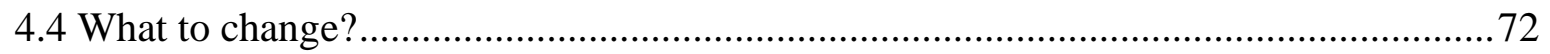

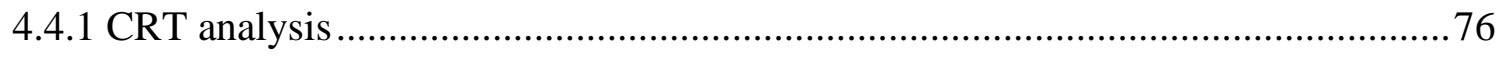

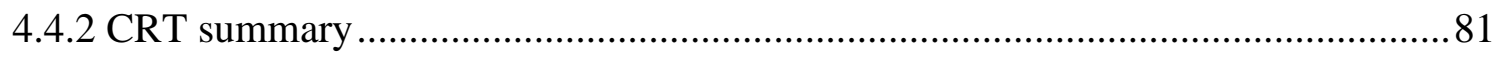


4.4.3 EC analysis. 82

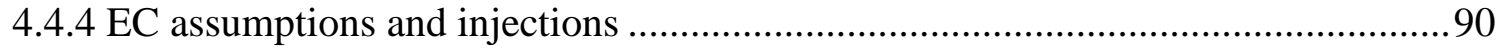

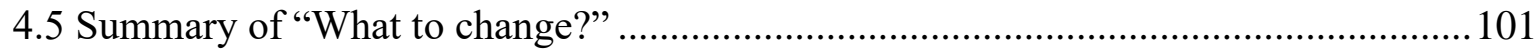

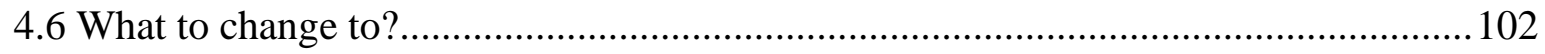

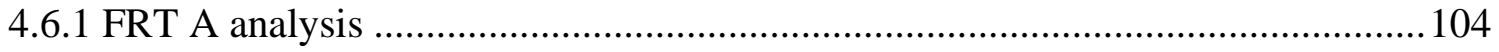

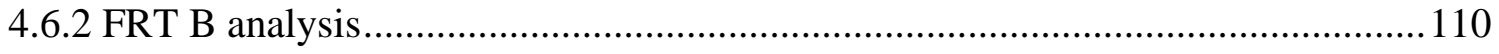

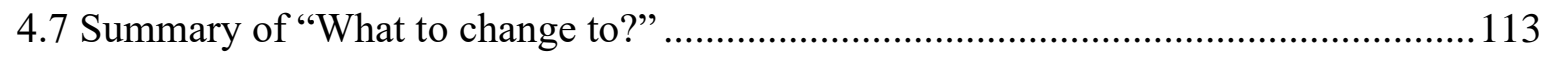

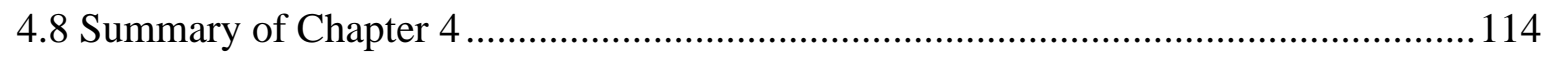

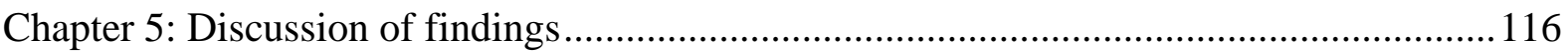

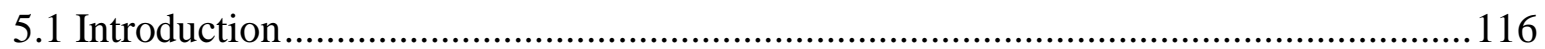

5.2 The causes to residents' negative perceptions of self-drive tourism ...........................116

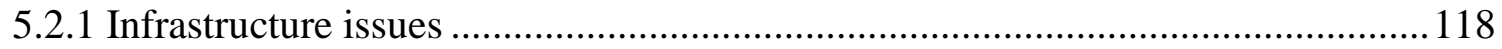

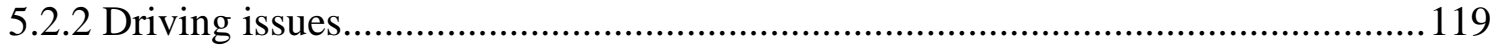

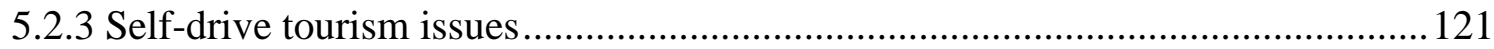

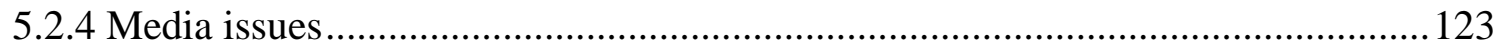

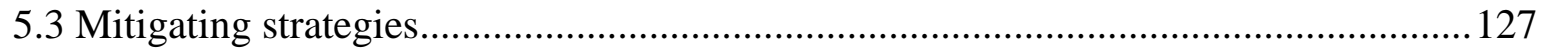

5.3.1 Mitigating strategies for infrastructure issues .............................................. 131

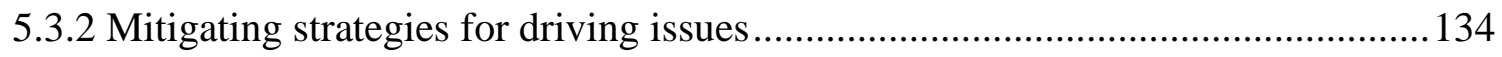

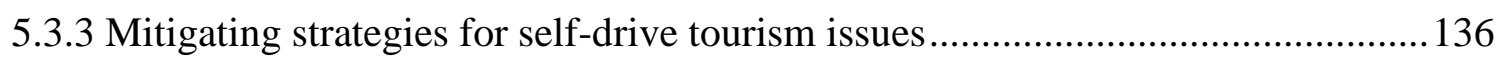

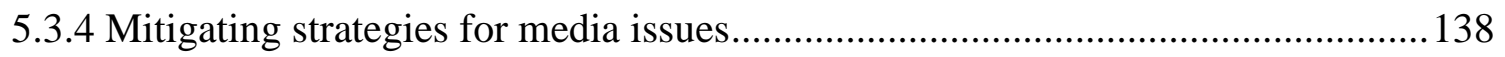

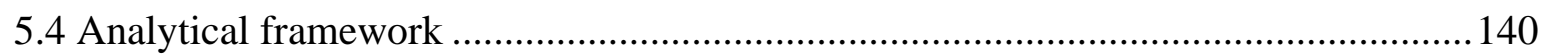

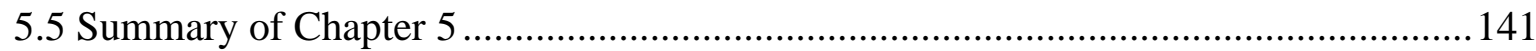

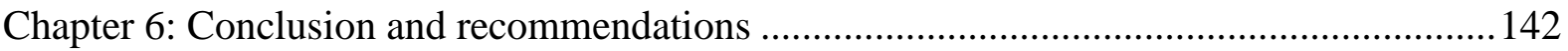

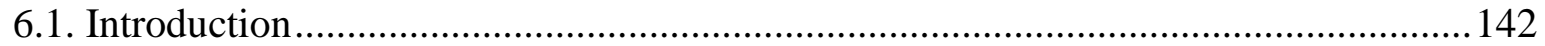

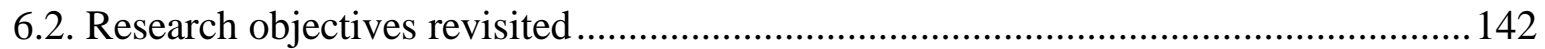

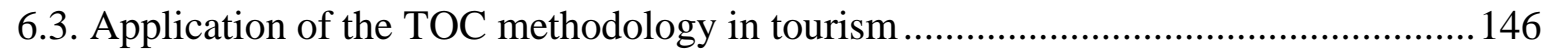

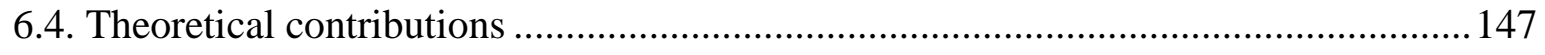


6.4.1 Practical contributions

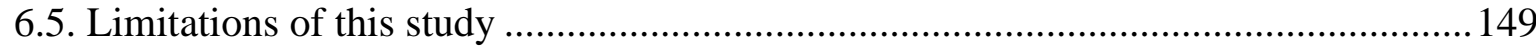

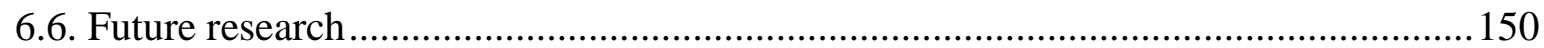

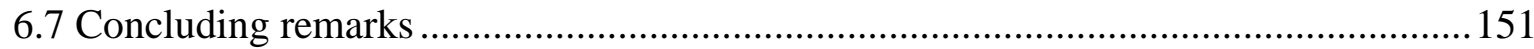

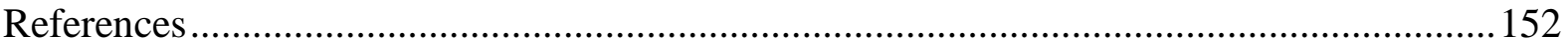

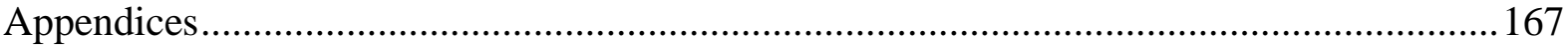

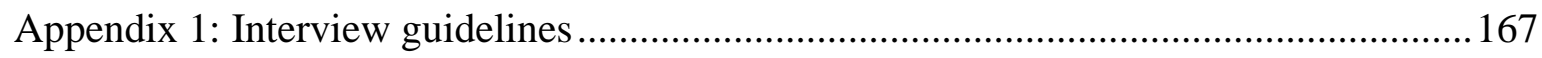

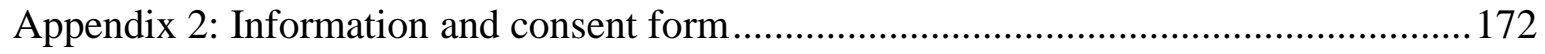




\section{List of tables}

Table 3. 1: Categories of Legitimate Reservation (CLR) …...............................................35

Table 3. 2: Participant's attributes ................................................................................ 39

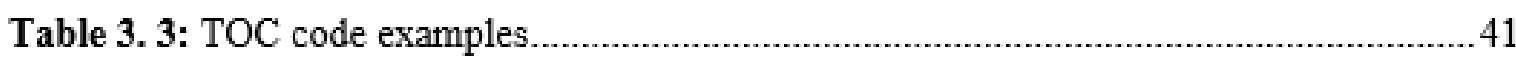

Table 4. 1: Descriptions of self-drive tourist participants...............................44

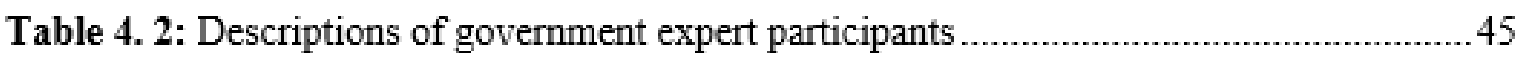

Table 4. 3: Descriptions of self-drive tourist participants' goal ........................................ 47

Table 4. 4: Descriptions of self-drive tourist participants' CSFs and NCs............................4 48

Table 4. 5: Descriptions of self-drive tourist participants' list of UDEs ..............................52

Table 4.5. 1: Refined list of self-drive tourist participants' described UDEs ...........................53

Table 4. 6: Descriptions of tourism academic participant's list of UDEs .............................55

Table 4.6. 1: Refined list of tourism academic participant's described UDEs ........................56

Table 4. 7: Descriptions of government expert participants' goal......................................57

Table 4. 8: Descriptions of government expert participants' CSFs and NCs .........................58

Table 4. 9: Descriptions of government expert participants' list of UDEs............................62

Table 4.9. 1: Refined list of government expert participant's described UDEs .....................64

Table 4. 10: Descriptions of New Zealand residents' list of UDEs......................................68

Table 4.10. 1: Refined list of New Zealand resident's described UDEs ................................69

Table 4. 11: Descriptions of non-commercial media's goal, CSFs and NCs ......................... 70

Table 4. 12: Descriptions of commercial media's goal, CSFs and NCs ................................ 71

Table 4. 13: Descriptions of media participants' list of UDEs ............................................ 73

Table 4.13. 1: Refined list of media participant's described UDEs ..................................... 74

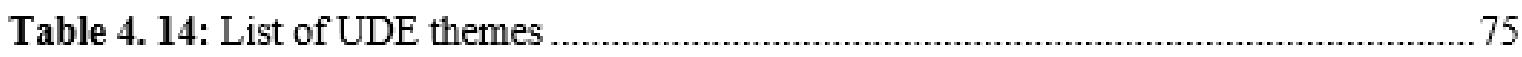

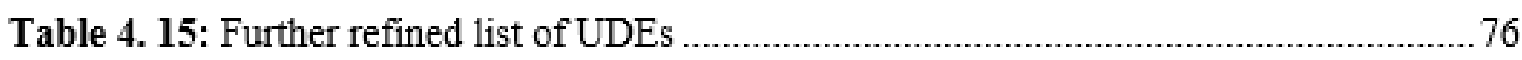

Table 4. 16: Participants' described conflicts .................................................................. 86

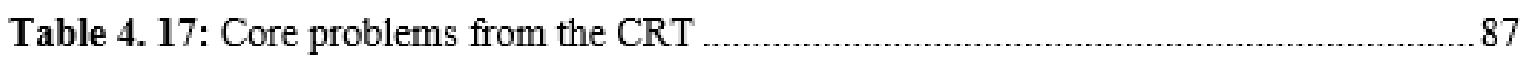

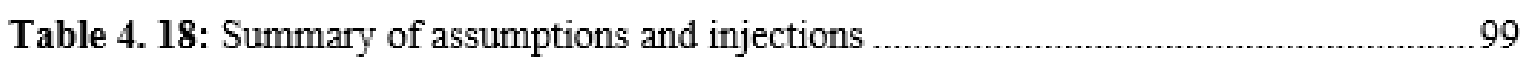

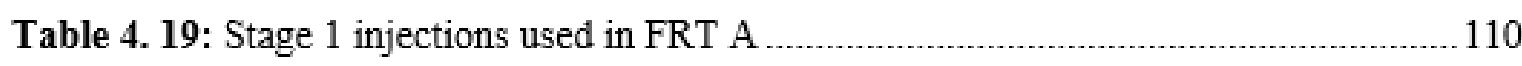

Table 4. 20: Stage 2 and 3 injections used in FRT A ................................................ 112

Table 4. 21: Stage 1 injections used in FRT B ......................................................... 116

Table 5. 1: Summarised mitigating strategies from surfacing $\mathrm{ECs} \ldots \ldots \ldots \ldots \ldots \ldots \ldots \ldots \ldots \ldots \ldots$ 


\section{List of Figures}

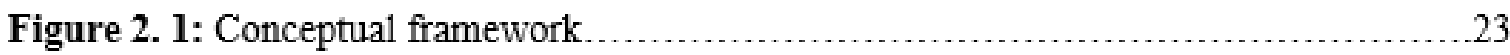

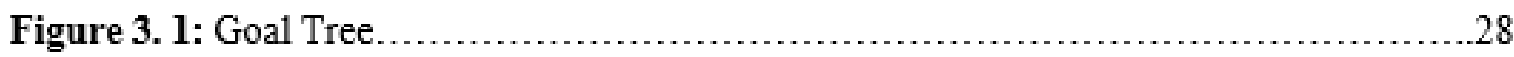

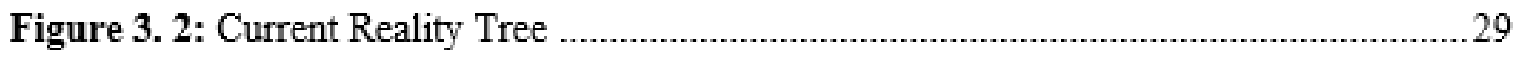

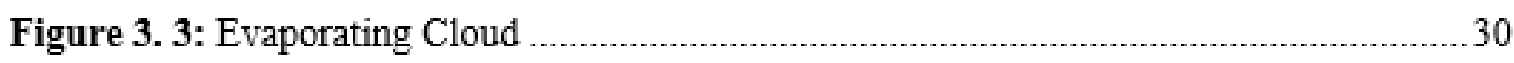

Figure 3. 4: Future Reality Tree …......................................................................... 31

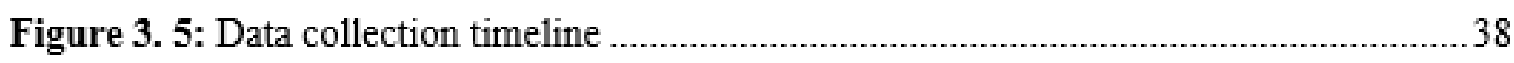

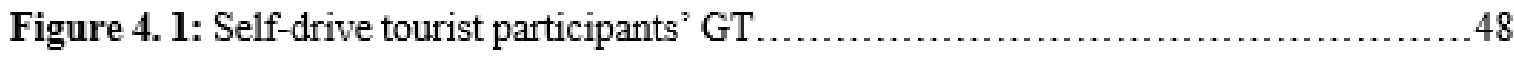

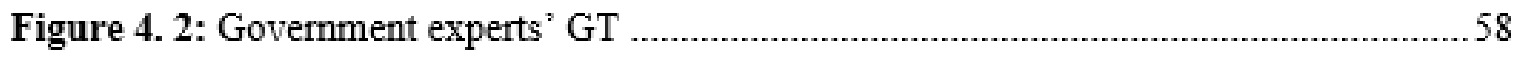

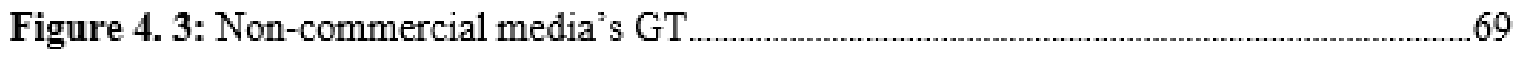

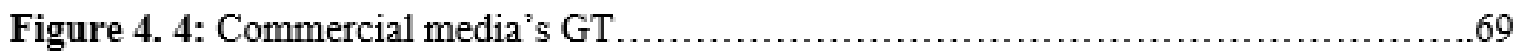

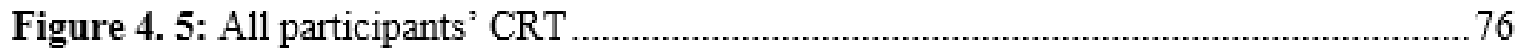

Figure 4. 6: Government's EC

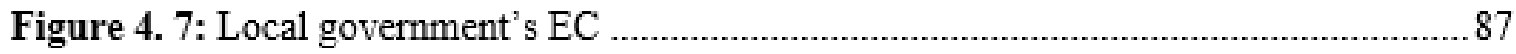

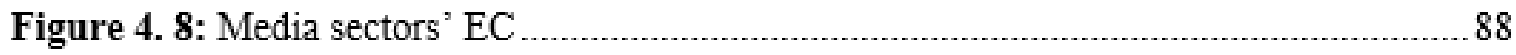

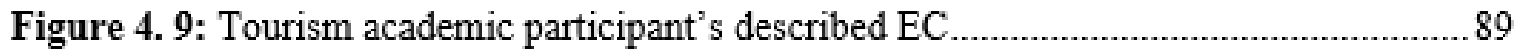

Figure 4. 10: Self-drive tourist participant's described EC ….........................................90

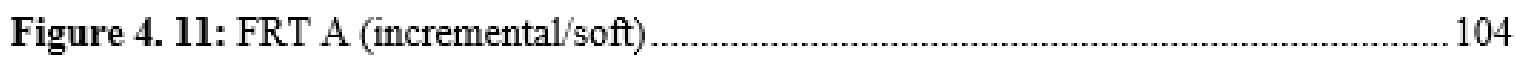

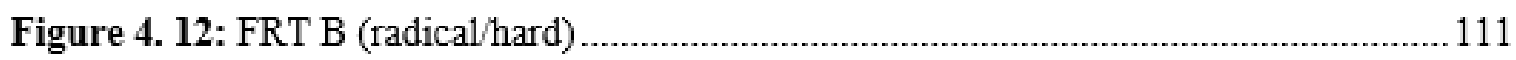

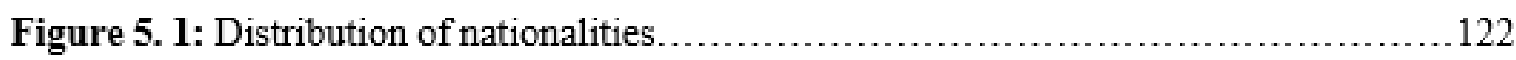

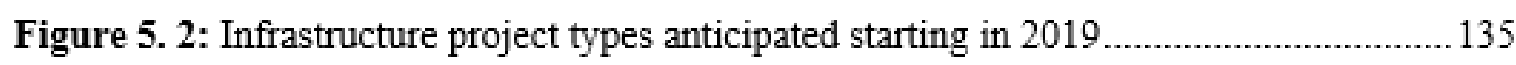

Figure 5. 3: Analytical framework of this study's results .......................................... 143 


\section{List of Acronyms}

CLRs Categories of Legitimate Reservation

CSFs Critical success factors

CRT Current Reality Tree

DEs Desirable effects

EC Evaporating Cloud

FRT Future Reality Tree

GT Goal Tree

HEC Human Ethics Committee

MBIE Ministry of Business, Innovation and Employment

MFE Ministry for the Environment

MOT Ministry of Transport

NCs Necessary conditions

NZ New Zealand

NZTA New Zealand Transport Agency

TIA Tourism Industry Aotearoa

TNZ Tourism New Zealand

TOC Theory of constraints

TP Thinking processes

UDEs Undesirable effects

VUW Victoria University of Wellington 


\section{Chapter 1: Introduction}

\subsection{Background}

This chapter gives a brief description of the motivation for this study, the background of New Zealand self-drive tourism, the purpose and objectives of the study, and its importance. The chapter ends with an outline of the thesis structure.

\subsection{Motivation for this study}

As a Chinese student and a holder of a New Zealand driver licence for nine years, I love to self-drive. I often encounter people who seem "lost" when driving and can feel myself becoming frustrated with their driving (e.g. driving slowly). I found myself stereotyping all vehicles that were slow and had a rental car sticker on them as being driven by tourists.

Why do I have this negative perception that all rental cars are driven by tourists and further, the tourist is more likely to be involved in car crashes and/or dangerous driving without considering that the vehicle may be being driven by a local driver? Through discussions with peers, it seems these negative perceptions of self-drive tourism are generally held by many local drivers and have been reported extensively by the media.

Thus, the motivation to do this study is an attempt to understand why people perceive selfdrive tourism as they do.

\subsection{Self-drive tourism background in New Zealand}

Self-drive tourism is defined as "tourism that centres on travelling from an origin point to a destination by car that is either privately owned or rented, and engaging in tourism-related activities during the journey" (Prideaux \& Carson, 2003, p.308).

Self-drive tourism is promoted by Tourism New Zealand (TNZ). Advertising slogans, like "With gorgeous, ever-changing scenery and so many amazing things to see along the way, you will want to stop often, and self-drive will let you do just that", are used to attract international and domestic visitors (TNZ, 2020). Statistics New Zealand (Stats NZ) recorded that in 2019, out of 3.88 million international visitor/tourist arrivals, 1.4 million of those rented a vehicle (Stats NZ, 2020). 
While self-drive tourism is a vital contributor to New Zealand's economy, tourists' self-driving is perceived negatively by residents, who express concerns about road related issues (Kantar, 2018). News items often report self-drive tourism in a negative light. These negative perceptions of self-drive tourism are worthy of investigation, to find ways to restore and/or build a positive relationship between residents and self-drive tourism.

\subsection{Purpose of the study}

The purpose of this study is to understand the causes of residents' negative perceptions of selfdrive tourism, and potential strategies to mitigate them, so that New Zealand may benefit more fully from such tourism.

\subsection{Objectives of the study}

The objectives of this study are twofold: to investigate the causes of residents' negative perceptions of self-drive tourism; and to develop strategies to mitigate these negative perceptions. To achieve these two objectives, this study is driven by five sub-objectives.

1. To identify the self-drive tourism system's goal(s), then to identify the critical success factors and necessary conditions to achieve the goal(s).

2. To identify the self-drive tourism system's undesirable effects and examine if there are any gaps preventing the system's goal(s) from being achieved.

3. To identify the causes of residents' negative perceptions of self-drive tourism via causeand-effect logic.

4. To identify and propose strategies to mitigate residents' negative perceptions of selfdrive tourism.

5. To explore the use of the Theory of constraints (TOC) methodology in tourism academic studies. 


\subsection{Importance of the study}

The study makes several important contributions:

1. Relationships between residents and tourists are complex and dynamic as stated by Sharpley (2018). There appears to be a lack of academic studies to understand why residents bear negative perceptions. Using the TOC methodology, the study allows a holistic analysis of residents-self-drive tourism relationship.

2. TOC methodology does not appear to be applied widely in the tourism sector. This study aims to fill the gaps to not only understand the "why" factor, but also illustrate TOC's usefulness in tourism.

3. The TOC methodology and tools provide a different approach to standard qualitative data analysis, contributing to a system based qualitative research methods.

4. Self-drive tourism in New Zealand has been under criticism and negative perceptions appear to have been formed. This study presents stakeholders an understanding of the causes of these negative perceptions and potential mitigating strategies.

\subsection{Structure of the thesis}

This thesis is divided into six chapters:

Chapter 1: Introduction, has discussed the motivation, given a background to New Zealand self-drive tourism, and has outlined the purpose, objective, and importance of this study.

Chapter 2: Literature review, provides a review of the literature which includes discussion on perception studies in tourism and possible causes that can influence perceptions. The aim of this chapter is to validate and highlight any research gaps. The TOC methodology will then be introduced to explain its suitability for exploring the causes and identifying potential mitigating strategies.

Chapter 3: Research methodology, provides the philosophical world view of this study. It then depicts detailed descriptions of the data collection process, data analysis, and a discussion on the trustworthiness of this study.

Chapter 4: Data analysis and findings, wherein the data is analysed, and the findings are presented. This chapter is guided by the research objectives and sub-objectives. First, the goal(s), critical success factors and necessary conditions are determined. Next the lists of undesirable effects are compared with the first step to discover if there are any gaps. The third step is to understand the cause-and-effect relationships of residents' negative perceptions. 
Finally, using the outcomes that surface from the aforementioned data analyses, strategies are suggested to mitigate these negative perceptions. This chapter will also show how TOC methodology can be applied in qualitative data analyses.

Chapter 5: Discussion of findings, wherein the findings will be discussed and compared with the literature surfaced in Chapter 2. Additional sources are provided where relevant to support the mitigating strategies and to address the other issues that emerged in the findings.

Chapter 6: Conclusion and recommendations, the final chapter, presents a summary of the key findings regarding the research questions, the application of TOC methodology in tourism, theoretical and practical implications, the limitations of the study, and future research. 


\section{Chapter 2: Literature review}

The goal of this literature review is to identify and critically review literature that is relevant for studying residents' perception of self-drive tourism and potential causes of such negative perceptions. Perception has been extensively researched in various disciplines, especially psychology and more recently, tourism. Moreover, due to media news stories consistently reporting on negative tourist driving and residents' opinion of them, this has shifted the study of perceptions, showing a need for future investigation on perception, especially on how media may influence perceptions.

That said, an initial search on Google Scholar revealed over 2,500 published articles which have studied residents' perception of tourism/tourists, including many other perception studies in the field of psychology (Google, 2020). A review by Sharpley (2014) noted that reviewing all tourism literature on residents' perception of tourists would be a difficult, if not an impossible task (p.42); this statement remains current. Therefore, this literature review is to determine what needs to be included in order to generate a fundamental background for this study of the causes of negative perceptions.

The first part of this review will explore perception from social psychology and tourism studies. The second part will aim to understand the social exchange theory and integrated threat theory from tourism, and how these two theories have been applied to study perception through the lens of resident-tourist relations. The third part will be exploring other possible factors that may influence perception, drawing on self-drive tourism, media and tourist driving behaviour literatures. Fourth, the theory of constraints literatures will be reviewed to examine what research in tourism studies have used the theory of constraints methodology. Last, a conceptual framework will be produced highlighting the research gaps and focus of this study.

It is important to highlight that literature about mitigating strategies are not included in this chapter. These strategies will be developed in Chapter 4 (Data analysis and findings) following the TOC methods. Cross-checks will be made with appropriate literature to examine if the strategies have been proposed before and/or to collect evidence that they can mitigate negative perceptions. 


\subsection{Perception studies in social psychology and tourism}

Psychological studies of human behaviour commenced with the investigation of perception in 1879 (Otara, 2011). According to Lindsay \& Norman (1977), perception is defined as the process in which way something is interpreted, understood, and organised to produce a meaningful experience of the world. Pickens (2005) explained perception as occurring when a situation or stimulus confronted by a person, such stimulus is interpreted into something meaningful based on previous experience. Perception is the way in which people interpret experience and different people experience a situation, sensation or personal experience in different ways (Otara, 2011).

In tourism studies, research on psychology and perceptions in tourism has focused on social perception and social cognition, referred to as the core building blocks of social psychological processes (Pearce \& Stringer, 1991). Fiske (1993) and Pearce and Stringer (1991) summarised the process of social psychology as the way a person obtains and organises knowledge of the society. Perception studies of tourism date back to the late 1970s (e.g. Rothman, 1978; Thomason et al., 1979). Since then, a significant number of studies have been published on this subject.

\subsection{Social exchange theory}

A number of theories such as social exchange theory and integrated threat theory have been applied in tourism perception studies to explain the positive and/or negative perceptions of residents towards tourism. In earlier studies, the employment of social exchange theory is pervasive throughout the studies of host perception, to explain the positive and/or negative perception of residents (Sharpley, 2014). According to this theory, if residents perceive the benefits of tourism are greater than the costs of tourism, then residents are likely to show support (Andereck et al., 2005). In contrast, if tourism cost is greater than its benefits, negative perceptions are likely to form and resident support on tourism will diminish (Andereck et al., 2005). Social exchange theory contributes to the understanding of how residents' perceptions are influenced, positively or negatively, depending on the weight of perceived tourism benefits and costs.

Social exchange theory research concerning perception is also mostly focused on either touristresident perception or resident-tourist perception (Shone et al., 2003; Andereck et al., 2005; 
Dorcheh \& Mohamed, 2013; Litvin et al., 2019; Hsu \& Chen, 2019). Academic attention has been directed to the economic, social-cultural and environmental impacts of tourism, and to the understanding of residents' perceptions of tourism/tourists in general (Sharpley, 2014). These studies provide solid evidence that residents typically have positive attitudes towards tourism because of the economic benefits (e.g. Rasoolimanesh et al., 2015), while also revealing tourism impact factors such as traffic congestion or exacerbating overcrowding are perceived negatively by residents (e.g. Almeida et al., 2016; Muresan et al., 2016).

The advantage of social exchange theory is its linear and sequential process through simple calculations of costs and benefits (Ap, 1992; Sharpley, 2014). To exemplify this, Ap (1992) stated that tourists and residents are identified as having a need to be satisfied and are motivated to engage in the exchange process. For the exchange process to be successful, both parties need to achieve satisfactory outcomes (Ap, 1992). In other words, social exchange suggests that tourists and residents are expecting a win-win negotiation, ultimately leading to satisfactory outcomes (Sharpley, 2014). However, social exchange could be perceived negatively without any exchange if the process is not considered equalised or if the expected benefits were not delivered (Sharpley, 2014).

Indeed, tourism is fundamentally host-guest relations and a social phenomenon, as Sharpley (2014) defined, "it is about people interacting with other places and other people, undergoing experiences that may influence their own or the host community's attitude, expectations, opinions and, ultimately, lifestyles"(p.38). In other words, on the one hand, the fulfilling and memorable tourist experience, and on the other hand, positive or negative impact experienced by the residents, which construct the residents' perceptions of tourism and tourists (Reisinger \& Turner, 2002; Sharpley, 2014). Further illustration by Sharpley (2018) summarised the hosttourist relations as interactions and experiences, outlining various potential factors that might influence the perceptions of residents, depending on how they are impacted by tourism, subsequently implying that the relationships between hosts and tourists are complex and dynamic. Yet, perception studies in tourism have been criticised for not capturing the relationships that exist between resident and tourist, that is, how residents on an individual level feel about tourists. Indeed, many of the variables only concern phenomena that are inadequate for capturing relationships (Woosnam, 2012, p.316).

Meanwhile, several researchers have raised questions concerning the usefulness of social exchange theory for explaining the factors influencing residents' perceptions (Pearce et al., 
1996; Sharpley, 2014). Pearce et al. (1996) criticised the theory for its assumption that humans are considered as isolated individuals and they respond like computer information processors (p.34). Woonsnam (2012) and, Hsu and Chen (2019) pointed out that the theory is oversimplified, calculated through a linear process, and does not consider the complex and dynamic host-tourist relations. Woonsnam (2012) highlighted that deeply held feelings between residents and tourists were not included when using social exchange theory.

Notwithstanding these criticisms, social exchange theory does generate a good framework of how positive and negative perceptions may be formed, and understanding such formations is beneficial for discovering the "why". Although the "why" factors are not extensively explained in the various literatures, many studies using social exchange theory were able to explain the relationships between different factors and how they may influence the way residents perceive tourism (e.g. Gursoy et al., 2009; Ward \& Berno, 2011; Bimonte \& Punzo, 2016; Hadinejad et al., 2019; Hsu \& Chen; 2019). For example, tourists are perceived negatively by residents due to traffic congestion and road accidents, measured by the social exchange theory as a cost (Gursoy et al., 2009). This implies traffic congestion and/or road accidents may be the "what" factors which are causing such negative perception of self-drive tourism. Yet, what factors have not been discussed adequately as the root causes or subsequent effects of these factors (e.g. traffic congestion), due to these studies' methodological or theorical limitations.

As discussed, social exchange theory helps explain how residents perceive tourism based on the costs and benefits between the two groups; such cost factors may be considered the cause of negative perception. To address the criticism that social exchange theory considers humans are isolated individuals and respond like computer information processors (Pearce et al., 1996), integrated threat theory incorporates an emotional dimension of intergroup relations, that is discovered to be a critical component of interaction between host and tourist (Ward \& Berno, 2011). Monterrubio (2016) concurs, stating that integrated threat theory contributes to greater understanding of residents' views towards tourism.

\subsection{Integrated threat theory}

In recent research, integrated threat theory has drawn academic attention to explain how residents negatively perceive tourism (Monterrubio, 2016; Litvin et al., 2019; Hsu \& Chen, 2019). A psychology-based theory, the integrated threat theory noted that the level of threat is dependent on the type, amount and quality of contact between interacting groups. Thus, if a 
resident had prior negative experience with an outgroup member (e.g. tourist), the resident is more likely to feel threatened with members of the outgroup in future contacts (Monterrubio, 2018). Likewise, Aberson (2015) stated that the theory addresses the relationships between interactive experiences and negative attitudes, proposing that with outgroup members result in feeling threatened by the in-group members (p.744). In essence, the theory assumes that a negative experience with an outgroup member has already occurred, and contact plays a distinct role in examining one's perception to another, because it generates more direct and immediate information about the other group (Stephan \& Stephan, 2000).

\subsubsection{Negative stereotypes}

Under the integrated threat theory, negative stereotypes can be considered as the most relevant variable in this case of perception and self-drive tourism. According to Stephan and Stephan (2000), because negative expectation, conflictual or unpleasant interaction are likely to be anticipated between residents and outgroup members (e.g. tourist), residents consider almost all outgroup stereotypes are a threat to them (p.27). In similar vein, ethnic stereotyping has been given specific attention in the studies of tourism, discussing how stereotyping is applied to foreign outgroup members (Pearce \& Stringer, 1991). Basically, stereotyping arises when an individual applies a set of traits to someone who is considered as an outgroup (Ratliff \& Nosek, 2011). It has also been discovered that individuals tend to target and apply stereotypical traits on outgroups that are homogeneous, compared to target outgroups that are heterogeneous (Simon et al., 1990). This is not only limited to ethnicity: outgroups who share similar interest, age, gender or behaviour could be segmented as homogeneous, compared to outgroups who have different attributes (Pearce \& Stringer, 1991; Tung et al., 2019). Stereotypes are considered to influence individual perceptions of others, thus affecting how people interpret other's behaviour and how people treat others (Duncan, 1976).

Indeed, negativity in tourism is not a new phenomenon, as residents are worried about the negative impact of tourism and often convey such emotions of anger, fear or sadness (Yeoman \& McMahon, 2020).

An illustration of NZ residents displaying negative stereotyping of tourist driving can be seen through comments in blogs, such as TripAdvisor, which are often prejudiced against tourists. 
For example, a Nelson resident posted about his/her unpleasant contact with a tourist while driving on the open road. The post soon sparked a volley of replies from other residents throughout New Zealand and other countries, agreeing and reinforcing the idea that tourists are dangerous drivers (Tripadvisor, 2019a). Ironically, limited posts have raised concerns about domestic drivers despite studies showing that domestic drivers crash for the same reasons as tourist drivers, suggesting domestic drivers are not much better than tourist drivers (MOT, 2017, p.7). Furthermore, residents commenting negatively about tourists are also found in general questions like road-trip planning (Tripadvisor, 2019b). These suggest that residents' concerns tend to question the competence of tourist driving, rather than also reflecting on their own driving behaviour and skills, indicating negative stereotyping of tourists who self-drive and reflecting how stereotypes are strongly linked with prejudice and racism as Stephan and Stephan (2000) suggested.

Extending the work of ethnicity stereotyping in the context of tourism, Pearce \& Stringer (1991) also agree that tourist stereotyping is about residents' prejudices of tourists in the destination setting (Tung \& King, 2019). MacCannell (1984) argued that due to the peculiar characteristic and fleeting nature, the relationships between resident and tourist are particularly vulnerable to formation of stereotypes, negative perceptions and behaviours. In contrast, it is equally important to acknowledge that stereotyping could be possibly developed in a positive light, as Evans-Pritchard (1989) suggested, "Stereotypical images can operate to defend and protect as well as to discriminate” (p.89). However, concurring with MacCannell's argument, van Veelen et al. (2016) pointed out that tourist stereotyping tends to have an inimical effect of biasing perception, therefore contributing more to discrimination and prejudices rather than to defend and protect. Whilst stereotypes may develop positively and negatively, assessing stereotyping can provide an understanding of how perceptions and behaviours are formed as a consequence of mutual biases between residents and tourists.

Broadly speaking, perception studies in tourism are either focused on resident-tourist or touristresident relations in tourism impact and development. The results of these academic studies depicted how residents generally feel about tourism, such as employment, crime rate or transportation (for example see Sinclair-Maragh et al., 2015). However, these studies did not generate insights on specific tourism phenomena such as self-drive tourism, in the sense of how residents feel about self-drive tourism. Moreover, most of the research on host/resident perceptions use quantitative methods to test the relationships between variables that influences residents' perception of tourism (Sharpley, 2014). The limitation of these quantitative methods 
is that they only describe what residents perceive but do not provide answers explaining "why" (Sharpley, 2014). Therefore, as Deery et al. (2012) and Sharpley (2014) suggested, more qualitative studies are needed to investigate in depth feelings of residents.

Arguably, these academic studies did document large numbers of studies producing variables and outcomes; Lankford and Howard (1994) highlighted an almost infinite variety of procedures for measurement and research paradigms have been applied to examine residents' perception. Still, perception studies, specifically on resident-tourist relations in self-drive tourism, are not well explored, and indeed appear to not have been studied directly.

\subsection{Perception studies in self-drive tourism}

Perception studies in self-drive tourism generally fall into two groups, covering either the tourists or destinations' attractiveness perspectives. Prideaux and Carson (2003) observed that many studies have focused on how to attract self-drive tourists or self-drive tourism route developments, while others have explored driving experiences, policy, safety and regional development. A search of recent studies in self-drive tourism and perception literatures shows little has changed since 2003. For example, Coghlan and Prideaux (2009) examined tourists' motivations, attitudes, and perceptions of 4WD-drive tourism in Australia. Dual perspectives from industry stakeholders and potential visitors regarding drive tourism in rural destination development were studied by Meng and Hudson (2016). Likewise, other researchers have primarily focused on investigating factors such as tourist motivations, behaviour or decision making from the tourists' perspective (e.g. Prideaux \& Carson, 2010; Wu \& Pearce, 2018), suggesting there are opportunities to investigate residents' perceptions of self-drive tourism.

In addition, tourism industry research in New Zealand since 2003 has explored community perceptions of tourism in Christchurch and Akaroa (Shone et al., 2003). Meanwhile, ongoing research such as New Zealand's Mood of the Nation and Views on Tourism surveys also revealed what New Zealanders feel about tourism with some details of residents' perceptions in self-drive tourism (Kantar, 2019; Angus \& Associates, 2019). Compared with academic studies, industry studies revealed a lack of theoretical background. However, these industry studies provide stronger reflection of the current reality. To illustrate, Shone et al. (2003)'s study explored the residents' perception from a real time destination setting, Mood of the Nation surveys are updated every six months to present findings of New Zealanders' most recent perceptions on tourism (e.g. Kantar, 2019). Views on Tourism surveys investigated 
residents' perceptions from an individual level, dedicated to exploring how residents personally feel about tourism (Angus \& Associates, 2019), which to some extent, answers Woosnam (2012)'s call for perception studies at an individual level.

Debatably, these industry studies do indirectly explain residents' perception on self-drive tourism. To illustrate, Shone et al. (2003)'s study concluded that Christchurch residents' top concern is tourists' dangerous driving and road safety. Likewise, one Views on Tourism question on the felt benefits of tourism at an individual level, $73 \%$ of respondents said they felt less safe driving on the road; verbatim comments like "testing the driving ability of the tourist" indicate residents' views on self-drive tourism (Angus \& Associates, 2019). As with academic studies on residents' perceptions, these industry research studies generate insights of how residents perceive tourism, but do not explain "why".

The foregoing review of perception studies under psychology and tourism reveals that psychology studies do provide explanations of how perception is formed, based on external stimuli and personal experiences (Pickens, 2005). Meanwhile, tourist stereotyping explains how people perceive others based on homogeneity and traits, falling under the social psychology process (Pearce \& Stringer, 1991; Tung \& King, 2019). From the theoretical perspective, the social exchange theory and the integrated threat theory also explain the different means that could consequently be influencing how residents feel about tourism.

Many factors have surfaced as possible causes of negative perceptions with extensive research in perception in the psychology/social psychology and tourism literatures. However, these have not investigated these potential causes of negative perceptions to answer the question "why". As one frequently cited possible cause, the media is considered next.

\subsection{Media's role in framing perceptions}

In particular, the role of the media has been discussed quite extensively in the literatures due to their power to influence perceptions and understanding. Negative news about tourism has been a regular topic in mainstream media (Yeoman \& McMahon, 2020). Indeed, extensive news stories about tourist driving in New Zealand have informed and underlined the need for this study. Media factors will be investigated next to understand their impact on residents' perception. 
The mass media holds the symbolic power to construct and diffuse opinions (Weaver, 2018 p.370). As one of the possible causes of residents' negative perception, it is postulated that news stories will have an influence on residents' views, particularly negative stories. Media effects could provide a feasible explanation of how mass media influences the perceptions of audience members (Neuman \& Guggenheim, 2011). Decades of research on media effects have proven that mass media has some extent of influences on audiences, varying from limited to powerful effects (Durfee, 2006). It is also stated in studies that media effects may affect public perceptions, attitudes, emotions and behaviour (Tsfati \& Cohen, 2012; Valkenburg et al., 2016).

Borah (2016) explained that media effect studies in the 1920s and 1930s assumed that audiences' perceptions are directly influenced by mass media; media were powered in shaping one's opinion, attitude and behaviour. However, this is debated by later research which claims that mass media ordinarily does not serve as a direct cause of negative perception, but rather functions among and through a nexus of mediating factors and influences (Severin \& Tankard, 2014 p.263). Klapper (1960) earlier stated that "the mediating factors are such that they typically render mass communication a contributory agent, but not the sole cause, in a process of reinforcing the existing conditions" (p.8). This indicates that when residents witness bad driving behaviour, they recall media news about bad tourist driving and may automatically stereotype it as tourist driving, reinforcing the negative perception.

As one example of media effects, the media framing concept has important implications of influencing people's opinions and perceptions (McLennan et al., 2017). The concept suggests that from an individual level, a person uses cues or frames to guide the understanding and act on an issue (Baran \& Davis, 2009). From a communication aspect, media framing is used to analyse how journalists apply frames to portray the same topic in different ways, therefore producing a particular meaning of an issue, as well as causal interpretation, moral evaluation and/or recommendation for a topic described (Entman, 1993). Media frames can be viewed as central organising ideas that have the power to influence public perceptions and political decisions, either by limiting or defining the message's meaning (Kumpel \& Haas, 2016).

Duhe and Zoch (1994) explain framing is a critical activity in the construction of social reality, and involves processes of inclusion, exclusion and emphasis, which assist how people see the world. Luhmann (2000) reinforced and debated that whatever people know about the society and the world are through the mass media. Framing fundamentally consists of selection and 
salience by the message creators; it is about selecting some aspects of perceived reality and transforming that reality into communicating text in a more salient way (Entman, 1993).

\subsubsection{Media hype}

The reporting of tourist driving in New Zealand has created huge reactions, due to negative framing; this has become a social problem and media play an important role in this process of social construction, sometimes described as 'media hype' (Vasterman, 2005). Media hype in simplified terms is defined by Vasterman as:

An event triggers increased media attentions, the media set their focus and enlarge on this specific topic or event, and by doing so evoke all kinds of social response, which will in turn become news as well, further stimulating the new waves. (p. 511)

Reviewing new stories regarding self-drive tourism available publicly between 2015 and 2019, it is visible that negative news stories dominate the headlines and fit the definition of media hype, with headlines such as "tourist drivers are terrifying”" (Newfield, 2015). Social responses reported in the media included a tourist's rental car key confiscated by the residents, and residents' suggestions such as T-plates for tourist drivers (Peterson, 2016; McNab, 2015). As an aftermath of media hype, because similar incidents are reported daily and reinforced repeatedly, the scope of the issue becomes broader gradually (Vasterman, 2005). Every incident or statement that appears to confirm the dominant news theme (self-drive tourism) will capture greater attention than before, ultimately becoming a social problem and political issue (Vasterman, 2005).

The intensity of negative news about self-drive tourism has dropped over the years, an overall decline of 57\% between 2015 and 2018 (McNamara Research Group, 2018). This seems to be driven by the New Zealand Government working proactively to influence media stories and coordinate communication between stakeholders to prevent exacerbation of self-drive tourism stories by media (Field et al., 2019). In addition, news headlines have been more friendly, moving from negatively framed headlines in 2015, to headlines like "Road toll: How bad are tourist drivers really?" in 2018 (Huffadine, 2018).

Statistically, it is recorded that the public's negative perception about self-drive tourism, specifically that it "increases the risk of serious road accidents" had dropped from $42 \%$ in 
2015 to 33\% in 2017 (Kantar, 2018). Yet, the same survey (Mood of the Nation) in 2019 reported $41 \%$ of respondents agreed tourism increases the risk of serious road accidents (Kantar, 2019), suggesting a return of residents' concerns about tourists and road accidents. Despite news headlines increasingly becoming friendlier towards tourists' driving over the years, the public perception on questions like "risk of serious road accidents" seems to remain consistent, with only $9 \%$ variation over the past five years. This suggests that even with decreased reporting of negative news, negative perceptions towards self-drive tourists still linger.

Aiming to answer the inconsistency between decrease of negative news and perception, some key psychology studies have aimed to explore why people's negative perceptions are likely to remain for a longer duration (Fiske, 1980; Medin et al., 1995; Hallahan, 1999). Valkenburg et al. (2016) noted that humans tend to automatically devote more attention to negative than positive information, referred to as negativity bias. Such information or knowledge is organised through cognitive structures or schemas, stored in human memory, that operate as constraints on the interpretation and arrangement of events and situations (Fiske, 1980). Subsequently, this influences how memory or traces of memories organised as schemas are activated to interpret a message (Hallahan, 1999). That is, people tend to believe and reinforce their pre-existing knowledge or favoured hypotheses with strong tenacity and confidence (Medin et al., 1995).

When residents come into contact with self-drive tourists, they reinforce and confirm negative perceptions based on information obtained from mass media; media acts as a mediating factor influencing one's assumptions, subsequently generating negative emotions and/or perceptions (Klapper, 1960; Severin \& Tankard, 2014). As Yeoman and McMahon (2020) observed, people may dismiss the details in each media story; however, the emotional reaction to that story can be persistent.

\subsubsection{Heuristics}

Such biases may be the result of heuristics, which are cognitive shortcuts that allow a person to make assessment on basic cues or rules, to avoid the complexity and cost of processing and exploring different possibilities, consequently for faster decision making or perception constructions (Marsh, 2002). Todd and Gigerenzer (2000) explored how people made decisions under constraints such as time and knowledge, using fast and frugal heuristics to solve problems with limited time and knowledge, by ignoring segments of information to find a good enough solution, rather than to discover a best solution (Gigerenzer, 2008). 
Fast and frugal heuristics limit the search of information or objects by adding in simple “stopping rules" to enable faster decision making (Todd \& Gigerenzer, 2000). "Stopping rules" could be cues or reasons that discontinue search as soon as any option is found that meets or exceeds a pre-established aspiration level (Marsh, 2002). Connecting to media and self-drive tourism, it may be hypothesised that residents employ heuristics when encountering self-drive tourists, and negative news from the mass media are acting as a cue, promoting discontinued search and reinforcing negatively how residents think about self-drive tourism.

Although tourist driving accidents are not the only events that can be publicised by the media, they certainly have attracted much public attention. In summary, media can play a significant role as a mediator to influence perception and heuristics, as a cognitive shortcut, which may explain why residents treat media stories as a cue to enable faster decision making. When residents witness or encounter bad tourist driving, the media effect and heuristics can trigger and reinforce residents' negative perception of bad tourist behaviour.

\subsection{Tourists' driving behaviour}

Tourists' driving behaviour is suspected to have an impact on how residents perceive them. As discussed above, residents' comments in blogs about their encounters with tourist drivers (Tripadvisor, 2019a) reveal emotions of fear and prejudice. Similarly, media news has also reported bad tourist driving and the consequences caused to residents, although these may be criticised as "framing". Nevertheless, a recent incident "Tourist charged after Queenstown woman killed in crash" was reported by journalists Kitchin and Guildford (2020) commenting that the local community was "in shock". This suggests that the behaviour of self-drive tourists could be causing residents' negative perceptions.

Academic research has investigated tourists' driving concerns and the influencing factors of their driving behaviour. Wu's (2015) study of Chinese tourist drivers' safety concerns conceptualised five themes that can impact on the driving behaviour of Chinese tourists. These are:

1. Unfamiliar vehicles (e.g. size, different arrangements).

2. Unfamiliar roads (e.g. roundabouts, highway systems, open road with similar landscape).

3. Unfamiliar driving rules (e.g. left-hand driving). 
4. Unfamiliar accommodation (e.g. office hours).

5. Personal factors, such as language skills, confidence of driving and physical conditions.

Likewise, Li (2020)'s study concurs with Wu (2015) which highlighted that safety problems encountered by Chinese tourists in New Zealand relate to external factors such as poor road infrastructure and internal factors like driving habits.

Indeed, the factors summarised by $\mathrm{Wu}$ (2015) have an influencing power on driving behaviour. A respondent interviewed in $\mathrm{Wu}$ (2015) stated that "we cannot drive at a certain speed as we do on the isolated Chinese motorways. We really need to slow down and to set [aside] more time than [it says on] Google maps" (p.806). This shows how road conditions can influence the selection of speed but also distracts attention from driving to electronic devices, potentially resulting in a road accident.

Carr and Shaheer (2019) conducted research to test international self-drive tourists' awareness of road safety in New Zealand via testing their knowledge on New Zealand driving rules and regulations. The findings revealed that self-drive tourists are not well prepared and have inadequate understanding of rules and regulations. As one of the consequences suggested by Thompson and Sabik (2018), also evidenced in news stories and government reports, a primary reason why road accidents happen is because tourist drivers fail to adjust to New Zealand rules or conditions (NZTA, 2017a; Zhang \& Kim, 2017).

Indeed, as the literature and government reports point out, unprepared drivers are more likely to cause road accidents (NZTA, 2017a; Zhang \& Kim, 2017; Thompson and Sabik, 2018). However, amongst the OCED countries, road safety in New Zealand is ranked in the bottom quarter, and on average, one person is killed every day, and another is injured every hour (MOT, 2019a). In addition, road safety technologies, such as electronic feedback signs and GPSenabled communication systems, are recognised as a weakness by the New Zealand Transport Agency (NZTA) (NZTA, 2016), hence potentially contributing to the increased risks of driving. More significantly, New Zealand's road infrastructure when compared to other developed countries does not score highly (MBIE, 2016a). A Ministry of Transport (MOT) report highlights that about $87 \%$ of current speed limits are not suitable for the road conditions and will require attention through improved road infrastructure and modified speed limits (MOT, 2019b). 
As shown above, there are definitely challenges when driving in New Zealand. As such, a tourist driver may lower their risk of a road accident by driving more slowly, and/or deliberately taking longer to reach a destination on an unfamiliar road. However, it has been found that residents perceive tourists' behaviour differently. Residents' perception of tourism is likely to be influenced by pre-existing attitudes or beliefs about certain types of tourists (Griffiths \& Sharpley, 2012; Sharpley, 2014). Hence, the possible outcomes of these safety actions taken by tourist drivers could be perceived by residents as "being a tourist" or prejudged as a particular ethnicity, thus amplifying negativity and promoting racism, that may also be reinforced by bad news stories.

While the tourists driving behaviour may have an impact of how residents perceive them, it is also important to consider other factors that may influence the behaviour of drivers such as road infrastructures and/or road technologies. As shown above, tourist behaviour can be influenced by other factors and as such, may be treated as one of the causes of residents' negative perception.

\subsection{Theory of constraints (TOC)}

Theory of constraints (TOC) methodology was developed by Dr Eliyahu M. Goldratt in 1979; Inman et al. (2009) defined it as a management philosophy that results in improved organisational performance by focusing on the constraints (p.342). Goldratt's first novel, "The Goal", included a series of concepts to explain the process of continuous improvement and decision making in a manufacturing setting (Goldratt \& Cox, 1984). Watson et al.'s (2007) summary of "The Goal" lists a number of heuristics and techniques which have become the foundation for TOC. At its most basic level, TOC, as outlined in "The Goal”, consists of Five Focusing Steps (5FS). These 5FS are sequential steps which focus on strengthening the weakest link. The first step is to identify the system constraint followed by exploit, subordinate everything to the constraint, elevate, and finally, returning to step one if the constraint has been resolved: do not allow inertia to cause a system's constraint (Watson et al., 2007).

As a sequel to the "The Goal" and the 5FS, "It's Not Luck" (Goldratt, 1994) presents a roadmap of methods to discover solutions for complex processes (Simsit et al., 2014). The methods, known collectively as "Thinking processes" (TP), focus on discovering root causes and core problems and generate potential solutions in logical and systematic ways. Tulasi and Rao (2012) highlight the TP focus on the factors that are inhibiting the system from achieving 
the goal. The TP roadmap comprises a series of logic trees to facilitate change which underpins all other parts of the methodology (Mabin, 1999). "TP are desired to obtain collaboration and consensus around win-win solutions built in the light of system constraints" (Ikeziri et al., 2019, p.5073). The advantage of TP is their ability to conceptualise cause-and-effect relationships via a series of logic trees, and academics have predicted that TP will have a lasting impact (Rahman, 2002).

The application of TOC has expanded into different areas such as production, supply chain, accounting, projects, retail and distribution (Ikeziri et al., 2019). Mabin (1999) observed that TOC had evolved over the past 20 years (now 40) from a production scheduling technique to a systems methodology for which managing change is the primary concern. Ikeziri et al. (2019) also stated that TOC has moved on from factory bottlenecks, production planning and control, and transformed to a global management philosophy that focused on leveraging performance (p.5068).

TOC has been well applied in different areas such as manufacturing, education and the supply chain (see Cox \& Spencer, 1998; Kim et al., 2008; Galvez et al., 2009; Bhowmik et al., 2018), with significant performance improvements including increased output, decreased inventory and lead time (Mabin \& Balderstone, 2003). Watson et al. (2007) concur that TOC has been applied in many organisations and businesses and is evidenced by good improvements. In tourism studies, TOC has been applied in the hotel sector (e.g. Schragenheim, 1999; Dalci \& Kosan, 2012; Perez Campdesuñer et al., 2017). TOC has also been used by university students for analysing tourism case studies obtained from media news stories as well as used in student projects and own workplaces (Mabin, V, personal communication, February 20, 2020; Kimes, 2020).

Applying TOC nevertheless is not straight forward and has a low profile in academic research (Ronen, 2005). He observed that in contrast to the vast application of TOC in practice, very few published journal articles had used TOC methodology. This is particularly valid in tourism where there have been limited studies using TOC methodology. A number of difficulties and limitations of using TOC are highlighted by Ronen (2005) and may be the contributing reasons to the application of TOC in tourism (p.1). These are:

1. TOC is a heuristic-oriented philosophy, yet many academic journals prefer processoptimising, quantitative approaches while the goal of TOC is simplicity. 
2. TOC processes are cause-effect driven. Academic journals often give preference to field studies with empirical data.

3. TOC was originated by practitioners, rather than by academic researchers. As a result, not enough academics have been exposed to its full contribution.

4. TOC is often misperceived as a simplistic toolkit that does not need thorough research.

However, TOC has major strengths. Dettmer (1995) highlighted TOC as effective in identifying policy constraints that have the most dramatic effect at the system level, and TOC provided a systematic process of continuous improvement, required to avoid having obsolete policies. Motwani et al. (1996) had a similar viewpoint, concurring that the strength of TOC, contrary to other management techniques, is its ability on achieving quicker bottom line improvements. Concurrently, TOC tools can conceptualise cause-and-effect relationships via a series of logic trees, to understand a phenomenon (Rahman, 2002; Ronen, 2005).

From a theoretical aspect, Naor et al. (2013) concluded that TOC adheres to the virtue of good theory, can be employed for theory building, and is not just merely a formal operations management theory (p.511), because:

1. Its concepts, relationships and logic are relatively simple to understand.

2. It is internally consistent.

3. Its innovative relationships and logic are fertile or hypotheses development.

4. TOC's key propositions are not self-verifying but are conceptually subject to disconfirmation.

5. TOC's theoretical statements have progressed towards higher levels of abstraction.

Ronen (2005) also called on scholars to apply academic methodologies to TOC concepts, to apply academic rigor in TOC research, as well as to confirm or improve the TOC method. Acknowledging TOC's strengths and weaknesses, Mabin and Davies (2010) also indicate that TOC methods need to be better understood and appreciated by mainstream disciplines. Therefore, Theory of constraints (TOC) methodology will be employed to structure causes and effects into hierarchies and logical maps by collating, sorting and analysing the different factors from the literature and data collected in this research, to deepen our understanding of the selfdrive tourism perception issues. The TOC methodology will be discussed further in Chapter 3 , Research methodology. 


\subsection{Conceptual framework and research gaps}

The conceptual framework in Figure 2.1 is constructed to highlight where the research gaps lie (coloured in red). In essence, it depicts three research gaps.

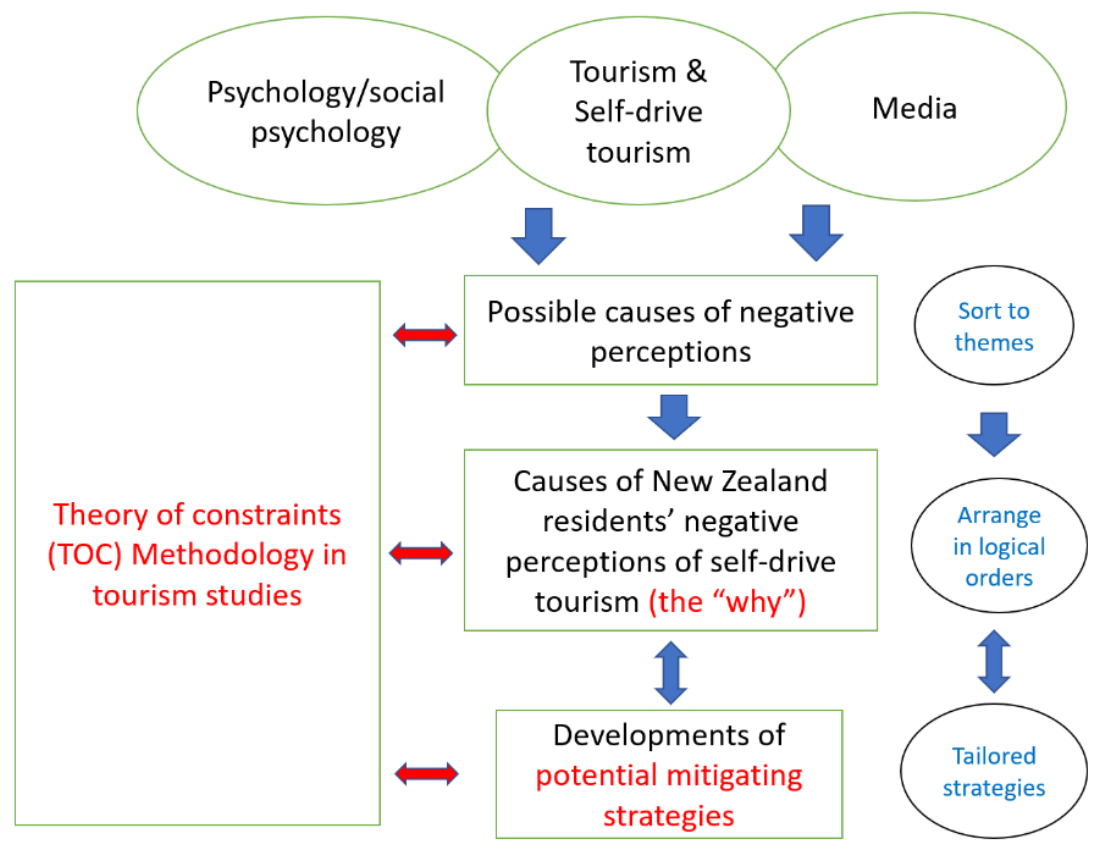

Figure 2. 1: Conceptual framework

1. Lankford and Howard (1994) highlighted that residents' perception can be measured via an almost infinite variety of procedures and research paradigms, and TOC methodology appears not to have been employed to study tourism.

2. As discussed in the review, more qualitative studies are needed to investigate in depth feelings of residents (Deery et al., 2012; Sharpley, 2014). Likewise, studies in self-drive tourism have primarily been focused from the tourists' perspective, rather than from the residents' perspective (Prideaux and Carson, 2010; Mahadevan, 2014; Wu \& Pearce, 2018). This study responds to these calls, aiming to understand the causes ("why") of negative perception from the resident's perspective.

3. As mitigating strategies were not discussed in this chapter this created a research gap of what strategies should be employed to mitigate residents' negative perceptions. TOC will address this research gap by developing potential strategies according to the analysed results. 


\subsection{Summary of Chapter 2}

This chapter provided a review of the possible causes to residents' negative perceptions from psychology/social psychology, tourism and self-drive tourism, and media literature. Causes such as social exchange, negative stereotyping, media effects and heuristics were identified. TOC methodology was briefly introduced and how it can be applied in this study. Lastly a conceptual framework was constructed to illustrate the research gaps. 


\section{Chapter 3: Research methodology}

\subsection{Introduction}

This chapter describes the research paradigm and justifies TOC as a research methodology for this study. The rationale for the research design, data collection and data analysis will be described, ending with the ethical considerations and trustworthiness of this study.

\subsection{Research paradigm}

A research paradigm is defined as a set of fundamental assumptions and beliefs on how the world is perceived which guide the behaviour of the researcher, serving as a thinking framework (Wahyuni, 2012). These include ontology, the fundamental assumptions a researcher makes, knowingly or unknowingly, about the nature of reality or the world view that one tries to understand. Epistemology is the development and the nature of that knowledge; what knowledge is and how we come to accept something as true. Methodologies are the methods used in the process of research (Creswell, 2007 p.16). This section will discuss the research paradigm of this thesis and the notion of selecting such a paradigm.

The core research paradigm of this study is pragmatism. According to Peirce's formulation of his pragmatic maxim, cited in Olshewsky (1983), he defined pragmatism as "Consider what effects, which might conceivably have practical bearings, we conceive the object of our conception to have. Then, our conception of these effects is the whole of our conception of the object." (p.199). In other words, it is based on the notion that researchers should apply the philosophical and/or methodological approach that works best for the specific research problem that is being examined (Kaushik \& Walsh, 2019 p.2). Wahyuni (2012) coined that pragmatism is about choosing the best view to achieve an answer to the research question. Hence, the ontology of pragmatism lies in external, multiple, views chosen to best achieve an answer to the research question (p.70).

The underpinning epistemology of pragmatism is that knowledge is always based on experience; it does not view knowledge as reality, instead, knowledge is constructed with a purpose to better manage one's existence and to take part in the world (Goldkuhl, 2012). Creswell and Clark (2011) also highlight that pragmatism is situated on solving practical problems in the real world and emerged as a method of inquiry for the more practical-minded researcher. Wahyuni (2012) concur with Creswell and Clark (2011) and highlighted the 
epistemology of pragmatism depends on the research question; either or both observable phenomena and subjective meaning can generate acceptable knowledge, while the development of knowledge is focused on practical applied research, also integrating different dimensions to help interpret the data.

Accepting that pragmatism is suited for practical problem solving and the knowledge gained under such a paradigm depends on the research question (Wahyuni, 2012; Creswell \& Clark, 2011), the research methodology of this thesis will employ TOC as it could best answer the research questions with its strong focus on solving a practical problem. TOC allows the researcher to analyse a problem via the construction of logic trees, then by following TOC processes it could solve the problem through its focus on cause-and-effect and system goals (Dettmer, 2007).

Pragmatism also allows the researcher freedom of choice of methods, techniques and procedures that best fulfil the researcher's needs and purposes (Creswell \& Poth, 2016, p.27). That is, it allows the researcher to freely select what is required in order to answer the research questions, drawing on materials and theories from different disciplines, secondary data and/or government reports.

More importantly, TOC as a methodology is viewed via the lens of pragmatism which only considers what needs to be included and what does not, to answer the research questions of this study.

\subsection{The TOC methodology}

The Theory of constraints (TOC) is a philosophy of system-based management (Kim et al., 2008). TOC as a methodology focuses on the interconnectedness of complexities inherent in systems. As Rahman (2002) and Houston (2007) observe, TOC can isolate and focus on identifying the critical factors via cause-and-effect logic. Essentially, TOC focuses on identifying constraints that are hindering a system from achieving its goal, and then dedicates efforts on the critical factors that can improve performance of the overall system. As part of TOC, as described by Davies et al., (2005) as a systems-based meta-methodology, the thinking processes contain different tools that may be used to operate through the stages of the problem structuring and diagnosis, and development and implementation of solutions. 
In this study, the application of TOC thinking processes methodology is desirable for several reasons. First, tourism perception studies have not been able to explain the "why" of residents" perceptions, with Sharpley (2014) pointing out that there may be factors beyond the tourism domain that influence residents' perceptions of tourism and a more complete understanding of residents' perceptions is only likely to emerge from a more multi-dimensional approach (p.46). A major component of this study is to discover factors that adversely affect residents' perceptions of self-drive tourism. TOC methodology will be used to discover the causal relationships between these factors and the underlying causes of any undesirable effects in selfdrive tourism.

Second, TOC takes a system view rather than dealing with symptoms individually, wherein a system includes many interdependent parts connected by cause-and-effect relationships (Dettmer, 2007). In this case, the system, as viewed by the TOC methodology, is self-drive tourism.

Third, unlike other theories such as social exchange theory that measures what residents perceive but does not specifically aim to provide solutions, TOC can provide potential solutions and focus on whatever should be changed to reach a positive outcome via its five fundamental steps of change, (Cox et al., 2012).

Last, TOC methodology has been successful in domains like manufacturing and education (see Galvez et al., 2009; Bhowmik et al., 2018), but its application in tourism studies remains a gap to be explored, despite its limited application in the hotel sector and its use in teaching (e.g. Dalci \& Kosan, 2012; Mabin et al, 2020). 


\subsection{TOC Thinking Processes (TP)}

The thinking processes (TP) within the TOC methodology consist of various sets of tools that may be used to structure and diagnose problems, and develop and implement solutions (Davies et al., 2005). Scheinkopf (1999) described the TP as providing a much needed focus on the factors that are hindering a system to achieve the desired goal, understanding why constraints exist, ability to define the steps to elevate the constraint and the steps that should be taken for improvements in a logical and systemic manner (p.4). Likewise, Rahman (1998) stated that the TP provide a generic approach for investigating, analysing, and tackling complex problems (p.337).

The self-drive tourism issue in New Zealand can be considered a complex problem. It has become a social problem that has drawn attention from various stakeholders including New Zealand residents and the Government. Kim et al., (2008) demonstrated that the main techniques applied in the thinking processes; the Goal Tree (GT), the Current Reality Tree (CRT), the Evaporating Cloud (EC), the Future Reality Tree (FRT), and the Prerequisite Tree (PRT), could be used to tackle such complex problems. Furthermore, Rahman (1998) and Mabin (1999) explained the TP cause-and-effect diagrams used to generate answers to the five fundamental questions (originally three), "Why change?", "What to change?", "What to change to?", "How to cause the change?", and "How to measure and sustain change?" The first and the last questions are later additions (Cox et al., 2012). This research will only focus on the first three questions as the main steps to understand the causes and provide potential strategies; the last two questions are open for future research to implement. 


\subsubsection{Why change?}

The answer to the first step of the TP "Why change?" uses the Goal Tree (GT) (previously called an Intermediate Objectives map), which comprises a clear goal statement that defines the system and the critical success factors (CSFs) that are required to achieve the goal; the CSFs are satisfied by the necessary conditions (NCs) (Dettmer, 2007; Dettmer, 2011), see Figure 3.1.

The purpose of the GT is to identify the actual and desired states of a system, thus revealing an improvement gap to be addressed to achieve the desired system. "Why change?" also includes identification of the undesirable effects (UDEs), negative aspects of a current reality which are undesirable relative to the system goal (Cox et al., 2012, as cited in Kimani, 2005). Indeed, UDEs can be identified as gaps made apparent from the GT and vice versa (Dettmer, 2007). In this study, the GT helps to reveal what is the desired goal ("perfect world") of the self-drive tourism system and to see if it is functioning as desired, by comparing it with the actual state.

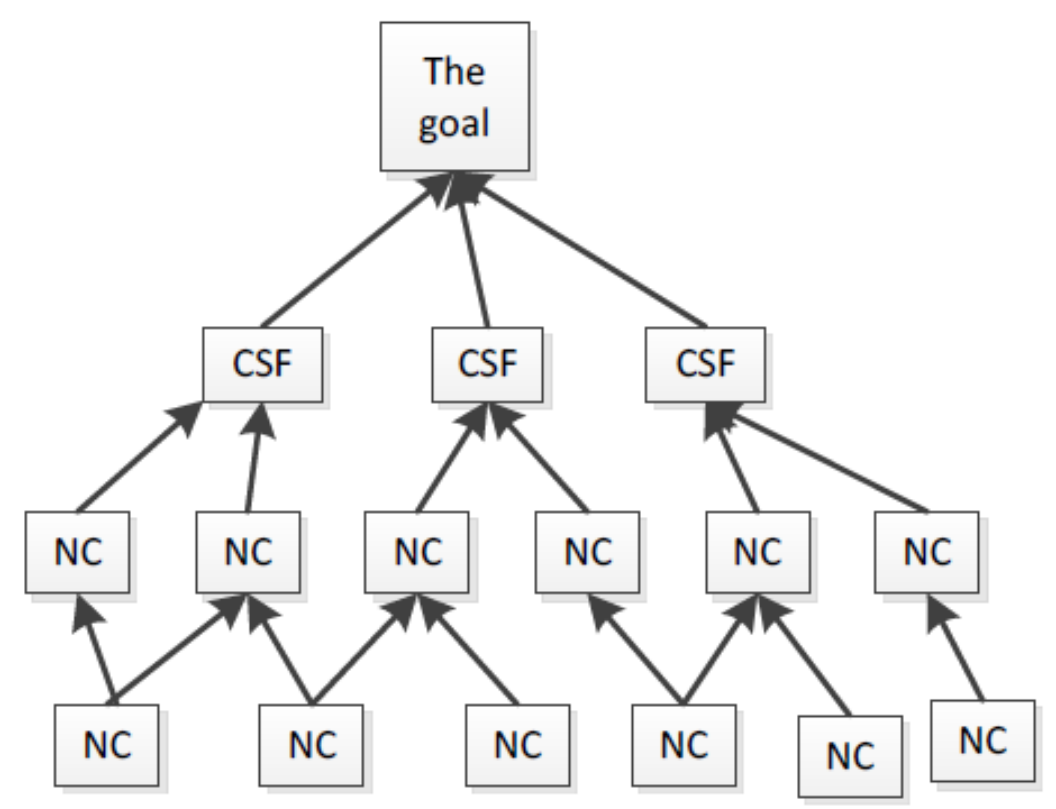

Figure 3. 1: Goal Tree (Source: Dettmer, 2011, as cited in Kimani, 2015) 


\subsubsection{What to change?}

The second question "What to change?" uses the Current Reality Tree (CRT) to identify, describe and connect the UDEs to identify the critical root causes (Cox et al., 2003), see Figure 3.2. Goldratt (1994) and Cox et al. (2005) stated that the initial step of the CRT is to list the UDEs that currently exist (identified in the "Why change?") and focus on the cause-and-effect relationships of that list. It should be noted that the CRT does not follow a set sequence or order but should ultimately diagnose one or more root causes derived from the UDEs.

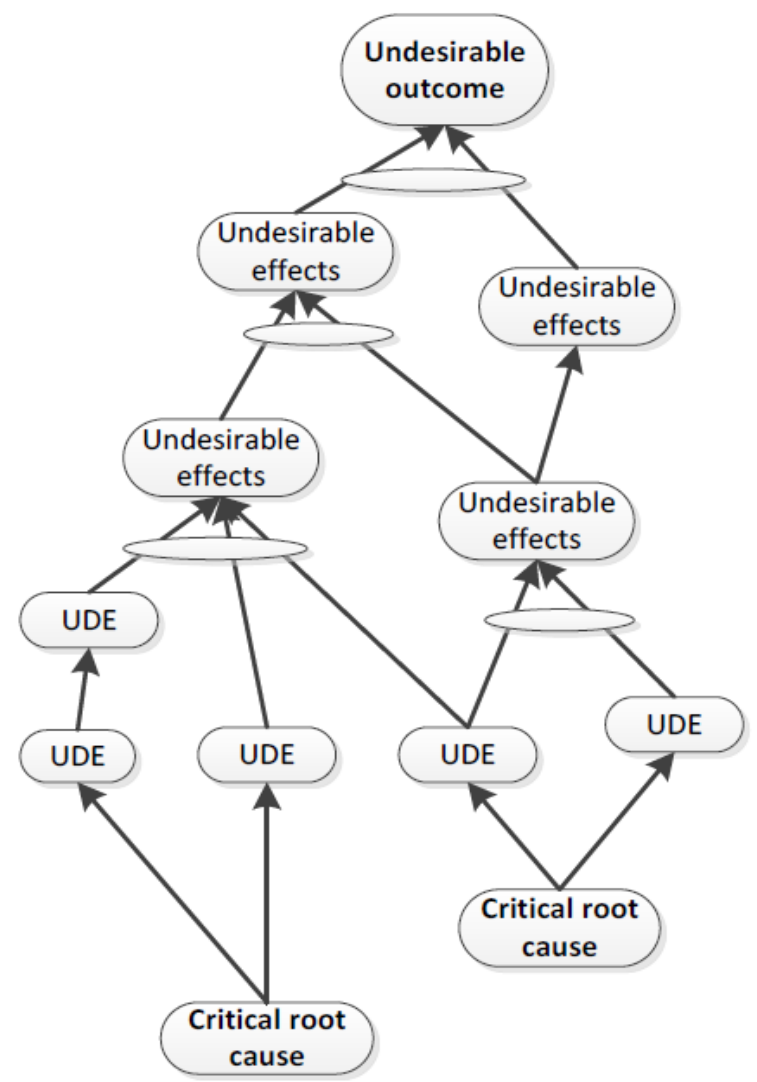

Figure 3. 2: Current Reality Tree (Source: Dettmer, 2007 p.117, as cited in Kimani, 2015)

Once the root causes are identified, the most critical of those root causes (or the core problem/s), need to be identified and then how to remove it/them. Moore \& Mabin (2014) stated that often the core problem is a result of an unresolved underlying conflict (p.29), at which stage the next tool in the TOC methodology is applied, namely the Evaporating Cloud (EC), also known as a Conflict Resolution Diagram (Dettmer, 2007). 
The EC has a set format with five boxes (see Figure 3.3), which consists of two opposing wants, representing the conflict, the need that each want is trying to satisfy, and a common objective or goal that both needs are trying unsuccessfully to fulfil, given the conflict. Assumptions underpinning the EC are examined to determine changes ("injections") that would lead to a win-win resolution (Mabin et al., 2001).

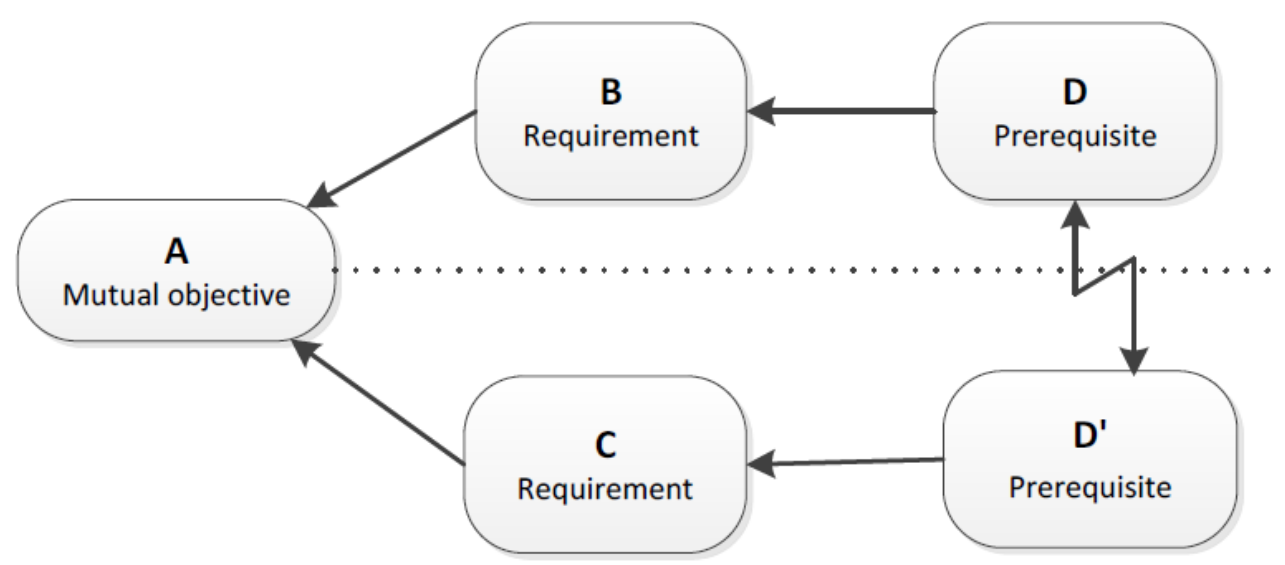

Figure 3. 3: Evaporating Cloud (Source: Cox et al., 2012, as cited in Kimani, 2015) 


\subsubsection{What to change to?}

The third step of "What to change to?" is answered through construction of a Future Reality Tree (FRT), see Figure 3.4. The FRT's primary purpose is to examine if the proposed solution from the EC will truly eliminate the majority of the UDEs, so that the desired future is attained; it shows the direct and indirect effects of implementing the proposed solution.(Cox et al., 2012; Kimani, 2015). Mabin et al. (2001) and Kim et al. (2008) explained that the FRT is constructed based on the best idea (primary injection) identified from the EC method, the solution that will most probably eliminate the UDEs and generate desirable effects (DEs). The FRT uses causeand-effect logic to map the effects of the proposed solution and identify possible negative side effects. These negative side effects are mitigated/avoided by adding supporting injections as required to ensure success of the solution (Mabin et al., 2001).

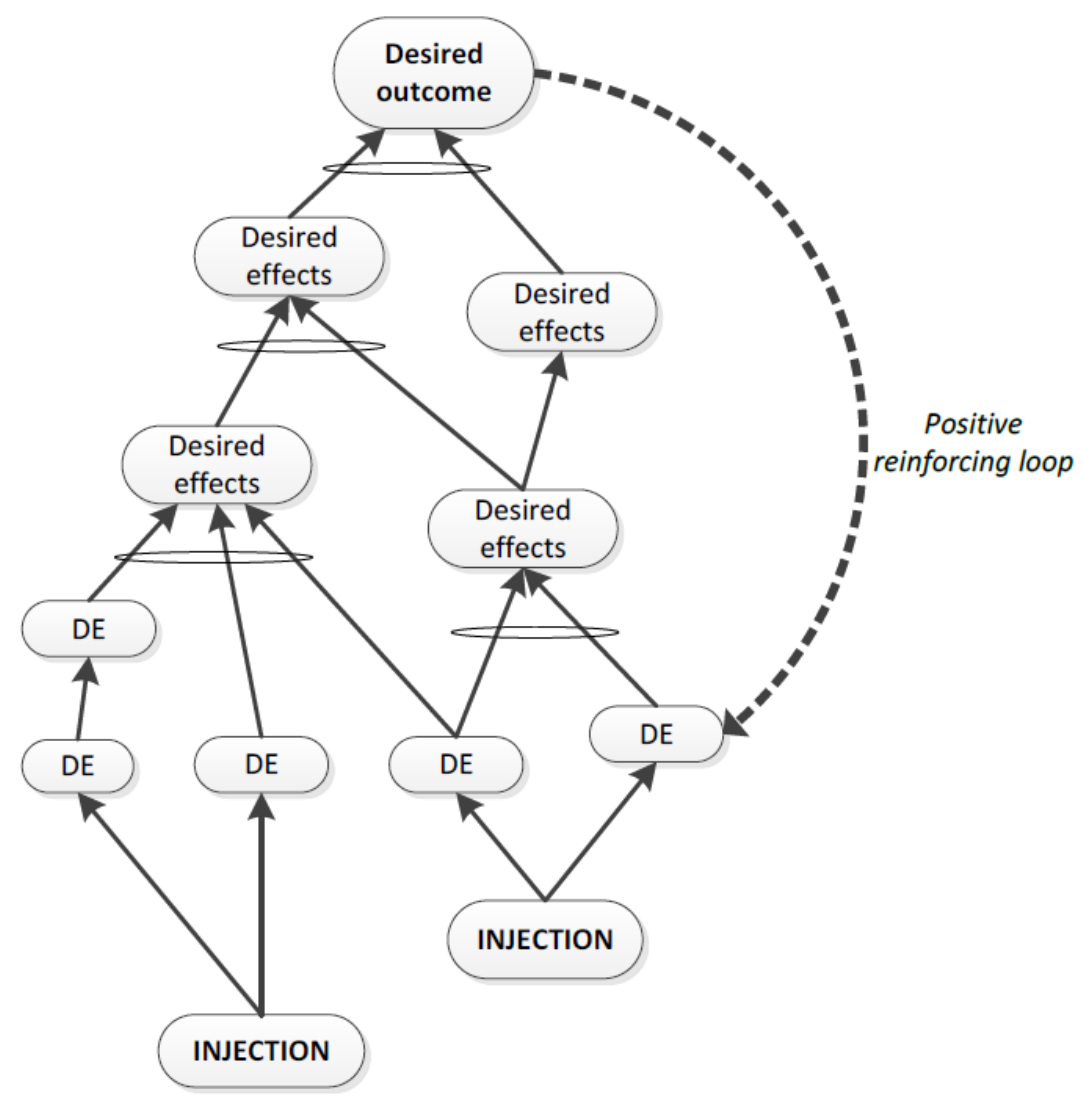

Figure 3. 4: Future Reality Tree (Source: Dettmer, 2007 p.207, as citied in Kimani, 2015) 


\subsection{TOC logics}

The TOC TP diagrams can be constructed using two types of logic, namely necessity condition and sufficient condition (Dettmer, 2007). The necessity condition logic (as, In order to... must...) describes the requirement(s) or prerequisites that are required to have a desired outcome; this logic is used in GT and the EC. The sufficient condition logic (as, If...then or If, and... then) describes effects as being the logical outcomes of causes and that the cause(s) are enough to cause the effect; this is applied in the CRT and the FRTs (Dettmer, 2007).

In his critique of TOC, Ronen (2005) pointed out that TOC is a heuristic-oriented philosophy and that some academics questioned it as a simplistic tool kit and the validity of these logics. To ensure the TOC maps are valid and logical, they are scrutinised using the Categories of Legitimate Reservation (CLR). The CLR contain eight checks (Cox et al., 2012, p.20), see Table 3.1. 
Table 3. 1: Categories of Legitimate Reservation (CLR)

\begin{tabular}{|l|l|}
\hline Checks & Definitions \\
\hline Clarity & $\begin{array}{l}\text { Checks the accuracy or completeness of an idea in communication, to ensure } \\
\text { statements are clear in meaning within the context. }\end{array}$ \\
\hline Entity existence & $\begin{array}{l}\text { An entity is a complete idea expressed as a statement. Any entity (cause or } \\
\text { effect) should be grammatically correct, contain no more than one idea, and } \\
\text { avoid embedded 'if-then' statements. The content of the statement should be } \\
\text { sound or have real meaning and be reasonably acceptable to the listener. }\end{array}$ \\
\hline Causality existence & $\begin{array}{l}\text { Addresses concerns such as 'does the stated cause actually lead to the stated } \\
\text { effect?', 'does the 'if-then' connection exist?', and 'is it a tangible/observable } \\
\text { cause?' }\end{array}$ \\
\hline Cause insufficiency & $\begin{array}{l}\text { Addresses concerns of 'is the cause enough to produce the stated effect? Or } \\
\text { are there conditions that are required for the stated cause to lead to the effect? } \\
\text { This (latter) signifies a missing 'and' condition. }\end{array}$ \\
\hline $\begin{array}{l}\text { Additional cause } \\
\text { logic) }\end{array}$ & $\begin{array}{l}\text { Concerned with 'could another completely independent cause produce or add } \\
\text { to the effect? This addresses the 'either/or' conditions. This signifies a missing } \\
\text { 'or' condition. }\end{array}$ \\
\hline $\begin{array}{l}\text { Cause-effect } \\
\text { reversal }\end{array}$ & $\begin{array}{l}\text { Concerned with distinction between 'why an effect exists vs how we know it } \\
\text { exists. Could the stated cause be an indicator rather than the cause? }\end{array}$ \\
$\begin{array}{l}\text { If a proposed cause-effect relationship is valid, some other unstated effect } \\
\text { would be expected, and can be tested for. }\end{array}$ \\
\hline The effect is offered erroneously as a rationale for the existence of the cause. \\
\hline
\end{tabular}

(Source: Cox et al., 2012, p.20).

These "rules" will be followed in this study to ensure the validity of the logic trees constructed using the TOC methodology.

Overall, TOC TP are a set of tools that can be applied to tackle complex problems. The TP enable users to successfully develop and implement change solutions logically and thoroughly. Mabin et al. (2001) stated that the TP tools provide users with the ability to deconstruct and diagnose any complex issues, resulting in a win-win situation (p.172). The TP tools can be used individually or together depending on how complex the situation is (Kim et al., 2015). In this study, multiple TP tools will be employed to ensure the self-drive tourism issues are robustly analysed. 


\subsection{Research design}

This research will employ qualitative research methods under the pragmatism paradigm. Pragmatism does not necessarily require a particular method or mix of methods, instead, it is about choosing the best method that is most effective in producing the desired results (Teddlie \& Tashakkori, 2009). Qualitative research methods place emphasis on the "lived experience" of people and are well fitted to explore the meanings people place on an event, providing rich descriptions that are vivid, truthful in a real-life situation (Van Manen, 1977; Amaratunga et al., 2002).

One of the aims of this research is to mitigate New Zealanders' negative perceptions of selfdrive tourism. Using qualitative research methods enables the capture of in-depth descriptions of the phenomenon being investigated and to understand how social experience is created and given meaning; ultimately exposing the causes contributing to negative perceptions (Yilmaz, 2013).

Indeed, qualitative methods are preferable to answer the five fundamental questions within the scope of TOC methodology. Guba and Lincoln (1982) argued that there seems to be little question about the propriety of pursing cause-effect relationships. That said, TOC focuses on analysing cause-and-effect relationships by using necessary and/or sufficient logics. For example, the "Why change?" question in terms of gathering UDEs as an initial step for the CRT, requires strong personal inputs from respondents. This qualitative data (opinions) will then be used to construct logic trees/Evaporating Clouds and analysed via TOC methodology, as well as exploring residents' perception from “why”, instead of what (Sharpley, 2014).

\subsection{Sampling design}

The design of sampling in this research employs convenience and snowball sampling techniques. Convenience sampling refers to using research subjects from the population that meet certain practical criteria and are easily accessible to the researcher (Etikan et al., 2016, p.5). Here, this sampling technique is applied to the recruitment of self-drive tourists from China, Germany and/or USA who fits the definition of tourist: "individual travelling and staying in places outside their usual environment for not more than one consecutive year for leisure, business and other purposes" (OCED, 2002, p.1). 
The rationale for recruiting tourists from these countries is because according to the New Zealand Transport Agency (NZTA), the six most frequently listed countries of drivers involved in fatal and injury causing crashes are Australia, Germany, China, India, USA and UK (NZTA, 2017a). Within these, self-drive tourists from China, Germany and USA drive on the opposite side of the road in their countries, thus driving on New Zealand roads would be "unfamiliar" to them. In addition, tourists from Germany tend to travel across both the South and North Islands, for longer periods, and explore beyond the state highway networks, while tourists from China travel the highest number of kilometres per day (NZTA, 2017b).

Convenience sampling selection allows the researcher to choose the best place for data collection that is where self-drive tourists are most likely to be situated, spatially or administratively (e.g. a holiday park). Additionally, the researcher only recruited self-drive tourists from selected countries who fit the definition of a tourist; they usually drive on the other side of road, and have had self-driving experience in New Zealand for more than 24 hours within the past three months. These are to ensure that the members of the target population are homogeneous and would be no different to the research results obtained from a random sample (Etikan et al., 2016).

Snowball sampling technique refers to the researcher accessing informants through contact information that is provided by other informants (Noy, 2008, p.330). This sampling technique helps the researcher in enriching sampling clusters and accessing new participants (Noy, 2008). This technique was applied to recruit government and tourism industry experts, a senior journalist, a media academic and tourism academic. The notion of using snowball sampling to recruit these participants is that within the systems of government and academic sectors it is believed that there will be some forms of networking. Rather than relying on search engines such as Google to seek potential respondents, the researcher believes that recommendations by the informants within their system may lead to people that are best suited for this study. More importantly, recruiting these participants will enable more in-depth understanding of the selfdrive tourism system in New Zealand.

New Zealand residents have been excluded in the sample selection as there are already survey reports available (Mood of the Nation and Views on Tourism) showcasing their tourism opinions. Also, due to funding and time limitations it would be difficult to visit multiple New Zealand regions to recruit residents. As an alternative, a government expert who has great 
knowledge of residents' opinions was recruited and was expected to provide a balance of these opinions.

\subsection{Data collection process}

After deciding on sampling techniques and who to recruit, the researcher then decided to target the West Coast region's holiday parks for self-drive tourist recruitment, because the West Coast region has a high density of tourist driving and is a popular tourism hotspot (NZTA, 2017b). The researcher also recruited short-term students from Victoria University of Wellington (VUW) who fitted the participant requirements (see sampling design). For the recruitments of government and tourism experts, the researcher commenced by contacting a known person from the Ministry of Business, Innovation and Employment (MBIE) and used their suggestions for other government experts and senior journalists. Media and tourism academics were recommended by the researcher's supervisors.

Interview guidelines were constructed based on TOC methodology questions adapted from Cox et al. (2003), and Dettmer (2011) aiming to discover the goals, UDEs and other factors in the self-drive tourism system (see Appendix 1). The interview guideline and participant recruitment method (via emails and posters) were approved by the Human Ethics Committee (HEC). For example, holiday parks in the West Coast region were contacted and confirmed via email to grant consent to conduct interviews on-site.

\subsubsection{Semi-structured interviews (face-to-face)}

Semi-structured interview guidelines were used in all interviews. One of the main advantages of semi-structured interviews is that they enable the interviewer to improvise follow-up questions based on participants' responses. This improvisation requires the researcher to have prior knowledge in the research topic area (Kallio et al., 2016). A set of interview guides with similar questions were used for all participants with some adjustments based on the role of the participants (see Appendix 1). After participants had agreed to an interview, it was conducted face-to-face in a secure location (e.g. office, public area, cafe). During the interviews, the interview guidelines were followed, and probing techniques such as "explanatory" and "silent" probes, as suggested by Leech (2002), were applied where necessary to encourage and prompt more details from the participants. 
For self-drive tourists, the interviews were conducted in two holiday parks in Franz Josef and Greymouth, as well as at VUW (for short-term international students). Participants were first screened to ensure that they fit the recruitment criteria prior to conducting any interviews and were only informed about the $\$ 30$ gift voucher once they had agreed to an interview.

For the government experts, the senior journalist and the academics, the interviews were conducted in Wellington offices and via Skype (for those who were not in Wellington). Interview questions were sent to these participants prior to the interviews for preparation purposes.

Table 3. 2: Participants' attributes

\begin{tabular}{|l|l|l|l|}
\hline Participant type & Participant numbers & Interview location & Recruitment method \\
\hline Self-drive tourists & $\begin{array}{l}\text { Chinese-4 } \\
\text { German-3 } \\
\text { US-1 }\end{array}$ & $\begin{array}{l}\text { Franz Josef \& } \\
\text { Greymouth } \\
\text { Victoria University of } \\
\text { Wellington }\end{array}$ & $\begin{array}{l}\text { Holiday park (on-site } \\
\text { recruitment) } \\
\text { Poster in University } \\
\text { campus }\end{array}$ \\
\hline $\begin{array}{l}\text { Government and } \\
\text { tourism industry }\end{array}$ & 5 & $\begin{array}{l}\text { Wellington office and } \\
\text { via skype }\end{array}$ & $\begin{array}{l}\text { Email and } \\
\text { recommendations }\end{array}$ \\
\hline Media academic & 1 & $\begin{array}{l}\text { Victoria University of } \\
\text { Wellington }\end{array}$ & $\begin{array}{l}\text { Recommendation by } \\
\text { supervisor }\end{array}$ \\
\hline Senior journalist & 1 & Wellington office & Email \\
\hline Tourism academic & 1 & $\begin{array}{l}\text { Victoria University of } \\
\text { Wellington }\end{array}$ & $\begin{array}{l}\text { Recommended by } \\
\text { supervisor }\end{array}$ \\
\hline
\end{tabular}




\subsubsection{Data collection timeline}

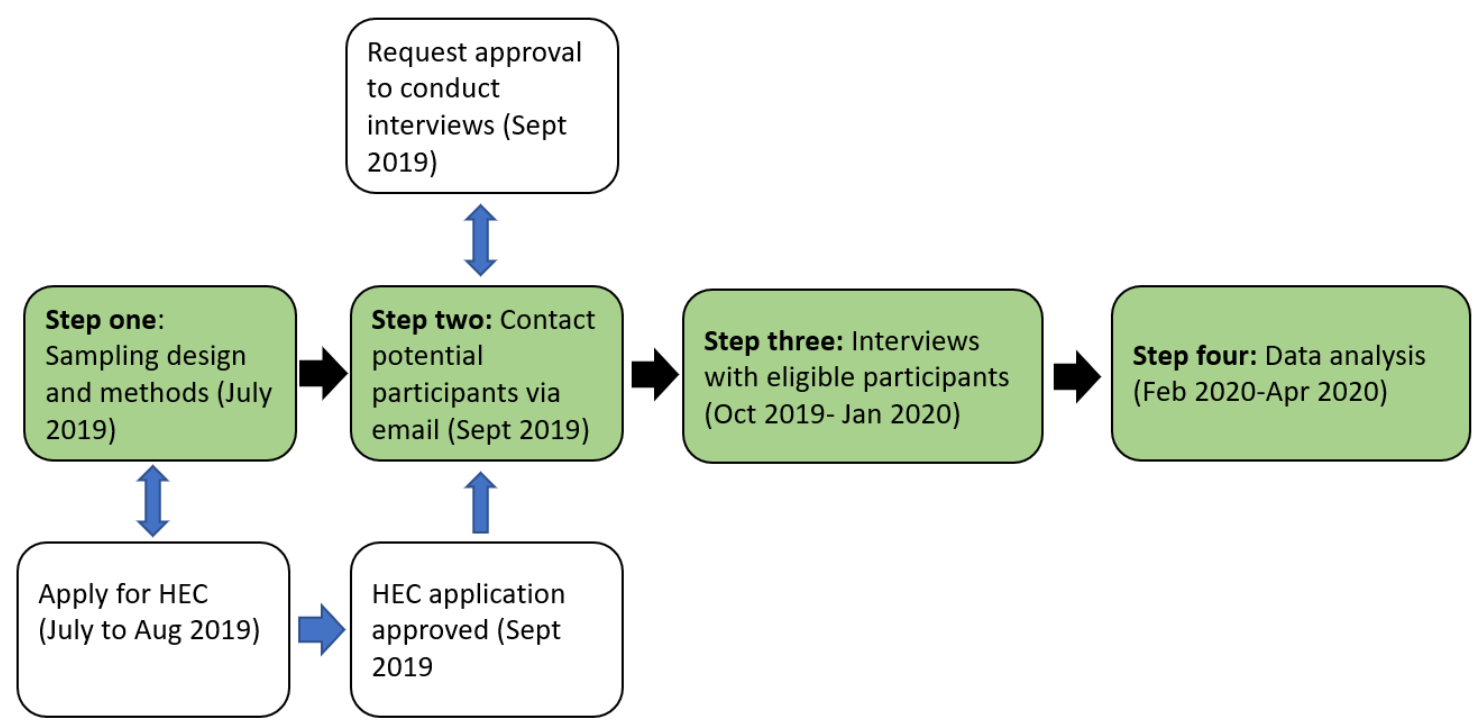

Figure 3. 5: Data collection timeline

\subsection{Ethical considerations}

Before starting any data collection, the ethical issues were considered following the VUW Human Ethics Committee Policy; the HEC application was approved by the University's ethics committee in early September 2019 (application number: 0000028062).

\subsubsection{Privacy of participants}

HEC guidelines were followed for all participants; time duration (45-60 minutes), audio recording, identity anonymity and study confidentiality was emphasised prior to the interviews. The information sheet and consent forms were explained thoroughly to ensure participants fully understood the purpose and applications of this study (e.g. publication), as well as their rights as a participant (see Appendix 2). The participants were also informed they had freedom not to answer any questions or could stop the interview and/or withdraw from the study completely within two weeks after the interview was taken. 


\subsection{Data analysis}

After the data collection was completed, the researcher transcribed the data in a secured personal space to ensure data confidentiality. Transcribed interviews were filed separately within the same folder of related groups, for example, the self-drive tourist group.

Once the data was transcribed, it was coded following a content analysis method. Content analysis is a qualitative method for systematically describing the meaning of the data (Flick, 2013). The primary reason for choosing content analysis is that the examination of the data uses constructs and ideas that have been decided in advance; a coding frame is at the heart of this method (Flick, 2013). In this case, the coding was predetermined and systematically organised according to TOC methodology. For example, the researcher developed a list of codes describing the kinds of data (e.g. Goal, CSFs) that were to be used to create the different logic trees in TOC (see examples in Table 3.3).

Table 3. 3: TOC code examples

\begin{tabular}{|c|c|c|}
\hline Coding & Description & TOC application \\
\hline Goal & Travel experience & GT \\
\hline $\begin{array}{l}\text { Critical success factors } \\
\text { (CSFs) }\end{array}$ & Regional dispersal & GT \\
\hline Undesirable effects (UDEs) & $\begin{array}{l}\text { There is lack of road } \\
\text { infrastructure }\end{array}$ & CRT \\
\hline
\end{tabular}

\subsection{Trustworthiness of the study}

According to Lincoln and Guba (1985), trustworthiness in qualitative research includes four criteria: credibility, transferability, dependability, and confirmability. The following provide an evaluation of how these have been achieved.

Credibility indicates how confident the researcher is with the truth value of the findings. This study ensures the credibility by employing triangulation and member checking (Lincoln \& Guba, 1985). Triangulation is a powerful strategy for augmenting the quality of credibility in qualitative research (Krefting, 1991). In this study, theoretical triangulation was mainly applied, that is ideas from diverse theories from different disciplines, including social psychology, management, tourism and media, in the conceptual interpretation of the causes for residents' 
negative perceptions. This study also applied triangulation using multiple data sources, including different classes of participants, published reports and literature. Additionally, member checking (Lincoln \& Guba, 1985) with participants was conducted to ensure the translated data was accurate and free of error.

Transferability relates to generalisability of an inquiry, it examines if the findings can fit into another context outside of the study (Krefting, 1991). Transferability is challenging in qualitative research, as such research is situational, and thus, the conclusions may not be transferable to another context (Krefting, 1991). Nonetheless, Lincoln and Guba (1985) argued that it is the responsibility of a person wishing to transfer the findings into another context, rather than the responsibility of the original researcher; as long as the original researcher has provided sufficient descriptive data for comparison then the problem of transferability has been addressed. To this point, the researcher has provided an in-depth descriptions of how the data are collected.

Dependability relates to the consistency of the findings; an extensive description of the research method and peer examination (Krefting, 1991). The former refers to the exact methods of data collection, analysis and interpretation. The latter refers to the checking of the research plan and implementation by methodological experts (Krefting, 1991). In this case, the researcher's supervisor Professor Vicky Mabin, a TOC methodology expert, was consulted to ensure the research plan was sound and the TOC methods are applied appropriately. Data collected is tabulated to allow traceability.

Confirmability relates to the freedom from bias in the research procedures and results (Krefting, 1991). As a confirmability strategy, Lincoln and Guba (1985) described that a confirmability audit is a major technique for establishing confirmability. This involves an external auditor attempting to track the research and to understand how and why decisions were made. At the beginning of this study, the Human Ethics Committee (HEC), as an external auditor, was approached to ensure that, for example, sampling and the research method were free of bias. Listing the data also facilitates bias-free interpretation. The researcher also reported to his supervisors regularly to ensure the integrity of the data, findings, discussion and implications.

Lastly, the TOC CLRs were to scrutinise the logic in the TOC logic maps to check they are credible, dependable and confirmable. 


\subsection{Summary of Chapter 3}

This chapter commenced with a justification of pragmatism as a research paradigm for this study. It then provided descriptions of the sampling, data collection and data analysis, followed by an explanation of the trustworthiness of this study. 


\section{Chapter 4: Data analysis and findings}

\subsection{Introduction}

This chapter provides the data analysis and findings of interviewed participants; self-drive tourists, government experts, academics, and a senior journalist. In addition, the published survey reports Mood of the Nation and the unpublished survey report Views on Tourism will be included as supplementary data to analyse the residents' perceptions of self-drive tourism.

This chapter is divided into three main sections following the sequence of change questions proposed in the TOC methodology (Cox et al., 2012, p.25).

In the first section, Goal Trees (GT) and lists of Undesirable Effects (UDEs) will be constructed to answer the question "Why change?" This section will first provide an understanding of the system, then identify if there are any gaps between the desired and the actual self-drive tourism system.

The second section addresses the question "What to change?" by developing a Current Reality Tree (CRT) that will be used to discover the root cause(s) and core problem(s) giving rise to the problematic symptoms. The CRT uses cause-and-effect logic to map the relationships between the UDEs surfaced in the first section and will generate an understanding of what is causing residents' negative perceptions of self-drive tourism.

The third question "What to change to?" will be addressed through resolution of the EC, followed by the Future Reality Tree (FRT) to analyse the best possible solution that could be made and to develop strategies that are appropriate to use for the self-drive tourism system. This section will provide potential mitigating strategies introduced by the participants as well as the researcher.

In essence, the GT, UDEs and CRTs will analyse the first part of the research question, "What is causing New Zealand residents' negative perceptions of self-drive tourism", and the EC resolution and FRT aims to answer the second part of the research question, "potential strategies to mitigate residents' negative perceptions". 


\subsection{Description of participants}

\section{Self-drive tourists}

A total of eight self-drive tourists participated in this study. Table 4.1 describes each participant's basic information. The code "TP" is given to each self-drive tourist participant for future identification (e.g. tourist participant one is TP1).

Table 4. 1: Descriptions of self-drive tourist participants

\begin{tabular}{|l|l|l|l|l|}
\hline Participants & Travel purposes & $\begin{array}{l}\text { Pervious driving } \\
\text { experience on } \\
\text { left-hand side }\end{array}$ & $\begin{array}{l}\text { Time spent in } \\
\text { NZ }\end{array}$ & $\begin{array}{l}\text { Time self- } \\
\text { driving in NZ }\end{array}$ \\
\hline TP1 German & Exchange student & Never & 4 months & 16 days \\
\hline TP2 German & Exchange student & Never & 4 months & 12 days \\
\hline TP3 German & Leisure & UK and Japan & 4 weeks & 28 days \\
\hline TP4 German & Business & Never & 7 months & 30 days \\
\hline TP5 Chinese & Business & Never & 1 month & 14 days \\
\hline TP6 Chinese & Leisure & Never & 12 days & 4 days \\
\hline TP7 Chinese & Visiting family & Never & 20 days & 10 days \\
\hline TP8 US & Leisure & Never & 5 weeks & 24 days \\
\hline
\end{tabular}

Other than TP3, these participants had never driven on the left-hand side of the road and this was their first experience of New Zealand.

\section{Government expert participants}

Five government experts were selected for their exceptional knowledge of one or more areas of tourism and transport. Table 4.2 describes the participants' expertise and the code "GP" is used to identify this group (e.g. government participant one is GP1). 
Table 4. 2: Descriptions of government expert participants

\begin{tabular}{|l|l|}
\hline Government expert participants & Area of expertise \\
\hline GP1 & Self-drive tourism, tourist, and resident insights \& research \\
\hline GP2 & Self-drive tourism, community relationship \& strategy \\
\hline GP3 & Self-drive tourism, road safety and environment \& road policy \\
\hline GP4 & $\begin{array}{l}\text { Self-drive tourism, tourism industry representative, advocacy \& } \\
\text { resident insights }\end{array}$ \\
\hline GP5 & Self-drive tourism, freedom camping \& research \\
\hline
\end{tabular}

\section{Academics and senior journalist participants}

Two academics with relevant expert knowledge were interviewed, one from tourism and the other a media academic. One senior journalist was also interviewed. Code "AP" will be used to identify academic participants (AP1 for the tourism academic, AP2 for the media academic), and "JP1" to identify the journalist participant.

\section{Survey reports}

Mood of the Nation and Views on Tourism survey reports on New Zealand residents' perception of tourism were reviewed in chapter 2. Data from these reports will be used to supplement and triangulate the interview data collected from the above participants.

\subsection{Why change?}

In this section, each participant group's Goals, CSFs and NCs will be identified to produce GTs to understand the desired versus the actual state. The GT is read from top to bottom (In order to... I must). The GT uses Hohmann (2014) colour coding system, where "Green" indicates achieved, "Orange" indicates not fully achieved, and "Red" indicates not achieved.

Then, UDEs will be identified to examine possible constraints that are preventing attainment of the Goal. This section aims to analyse the first and second research sub-objectives:

1. To identify the self-drive tourism system's goal(s); then to identify the critical success factors and necessary conditions for achieving the goal(s).

2. To identify the self-drive tourism system's undesirable effects and examine if there are any gaps preventing the system's goal(s) from being achieved. 


\subsubsection{Self-drive tourist participants}

\section{Goals}

Self-drive tourist participants highlighted many similar aspirations for their self-drive experience. Table 4.3 summarises their goals, italics are used to indicate similar variables.

Table 4. 3: Descriptions of self-drive tourist participants' goal

\begin{tabular}{|c|c|}
\hline Participants & Goal descriptions \\
\hline TP1 & Unique experience and flexibility. \\
\hline TP2 & $\begin{array}{l}\text { Get all the stops in between the cities and experience lots of NZ. } \\
\text { Be able to access activities and sites that will not be possible with bus tours/public } \\
\text { transport. } \\
\text { Sense of freedom- we can do whatever we want to do or stop in specific places for } \\
\text { sightseeing, hikes }\end{array}$ \\
\hline TP3 & I am not sure. \\
\hline TP4 & $\begin{array}{l}\text { See and experience as much as possible. } \\
\text { The flexibility I can decide in the morning depend on the weather, where and when } \\
\text { to drive. }\end{array}$ \\
\hline TP5 & Experience New Zealand culture and stay with my friends. \\
\hline TP6 & Good experience, to challenge myself and achieve self-actualisation. \\
\hline TP7 & $\begin{array}{l}\text { Stay with family, having a good experience in NZ, visit attraction, validate what we } \\
\text { heard in China about NZ's great scenery. } \\
\text { Able to experience things we cannot do in China }\end{array}$ \\
\hline TP8 & Maximum flexibility. \\
\hline $\begin{array}{l}\text { Common } \\
\text { goal }\end{array}$ & Great tourism experience \\
\hline
\end{tabular}

According to our participants' information, as organised in Table 4.3, "experience seeking" and "flexibility" are the main outcomes that self-drive tourists often seek during their visit to New Zealand. As a more general goal, "Great tourism experience” would encompass both experience and flexibility for self-drive tourists. 


\section{CSFs and NCs}

Self-drive tourists' goal set the scene of what they would like to achieve. Table 4.4 presents the self-drive tourists' CSFs and NCs.

Table 4. 4: Descriptions of self-drive tourist participants' CSFs and NCs

\begin{tabular}{|c|c|c|}
\hline Participants & Critical success factors (CSFs) & Necessary conditions (NCs) \\
\hline \multirow[t]{6}{*}{ TP1 } & Guided tour (NC1) & \multirow[t]{2}{*}{$\begin{array}{l}\text { Some kind of internet platform for car } \\
\text { sharing (NC9) }\end{array}$} \\
\hline & Interaction with local (NC1.2) & \\
\hline & Car sharing (NC1.1) & \multirow[t]{2}{*}{ Mobile app (NC1.1) } \\
\hline & $\begin{array}{l}\text { Able to leave the car anywhere you like } \\
\text { and pick it up the next day (NC3.1) }\end{array}$ & \\
\hline & Good road infrastructure (NC2) & \multirow[t]{2}{*}{ Time for driving adjustment (NC2.3) } \\
\hline & Number of cars on road & \\
\hline \multirow[t]{3}{*}{ TP2 } & Sense of freedom (CSF3) & $\begin{array}{l}\text { A car that can go anywhere (including } \\
\text { gravel road) (NC1.3, NC3.1) }\end{array}$ \\
\hline & Individual mobility (CSF3) & $\begin{array}{l}\text { Price comparison between rental car } \\
\text { company }\end{array}$ \\
\hline & $\begin{array}{l}\text { Trip recommendation from friends } \\
\text { (NC1) }\end{array}$ & Google GPS (NC3.3) \\
\hline TP3 & Not sure & Not sure \\
\hline \multirow[t]{3}{*}{ TP4 } & $\begin{array}{l}\text { A car that is working and can adjust to } \\
\text { different road conditions (NC1.3) }\end{array}$ & \multirow[t]{3}{*}{ GPS (NC3.3) } \\
\hline & Good infrastructure (NC2) & \\
\hline & Good road signs (NC2.1) & \\
\hline TP5 & Be able to interact with locals (NC1.2) & Flexibility to go anywhere (NC5) \\
\hline
\end{tabular}




\begin{tabular}{|c|c|c|}
\hline & $\begin{array}{l}\text { Encounter with other Chinese tourists } \\
\text { (NC1.5) }\end{array}$ & More mobile reception (NC6) \\
\hline & $\begin{array}{l}\text { Experience local culture and stay with } \\
\text { my friend (NC1.5) }\end{array}$ & More rest area and fuel station (NC2) \\
\hline & Good road infrastructure (NC2) & No stress when driving (NC7) \\
\hline TP6 & $\begin{array}{l}\text { Good road infrastructure (NC2) } \\
\text { Good road signs (NC2.1) }\end{array}$ & Good public transport system (NC2) \\
\hline TP7 & Good road signs (NC2.1) & Rental car in good condition (NC2.2) \\
\hline & Good road infrastructure (NC2) & Good local drivers (NC7.1) \\
\hline & $\begin{array}{l}\text { Ability to access to the attraction and } \\
\text { take photos where needed safely } \\
\text { (NC3.1) }\end{array}$ & Good technologies (NC8) \\
\hline TP8 & Cost reduction & Friendly locals (NC1) \\
\hline & Road infrastructure (CSF2) & \\
\hline & Price of fuel & \\
\hline
\end{tabular}




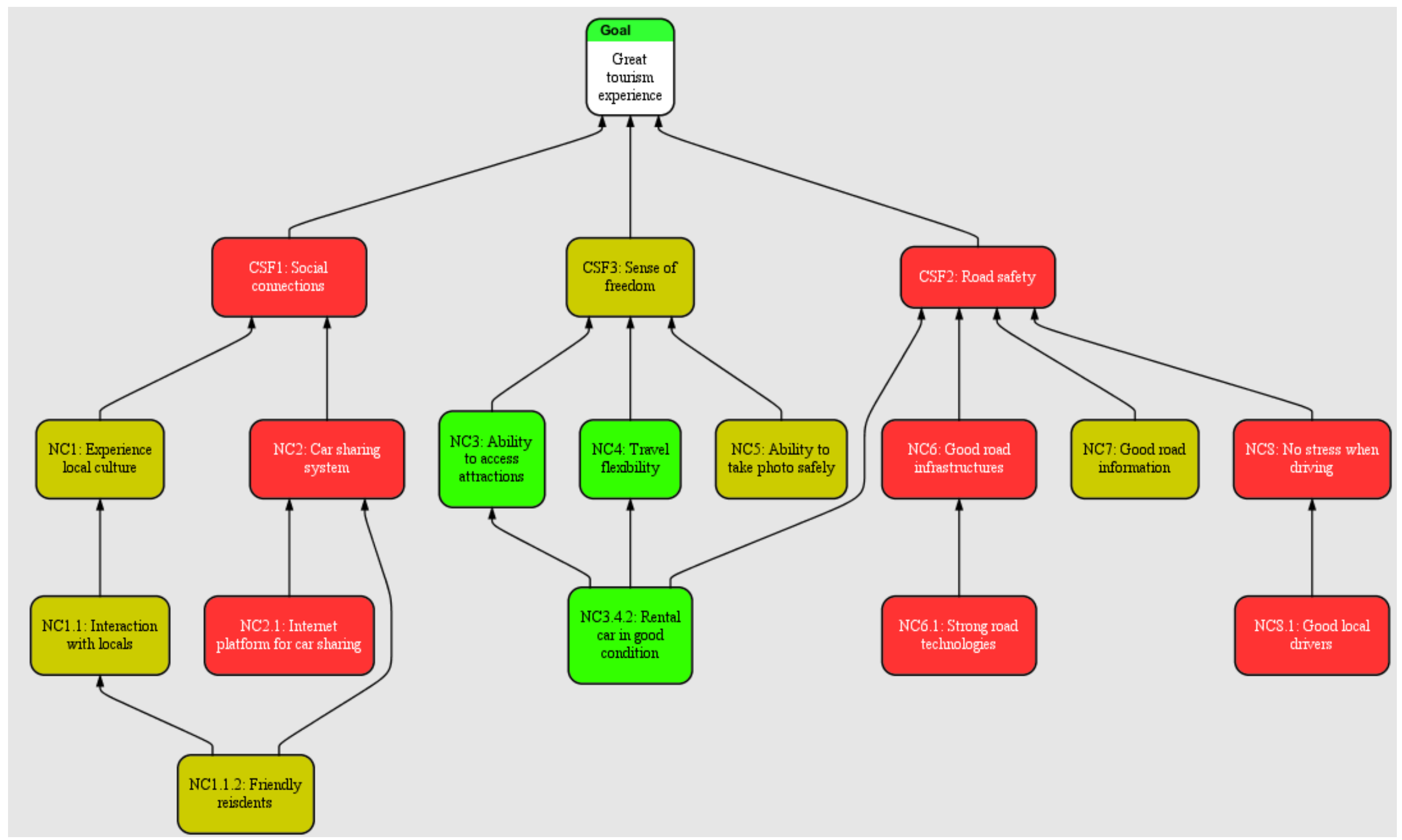

Figure 4. 1: Self-drive tourist participants' GT 
An insight gained from this GT is that the tourists' goal for their desired self-drive system is more concerned about their own pleasure, and subsequently CSFs and NCs are there to satisfy that goal (see Figure 4.1).

The big component that motivates them is a sense of freedom and independence of doing things on your own terms, on your own schedule based on what you want to do. Freedom of whatever you want to do, not what others want you to do. I think the other motivation might also be the social component. (AP1)

The above quote highlighted the factors that motivate tourists to self-drive; this correlates well with what participants described in their CSFs. However, "Social connection" (CSF1) and "Road safety" (CSF2) are not being met according to participants (coloured red), and "Sense of freedom" (CSF3) is only partially achieved (coloured orange), they are constrained by the lower NCs.

Thus, the following analysis of UDEs will seek to understand the undesirable experience during the participants' self-driving trip in New Zealand.

\section{List of UDEs}

After identifying the participants' desired system, the follow-up question was asked: “How does your desired self-drive tourism compare to your actual self-drive experience in New Zealand?". The answers to this question indicate gaps where the actual self-drive system is not currently able to deliver the desired goal. Participants further identified factors that negatively affected their travel experience (see Table 4.5). 
Table 4. 5: Descriptions of self-drive tourist participants' list of UDEs

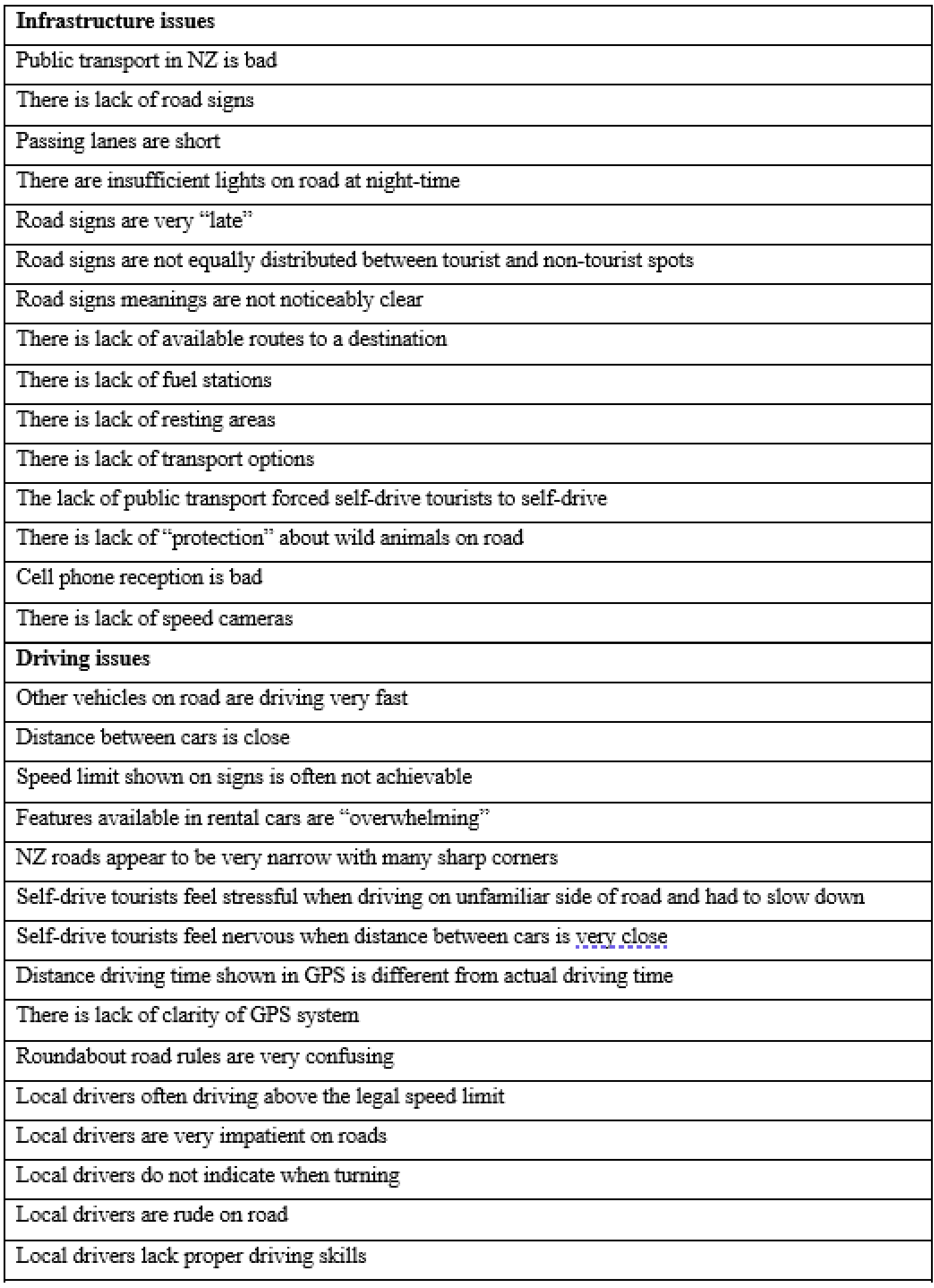




\begin{tabular}{|l|}
\hline Self-drive tourist got told off by local driver for driving too slowly \\
\hline Self-drive tourism issues \\
\hline There is lack of driving experience of our peer driver \\
\hline There is lack of consistency of road knowledge \\
\hline Rental car companies do not spend too much time explaining road rules to Chinese tourists \\
\hline Rental car companies do not provide much information about rental car's features to Western tourists \\
\hline There is a lack of consistency in communication by rental car companies \\
\hline
\end{tabular}

The issues highlighted in Table 4.5 are further refined, following the protocols for stating a UDE as outlined by Cox et al. (2012). Within the table, intermediate effect refers to an entity that is neither negative nor positive but it exists as a consequence of other causes, and precondition refers also to a neutral entity but is something over which you have no significant influence (McNally, 2020, p.34).

Table 4.5. 1: Refined list of self-drive tourist participants' described UDEs

\begin{tabular}{|l|}
\hline Infrastructure issues \\
\hline There is lack of roadside infrastructure \\
\hline There are limited public transport options in New Zealand \\
\hline Speed limits shown on signs are not achievable on some roads \\
\hline Driving issues \\
\hline New Zealand roads are challenging to drive (precondition) \\
\hline Self-driving is the only option to access everywhere in New Zealand freely (precondition) \\
\hline Tourists choose to self-drive (intermediate effect) \\
\hline Self-driving on unfamiliar NZ roads is cognitively demanding \\
\hline Self-drive tourists do not follow the maximum speed limit allowed \\
\hline Slow tourist drivers are "unwelcome" on road \\
\hline Local drivers display bad driving behaviours \\
\hline Self-drive tourism issues \\
\hline Self-drive tourists' knowledge level of NZ roads is inconsistent \\
\hline Self-drive tourists' road experience is not always positive \\
\hline Self-drive tourists are not receiving road information consistently \\
\hline
\end{tabular}

Key: Intermediate effect Precondition 
Before advancing to the next stage of constructing a CRT to link these effects and examine what causes self-drive tourists to be perceived negatively by local residents, data from other participant groups on this question "Why change?" will be analysed to discover any similarities and/or differences. 


\subsubsection{Tourism academic participant}

\section{List of UDEs}

The following structure is the same as pervious list of UDEs in section 4.2.1.

Table 4. 6: Descriptions of tourism academic participant's list of UDEs

\begin{tabular}{|l|}
\hline Infrastructure issues \\
\hline There is lack of public transport/road infrastructure \\
\hline Driving issues \\
\hline New Zealand is seen as a self-drive destination \\
\hline New Zealand's scenery can cause distraction to self-drive tourists \\
\hline Self-drive tourists can get distracted by peers when driving \\
\hline Self-drive tourists sometime drive too slowly \\
\hline Speed limit allowed does not align with the road condition \\
\hline Rental car company lack of time to explain road information to tourists \\
\hline Self-drive tourism issues \\
\hline Self-drive tourism is complex and involves a lot of different stakeholders \\
\hline Self-drive tourists lack familiarity with different road rules \\
\hline Some tourists are driving under the influences of jetlag and exhaustion \\
\hline Self-drive tourists who are from similar driving environment may not think critically about the \\
potential risks when driving in New Zealand \\
\hline Photo taking is important for self-drive tourists to capture travel experiences \\
\hline Self-drive tourists' travel/driving decisions can be influenced by travel companions \\
\hline Self-drive tourists lack knowledge about how residents perceive them \\
\hline Media issues \\
\hline Media report more negative new stories than positive stories \\
\hline Media new stories are not representing in an accurate way \\
\hline Media can affect perception in negative ways \\
\hline Perception issues \\
\hline There are other tourism issues that contribute to residents' perception of tourism \\
\hline Self-drive tourists are not aware of how residents perceive them \\
\hline Tourists often think they can do whatever during a holiday \\
\hline Residents' daily schedule are impacted by self-driving activities (e.g. photo-taking) \\
\hline
\end{tabular}


Table 4.6. 1: Refined list of tourism academic participant's described UDEs

\begin{tabular}{|l|}
\hline Infrastructure issues \\
\hline There is lack of public transport infrastructure \\
\hline Driving issues \\
\hline New Zealand has great scenery (pre-condition) \\
\hline Speed limit allowed does not align with the actual road conditions \\
\hline Self-drive tourists lack understanding of NZ road rules \\
\hline Self-drive tourists can get distracted when driving \\
\hline New Zealand is perceived as a self-drive destination (intermediate effect) \\
\hline Self-drive tourism issues \\
\hline Self-drive tourists are overly focused on their personal schedule (pre-condition) \\
\hline Self-drive tourists who are from similar driving background are overly confident \\
\hline Some tourists place less value in meeting other people (e.g. local) \\
\hline Tourists think less about obligation when in holiday mode \\
\hline Self-drive tourists lack of knowledge about how residents perceive them \\
\hline Media issues \\
\hline Media new stories are not represented in an accurate way \\
\hline Media can affect perception in negative ways \\
\hline Perception issues \\
\hline There are other tourism issues that contribute to residents' perception \\
\hline Residents' daily schedule are impacted by self-driving activities (e.g. photo-taking) \\
\hline
\end{tabular}

Key: Intermediate effect Precondition 


\subsubsection{Government expert participants}

\section{Goals}

The government expert participants hold related knowledge of the New Zealand transport system and the positions of other stakeholders (e.g. tourists, residents). They were asked to describe what they think are the goals of self-drive tourism (see Table 4.7).

Table 4. 7: Descriptions of government expert participants' goal

\begin{tabular}{|l|l|}
\hline Participants & Goal descriptions \\
\hline GP1 & $\begin{array}{l}\text { Improve the safety for self-drive tourist, education, and the ability to understand } \\
\text { that our roads are different, and simply understand of where they are different }\end{array}$ \\
\hline GP2 & They have a safe enjoyable experience while they are here. Safety is very important \\
\hline GP3 & It should always be a safe, enjoyable, and reliable experience. \\
\hline GP4 & $\begin{array}{l}\text { Places to rest, invest money into those regions, passing lane areas, so people can } \\
\text { travel safety }\end{array}$ \\
\hline GP5 & $\begin{array}{l}\text { Visitor safety is a fundamental aspect, safe vehicle and roading network. We want } \\
\text { a high-quality visitor experience, include the roads but also the experiences and } \\
\text { destination on offer. }\end{array}$ \\
\hline Common goal & High quality visitor experience \\
\hline
\end{tabular}

Despite the government experts having different expertise and holding different roles, the responses given to this question are consistent. That is, they emphasise the road safety aspect and their desire that tourists have a good self-drive experience; whether domestic or international. 


\section{CSFs and NCs}

This follows the same pervious structure.

Table 4. 8: Descriptions of government expert participants' CSFs and NCs

\begin{tabular}{|c|c|c|}
\hline Government experts & CSFs & NCs \\
\hline \multirow[t]{5}{*}{ GP1 } & $\begin{array}{l}\text { Strong roading network } \\
\text { (CSF1) }\end{array}$ & $\begin{array}{l}\text { Good transport infrastructure } \\
\text { (NC1.1) }\end{array}$ \\
\hline & Regional dispersal (CSF2) & $\begin{array}{l}\text { Tourist education and } \\
\text { communication (NC2.1) }\end{array}$ \\
\hline & $\begin{array}{l}\text { Destination management } \\
\text { planning (CSF3) }\end{array}$ & $\begin{array}{l}\text { Encourage public transport and } \\
\text { other viable options (NC4) }\end{array}$ \\
\hline & \multirow[t]{2}{*}{ Accessibility (NC2.3) } & $\begin{array}{l}\text { Support from local } \\
\text { communities (NC3.1) }\end{array}$ \\
\hline & & $\begin{array}{l}\text { Accessibility to regions } \\
(\mathrm{NC} 2.3)\end{array}$ \\
\hline \multirow[t]{4}{*}{ GP2 } & A good bus system (NC1.1) & $\begin{array}{l}\text { Education of local } \\
\text { communities (NC3.1) }\end{array}$ \\
\hline & $\begin{array}{l}\text { Good relationship between } \\
\text { locals and visiting tourists } \\
\text { (NC3.1) }\end{array}$ & Good road signs (NC1.1) \\
\hline & \multirow[t]{2}{*}{$\begin{array}{l}\text { Education from rental car } \\
\text { company (NC2.1) }\end{array}$} & $\begin{array}{l}\text { Investment in infrastructure } \\
\text { (NC1.1.1) }\end{array}$ \\
\hline & & $\begin{array}{l}\text { Positive media new stories of } \\
\text { self-drive tourists (NC5) }\end{array}$ \\
\hline GP3 & $\begin{array}{l}\text { Strong roading network } \\
\text { (CSF1) }\end{array}$ & $\begin{array}{l}\text { Appropriate speed limits } \\
\text { (NC1.1) }\end{array}$ \\
\hline
\end{tabular}




\begin{tabular}{|c|c|c|}
\hline & Good infrastructure (NC1.1) & $\begin{array}{l}\text { Government initiatives } \\
\text { (NC3.2) }\end{array}$ \\
\hline & $\begin{array}{l}\text { Good communication to } \\
\text { tourists (NC2.1) }\end{array}$ & \\
\hline \multirow[t]{5}{*}{ GP4 } & Regional dispersal (CSF1) & $\begin{array}{l}\text { Investment in infrastructure } \\
\text { (NC1.1.1) }\end{array}$ \\
\hline & $\begin{array}{l}\text { Strong roading network } \\
\text { (CSF2) }\end{array}$ & $\begin{array}{l}\text { Good attitude toward visitors } \\
\text { (NC3.1) }\end{array}$ \\
\hline & $\begin{array}{l}\text { Good roadside infrastructure } \\
\text { (NC1.1) }\end{array}$ & $\begin{array}{l}\text { Regional government } \\
\text { initiatives (NC3.2) }\end{array}$ \\
\hline & \multirow[t]{2}{*}{$\begin{array}{l}\text { Destination management } \\
\text { planning (CSF3) }\end{array}$} & $\begin{array}{l}\text { Understanding of different } \\
\text { tourist market (NC3.3) }\end{array}$ \\
\hline & & Balanced media stories (NC5) \\
\hline \multirow[t]{4}{*}{ GP5 } & $\begin{array}{l}\text { Strong roading network } \\
\text { (CSF1) }\end{array}$ & Good road signs (NC1.1) \\
\hline & Tourist education (NC2.1) & $\begin{array}{l}\text { Investment in infrastructure } \\
\text { (NC1.1.1) }\end{array}$ \\
\hline & \multirow[t]{2}{*}{$\begin{array}{l}\text { Destination management } \\
\text { planning (CSF3) }\end{array}$} & $\begin{array}{l}\text { Cooperation across } \\
\text { government departments } \\
(\mathrm{NC} 2.2)\end{array}$ \\
\hline & & $\begin{array}{l}\text { Communication with media } \\
\text { (NC5) }\end{array}$ \\
\hline
\end{tabular}




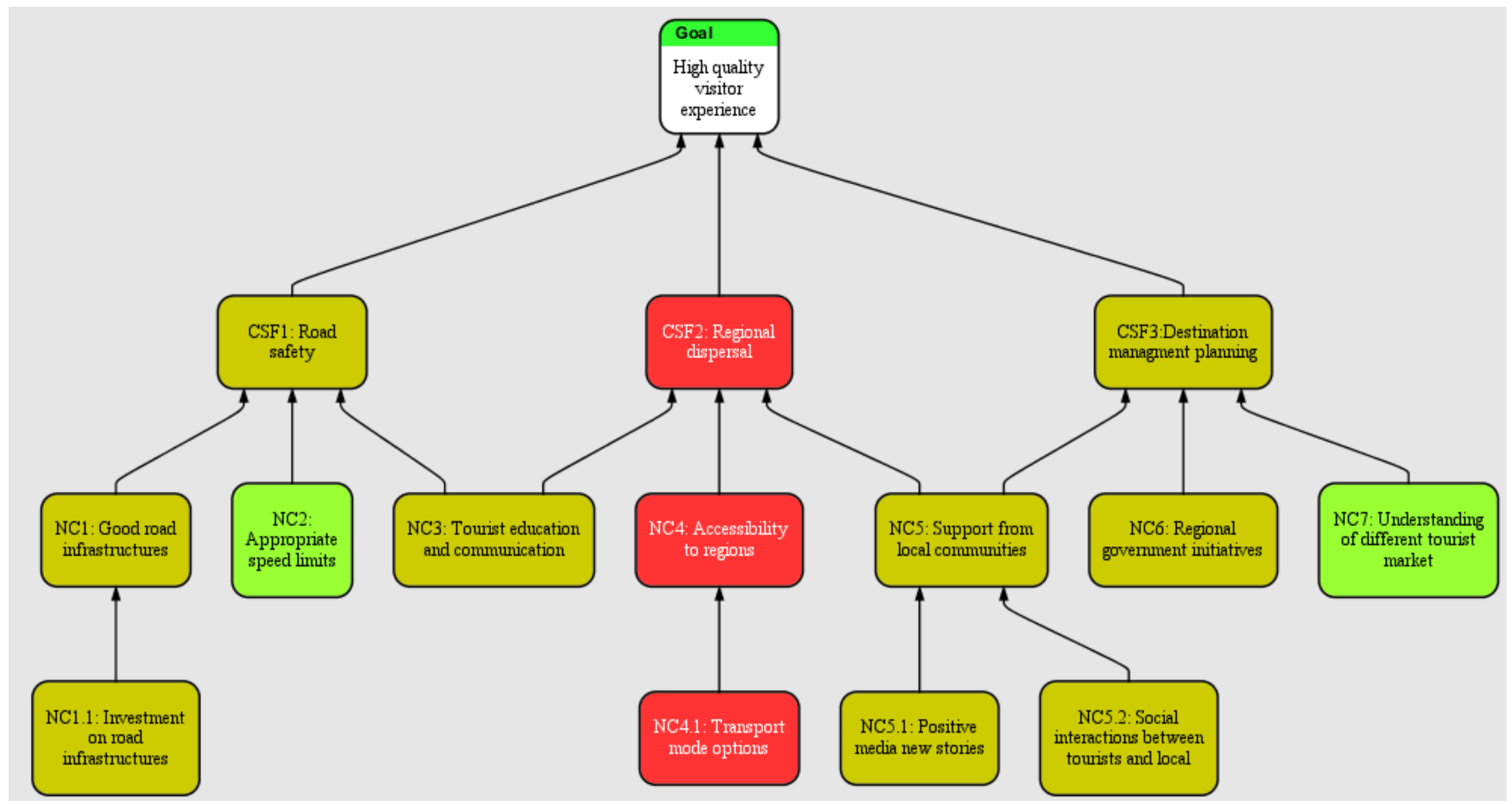

Figure 4. 2: Government experts' GT 
Comparing the government experts' GT (see Figure 4.2) with the self-drive tourists GT (see Figure 4.1); both participant groups have "Good experience" as their common goal. However, in terms of CSFs, the self-drive tourist group places stronger emphasis on personal factors such as "Sense of freedom" (see Figure 4.1) as prerequisites to achieve their goal. The below quote indicates self-drive tourists' strong desire of personal wants:

See as much as possible, have the freedom to decide in the morning depend on the weather, where and when to drive. (TP3)

In contrast, government experts' CSFs focus more on the collective benefits for both tourists and residents, such as Road safety (see Figure 4.2). Their main purpose is to support safe travel and to ensure regions benefits from tourism. An important enabler for regions to benefit from tourism is through self-drive tourism, as noted by some of the participants:

Self-drive tourism is the important part of the offering here to support regional dispersals, to get more people around the country. (GP4)

That is about encouraging spending in our regions, participating activities. (GP5)

Plans to achieve these CSFs have been initiated, as stated by the government participants:

The government has got a large program of work to improve the safety of the whole network, which will benefit all our visitors and locals. (GP3)

There are many programs of work to improve the overall road safety for everyone. (GP3)

However, such plans are not yet well-implemented

In terms of government priority, it is around destination management planning, accessibility, safety, these are all factors considered in that space. In terms of that, we are just beginning. (GP5) 


\section{List of UDEs}

The current self-drive system is not yet aligned with the desired system (GT), according to government expert participants, who are also speaking on behalf of residents (see Table 4.9).

Table 4. 9: Descriptions of government expert participants' list of UDEs

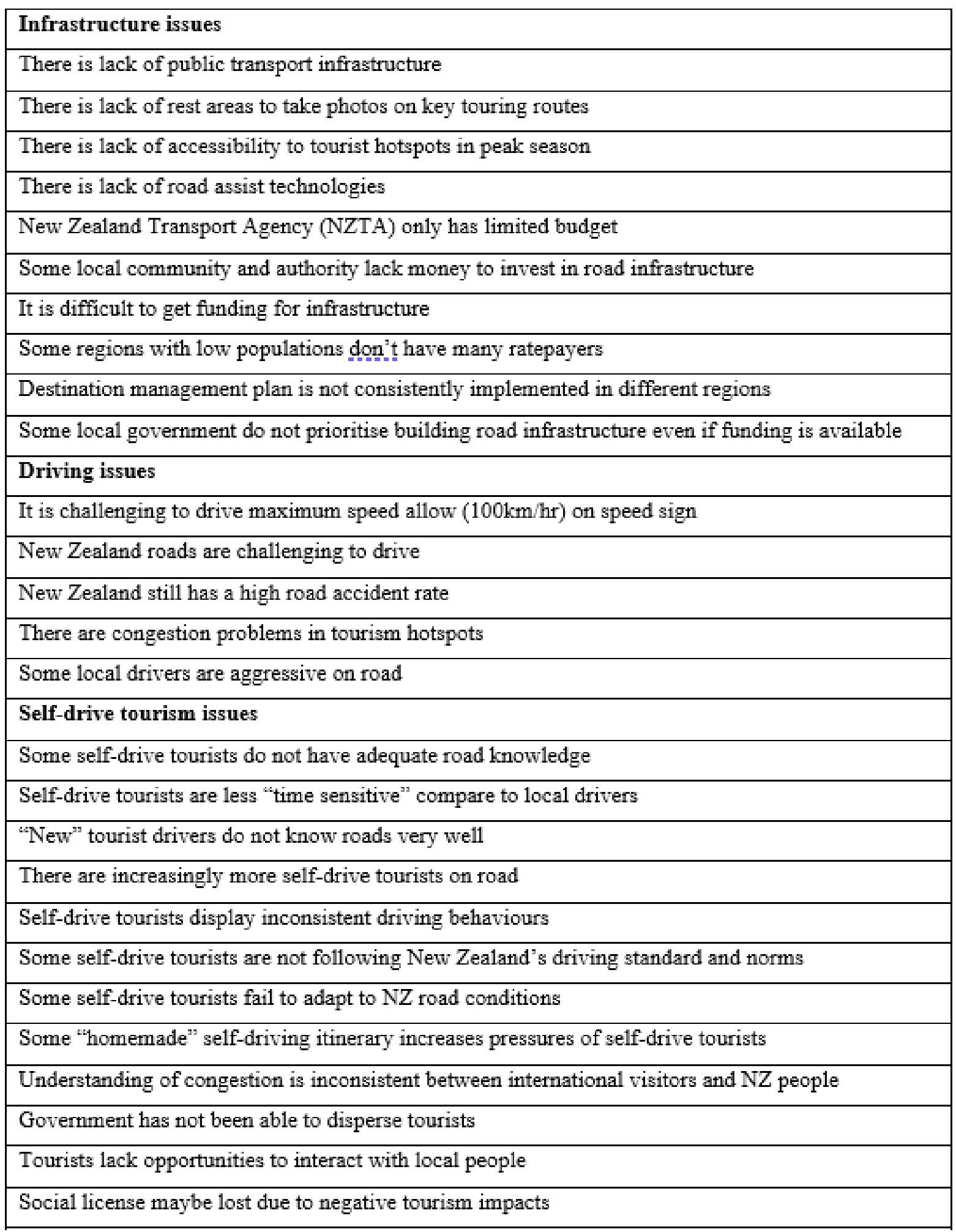




\begin{tabular}{|l|}
\hline Media issues \\
\hline Negative stories are very influential via media channels \\
\hline It is challenging to maintain consistent relationship with the media \\
\hline Media sector has high staff turnover rate \\
\hline Some media stories published are not based on evidence and data \\
\hline People like to read negative stories about tourism \\
\hline Residents' perception is fed and fuelled by media \\
\hline Perception issues \\
\hline There is a perception that international tourists are causing congestions \\
\hline Local communities are extremely concerned about visiting drivers \\
\hline Some residents do not make visiting tourists feel welcome \\
\hline Crash-related statistics are not consistently understood by New Zealand residents \\
\hline Negative world of mouth about self-drive tourists are spread amongst local communities \\
\hline New Zealand residents like to make negative assumptions about rental car and self-drive tourist on \\
road \\
\hline There is a streak of racism towards Asian international visitors \\
\hline New Zealand people do not like to self-reflect \\
\hline Some local have misconceived ideas about international tourists \\
\hline Self-drive tourists are affecting residents' day to day life \\
\hline On-going challenges in communication between government and community \\
\hline Rental cars are always perceived to be driven by international tourists \\
\hline Asian self-drive tourists are targeted more often than others \\
\hline
\end{tabular}

The list of UDEs is further refined (see Table 4.9.1). 
Table 4.9. 1: Refined list of government expert participant's described UDEs

\begin{tabular}{|l|}
\hline Infrastructure issues \\
\hline There is only limited government budget \\
\hline There is lack of public transport infrastructures \\
\hline New Zealand transport system is under stress \\
\hline Some local government do not prioritise road infrastructures even if funding is provided (pre- \\
condition) \\
\hline Driving issues \\
\hline New Zealand has a congestion problem in peak season \\
\hline New Zealand still has high road accident rate \\
\hline New Zealand roads are challenging to drive \\
\hline It is challenging to maintain maximum speed allowed (100km/hr) on roads \\
\hline New Zealand has regional dispersal problems \\
\hline Self-drive tourism issues \\
\hline New Zealand has increasingly more self-drive tourists (pre-condition) \\
\hline Self-drive tourists display bad driving behaviours \\
\hline Self-drive tourists primarily focus on their own pleasure rather than others \\
\hline Self-drive tourists are adversely? affecting residents' day to day life (intermediate effect) \\
\hline Media issues \\
\hline Some media stories are not based on hard evidence and facts (pre-condition) \\
\hline Media sector has high staff turnover rate \\
\hline Perception issues \\
\hline Residents' perception is fuelled and fed by media \\
\hline There is a streak of racism towards Asian international tourist \\
\hline Negative stories are very influential via media channels \\
\hline Residents do not have accurate knowledge about self-drive tourists \\
\hline Residents perceive self-drive tourists negatively \\
\hline There is some aggressive driving behaviour on road against rental cars \\
\hline The public are drawn to negative new stories \\
\hline There are on-going challenges in communication between government and community \\
\hline Intermediate effect Precondition \\
\hline
\end{tabular}




\subsubsection{Residents' perceptions survey reports}

Two on-going survey reports on residents' perceptions of tourism were used to complement and/or triangulate the government experts' advice.

\section{Mood of the Nation survey 2015-2020}

The Mood of the Nation survey conducted by Tourism New Zealand (TNZ) and Tourism Industry Aotearoa (TIA) measures New Zealanders' perceptions of tourism twice yearly with a sample size of over 1,000 (TNZ, 2020).

Between 2015 and 2020, the top three pros and cons of tourism perceived by residents' remained reasonably consistent (Kantar, 2015; Kantar, 2016; Kantar, 2017; Kantar, 2018; Kantar, 2019; Kantar, 2020).

The top three pros of tourism are:

1. Creates economic growth for the regions.

2. Creates growth opportunities for businesses.

3. Creates employment opportunities for residents.

The top three cons of tourism are:

1. Increases the risk of serious road accidents.

2. Results in increased traffic congestion on holiday routes.

3. Results in a higher number of road accidents.

One inconsistency was the $3^{\text {rd }}$ con "Results in a higher number of road accidents" which was replaced by "Results in increased littering” in years 2017 and 2019.

In addition, the survey results in 2015 also stated that the key contributor to residents' perceived cons of tourism is likely to be because of media:

Media is likely to be a key contributor to the most commonly perceived negative aspects of tourism, all of which focus on our roads. (Kantar, 2015 p.17)

However, negative news of self-drive tourism has eased in recent years due to the government's communications with commercial media: 
The media plays an incredible role, that's why the central government agreed on a policy and communication plan, that when a road accident happens, people's nationality will not be published because it sparks perception and assumptions that are incorrect. (GP5)

If I use the visitor driver example, the media was a lot worse 3-4 years ago compared to now and a lot of the improvement is because we [government] try really hard to inform the media and local community about the crash statistics... and we're seeing more balanced reporting. (GP3)

Presumably, with the decreased exposure of negativity by media, residents' perceptions of selfdrive tourism should improve. However, according to the surveys, the top three perceived cons of tourism remained generally consistent, usually related to road use. This suggests that there may be other factors influencing residents' perceptions.

Indeed, some verbatim comments from the Mood of the Nation surveys in 2019 and 2020 include:

We do not have the infrastructure/public transport or the resources to maintain our highways. (Kantar, 2019, p.26)

Tourist spots are too crowded, we don't have the infrastructure to support, they don't respect our country... Overcrowding at tourist spots and on the roads. (Kantar, 2020, p.19)

These suggest the persistence of negativity towards self-drive tourism despite the easing of negative stories. These results are consistent with the government participants' comments, such as:

There seems to be a perception of congestions in some of the really popular tourism sites that means that locals cannot access it, and it doesn't feel right. (GP3) 


\section{Views on Tourism survey 2019-2020}

The Views on Tourism survey also measures residents' perceptions on tourism using a different set of questionnaires and sampling sizes; its survey analysis yielded similar results.

On-going Views on Tourism survey reports by Angus and Associates measure public opinion on the value of inbound and domestic tourism, and the extent of adverse impact that tourism might bring (Angus and Associates, 2019).

Between July 2019 and June 2020, 2,863 New Zealander's were surveyed. The most selected perceived negative impacts that tourism brought are:

- It takes longer to get to a place due to traffic/congestion.

- Greater difficulty finding a car park.

- I/we have observed increased litter and waste generation.

Comparing Views on Tourism survey results to the Mood of the Nation survey results between 2019 and 2020, the most selected negative impacts in both surveys are congestion and littering. In addition, verbatim comments from Views on tourism surveys also highlighted residents' comments about self-drive tourism:

Not racist, but I have followed campervans going all over the road. The foreign drivers don't bother to stop at an intersection... Foreigners need to do a defensive driving course or sit for an NZ driver's license. They are causing many accidents and will continue to do this. (Angus and Associates, 2020)

It should be compulsory for tourists to sit for a driver's licence here or not drive at all. (Angus and Associates, 2020)

These verbatim comments indicate some lingering negative opinions about self-drive tourists despite an increase of balanced new stories. The comments also reflect prejudice against selfdrive tourism, as these government experts highlighted:

There are some perceptions amongst New Zealanders, that concerns international visitors and their driving... even though we know that only $6 \%$ of serious and fatal accidents in NZ are involved/caused by international drivers. (GP4)

I certainly see in the visiting driver space, that locals have the perception that international visitors are causing all the crashes...The vast majority of crashes are locals, not international visitors. (GP3) 
Negative stories about self-drive tourism in earlier years may have influenced the perceptions of residents. More critically, residents' encounters with bad driving behaviour may remind them of negative stories seen in the media, subsequently linking it to self-drive tourism.

This residual resentment towards self-drive tourism is also evident in the two survey reports discussed above. However, some of the comments such as "self-drive tourists are causing the road accidents" displays a lack of understanding and indicates a prejudiced view of self-drive tourism.

Residents' UDEs are summarised below in Table 4.10 and refined in Table 4.10.1.

Table 4. 10: Descriptions of New Zealand residents' list of UDEs

\begin{tabular}{|l|}
\hline Infrastructure issues \\
\hline There is lack of public transport infrastructure \\
\hline New Zealand does not have adequate infrastructure to support increasing tourism \\
\hline There is not enough support placed from councils or government \\
\hline Areas are having difficulties coping with increased tourism activities \\
\hline Self-drive tourism issues \\
\hline Self-drive tourists are responsible for causing road congestion \\
\hline Self-drive tourists increase the risk of serious road accidents \\
\hline Self-drive tourists result in higher numbers of road accidents \\
\hline Self-drive tourists lack understanding of New Zealand road rules \\
\hline Increased tourist numbers will exacerbate already existing problems \\
\hline New Zealand residents feel less safe driving \\
\hline Media issues \\
\hline Media is contributing to the negative aspects of self-drive tourism \\
\hline
\end{tabular}


Table 4.10. 1: Refined list of New Zealand resident's described UDEs

\begin{tabular}{|l|}
\hline Infrastructure issues \\
\hline There is lack of road infrastructure \\
\hline Areas are having difficulties coping with increased tourism activities \\
\hline There is not enough support from councils or government \\
\hline Increased tourist numbers will exacerbate already existing problems \\
\hline Self-drive tourism issues \\
\hline Self-drive tourists lack understanding of New Zealand road rules \\
\hline Self-drive tourists are the cause to road accidents \\
\hline Media issues \\
\hline Media is contributing to the negative aspects of self-drive tourism \\
\hline
\end{tabular}

\subsubsection{Media sector}

\section{Goal, CSFs and NCs}

It is visible that the media sector can influence how residents perceive self-drive tourism:

The media is very influential, and fortunately they are being more responsible [now], in my view, of stories that have been published [lately]. (GP2)

It is important to look at how the media functions, hence this sub-section will analyse the data from media participants to explore their perspectives.

According to the senior journalist interviewed, the core function of media is to inform the general public about important issues:

I think in an ideal world, you want the media to be reporting the truth, to be reporting things that are important to everyday people. You want to report on what government is doing, whether the government is delivering on promises that you elected them in for, say that NZTA are delivering what they supposed to be delivering. (JP1)

However, there are differences between commercial and government owned media as AP2 explained:

Most of the news media [in NZ] are run as commercial businesses, although they do have a function in informing the general public, providing analyses of social issues. They are also there to make money. (AP2) 
If you are a public service broadcaster, you don't have to worry as much about the rating or attractiveness of news content... they [public service] are not just publishing what is the most popular, they also providing information and education. A lot of commercial media don't do a very good job on that. (AP2)

The above quotes explained that the media's goal is about informing the public. However, commercial media has emphasised pursing profit is their major goal. Therefore, their news contents need to be attractive enough to the public to lure subscriptions or generate revenue from advertising, hereby, undermining the purpose of public informing and educating:

If you are trying to make money...You need to make the content attractive...that in turn significantly limits the range of contents that can be produced. (AP2)

They [commercial media] are very good at entertaining but not always very good at informing and educating. (AP2)

Therefore, two GTs are presented for the media sector (see Table 4.11 and 4.12).

Table 4. 11: Descriptions of non-commercial media's goal, CSFs and NCs

\begin{tabular}{|l|l|l|}
\hline Goal & To inform the public of important issues (non-commercial media) \\
\hline Participants & CSFs & NCs \\
\hline AP2 & Financial sustainability (CSF1) & More budget allocation (NC2.2) \\
\cline { 2 - 3 } & Balanced new stories (CSF2) & Good journalists (NC1.2) \\
\cline { 3 - 3 } & & Accurate information source (NC1.1) \\
\hline JP1 & $\begin{array}{l}\text { Reporting things that are important to } \\
\text { everyday people (CSF2) }\end{array}$ & Correct data and evidence (NC1.1) \\
\cline { 2 - 3 } & Balanced new stories (CSF2) & Accurate information source (NC1.1) \\
\cline { 3 - 4 } & & Enough time and resources (NC1.1.1) \\
\hline
\end{tabular}


Table 4. 12: Descriptions of commercial media's goal, CSFs and NCs

\begin{tabular}{|l|l|l|}
\hline Goal & \multicolumn{2}{|l|}{ To make a profit (commercial media) } \\
\hline Participants & CSFs & NCs \\
\hline AP2 & $\begin{array}{l}\text { Advertising dollar and subscriptions } \\
\text { (CSF1) }\end{array}$ & Good quantity of stories (NC2.2) \\
\cline { 2 - 3 } & $\begin{array}{l}\text { To reach large numbers of audiences } \\
\text { (NC1.1) }\end{array}$ & Interesting stories (NC1.2) \\
\cline { 3 - 3 } & & Good headline framing (NC1.2.1) \\
\hline JP1 & To produce interesting stories (NC1.2) & Headline framing (NC1.2.1) \\
\cline { 3 - 3 } & & $\begin{array}{l}\text { Write stories that interest the public } \\
\text { (NC2.1) }\end{array}$ \\
\cline { 3 - 3 } & & Enough time and resources \\
\hline
\end{tabular}

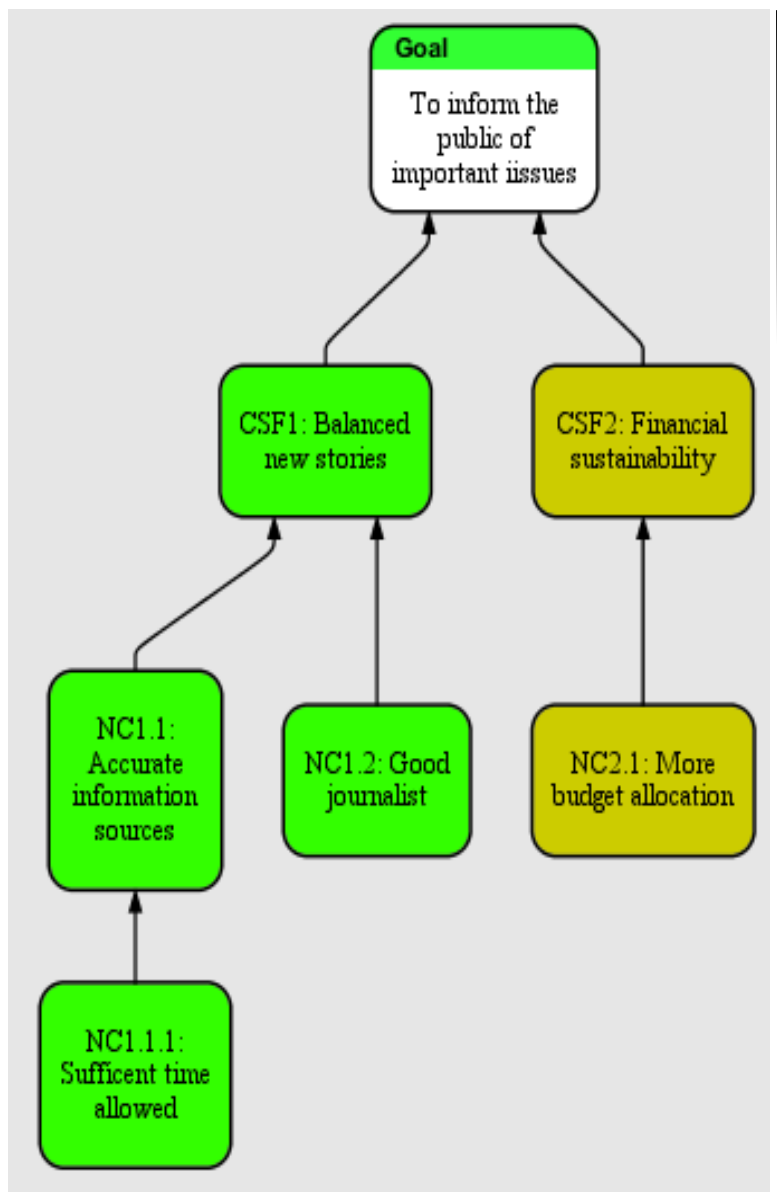

Figure 4. 3: Non-commercial media's GT

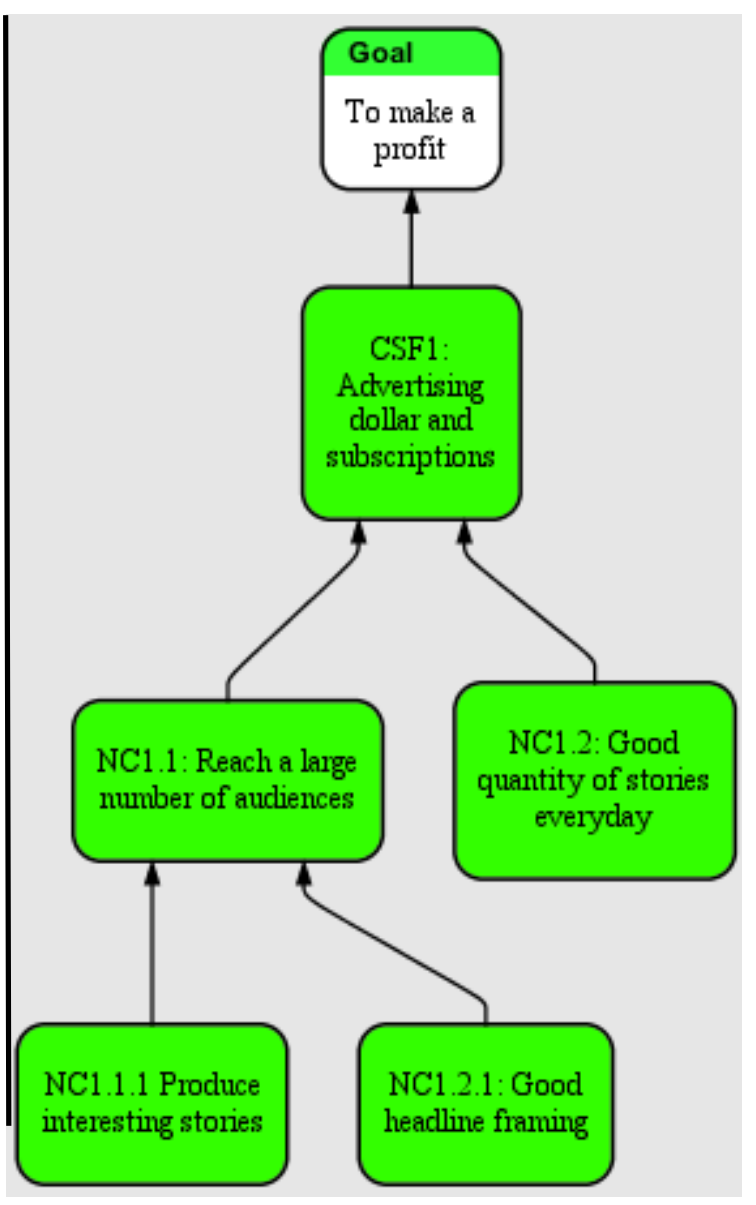

Figure 4. 4: Commercial media's GT 
When asked if the current media environment is close to the desired system, AP2 has illustrated that the non-commercial media (e.g. RNZ) is close to the "perfect world" (see Figure 4.3):

It is reasonably close to the ideal [RNZ]. It has comprehensive new services, it employs a lot of good journalists, it is willing to question the government and the industry. (AP2)

In contrast, commercial media has come under criticism for prioritising stories that lead to better profit. They certainly have journalists who wish to inform the public about important issues; however, it is dictated by the story preferences of the audience and the needs of the shareholders. Consequently, this erodes their motivation to inform the public of important issues:

I think the other media [commercial], there are still a lot of good journalists, but they operate in an environment where the decision about how you spend the resources is always configured in alignment with the needs of the shareholders.

As seen in the commercial media GTs (see Figure 4.4), the focus on profit making requires them only to be as interesting as possible and with a good number of stories produced every day. As an analogy, AP2 described, "commercial media is like KFC and public service is like green vegetables- it is important to have a balanced diet".

Not surprisingly, most of the UDEs are derived from commercial media, acting as constraints preventing "good stories" being reported (see Table 4.13). 
Table 4. 13: Descriptions of media participants' list of UDEs

\begin{tabular}{|l|}
\hline Media issues \\
\hline There is lack of journalists in New Zealand \\
\hline The public often forget what important news are \\
\hline Positive new stories do not interest people as much \\
\hline There is often bias when journalists report a story \\
\hline Audience can become more sensitive to negative stories \\
\hline There is a structural problem in the media sector \\
\hline Positive new stories do not get representative enough \\
\hline The public enjoy reading negative stories \\
\hline The majority of media in New Zealand is owned by commercial businesses \\
\hline Media new stories are not "controllable" by government \\
\hline Commercial media issues \\
\hline There is lack of accuracy in news headlines \\
\hline Stories that are lucrative to the public might not be as important \\
\hline There is lack of time to investigate a story \\
\hline Commercial media prefer to "feed" stories that public like \\
\hline Commercial media emphasise on generating revenue \\
\hline Commercial media journalists are under great amount of stress \\
\hline There is lack of budget in commercial media \\
\hline Advertising dollars are diminishing in the commercial media \\
\hline
\end{tabular}


Table 4.13. 1: Refined list of media participant's described UDEs

\begin{tabular}{|l|}
\hline General media issues \\
\hline There is lack of journalists in New Zealand \\
\hline Most media in New Zealand are owned by commercial businesses (pre-condition) \\
\hline Negative stories are more attractive to the public \\
\hline There is often bias when journalists report a story \\
\hline Commercial media issues \\
\hline There is high time pressure in commercial media \\
\hline There is lack of exposure of positive new stories \\
\hline Profit is a critical factor for commercial media to sustain (intermediate effect) \\
\hline Commercial media prefer to "feed" stories that public like \\
\hline Social media channels (e.g. Facebook) are squeezing the revenue gain of commercial media \\
\hline There is lack of time to investigate a story \\
\hline There is lack of accuracy in news headlines \\
\hline
\end{tabular}

Key: Intermediate effect Precondition

\subsection{Summary of "Why change?"}

This section illustrated "Why change?" by first determining the desired state of each system (GTs) and then comparing this with the current state to identify if gaps exist. The resulting gaps according to participants are indicated in their lists of UDEs that stop the desired state from being achieved. To gain better insights, the next section "What to change?" will logically organise these UDEs to construct a CRT. From the CRT, the root causes and core problems of these UDEs should surface and then the conflicts and/or dilemmas can be identified. 


\subsection{What to change?}

This section aims to answer the third sub-objective:

3. To identify the causes of residents' negative perceptions of self-drive tourism via causeand-effect logic.

The UDEs lists reveal themes that are reoccurring and highlighted by a great majority of the participants. Table 4.14 shows the different themes and which participant groups have mentioned them.

Table 4. 14: List of UDE themes

\begin{tabular}{|l|c|c|c|c|c|}
\hline UDE Themes & TP & \multicolumn{1}{l|}{ GP } & AP1 & AP2/JP & Residents \\
\hline Infrastructure issues & $\sqrt{ }$ & $\sqrt{ }$ & $\sqrt{ }$ & & $\sqrt{ }$ \\
\hline Driving issues & $\sqrt{ }$ & $\sqrt{ }$ & $\sqrt{ }$ & & \\
\hline Self-drive tourism issues & $\sqrt{ }$ & $\sqrt{ }$ & $\sqrt{ }$ & & $\sqrt{ }$ \\
\hline Media issues & & $\sqrt{ }$ & $\sqrt{ }$ & $\sqrt{ }$ & $\sqrt{ }$ \\
\hline Perception issues & & $\sqrt{ }$ & $\sqrt{ }$ & $\sqrt{ }$ & \\
\hline
\end{tabular}

As shown above, infrastructure, self-drive tourism and media issues are the most mentioned themes by the participants, this suggests that most of the problems are within these three themes. However, depending on the goal and the participants the areas of concern carry differing emphasis. For example, residents (from the survey reports) focus more on expressing opinions about self-drive tourism, while the self-drive tourist participants are more vocal about their interactions with other drivers.

The second step of the TOC TP addresses "What to change?" The lists of UDEs in the "Why change?" are further refined (see Table 4.15), this refined list is used to create the CRT as depicted in Figure 4.5. 
Table 4. 15: Further refined list of UDEs

\begin{tabular}{|c|c|}
\hline & Infrastructure issues \\
\hline 24 & There is lack of viable transport options \\
\hline 23 & New Zealand roads do not have good road infrastructures \\
\hline 22 & There is only limited government budget \\
\hline 21 & Destination management plan is not consistently implemented in different regions \\
\hline 20 & $\begin{array}{l}\text { Some local government do not prioritise building road infrastructures even if funding is } \\
\text { available }\end{array}$ \\
\hline \multirow[t]{2}{*}{30} & New Zealand has a regional dispersal problem \\
\hline & Driving issues \\
\hline 27 & New Zealand roads are challenging to drive (intermediate effect) \\
\hline 25 & $\begin{array}{l}\text { Self-driving is perceived the best option to access everywhere in New Zealand freely } \\
\text { (intermediate effect) }\end{array}$ \\
\hline 26 & Tourists choose to self-drive (intermediate effect) \\
\hline 19 & New Zealand has great scenery (precondition) \\
\hline 18 & Speed limit allowed does not align with the actual road conditions \\
\hline 28 & Self-drive tourists can get distracted when driving \\
\hline 16 & New Zealand is promoted as a self-drive destination (precondition) \\
\hline 31 & New Zealand has a congestion problem in peak season \\
\hline 14 & Self-drive tourists are not receiving road information consistently \\
\hline \multirow[t]{2}{*}{36} & Driving decisions are challenging \\
\hline & Self-drive tourism issues \\
\hline 17 & Self-drive tourists lack understand of New Zealand road rules \\
\hline 13 & Self-drive tourists who are from similar driving background are overly confident \\
\hline 10 & Tourists think less about obligation when in holiday mode \\
\hline 9 & New Zealand has increasingly more self-drive tourists (intermediate effect) \\
\hline 29 & Self-drive tourists display bad driving behaviours \\
\hline 32 & Self-drive tourists are affecting residents' day to day life \\
\hline 8 & Self-drive tourists lack knowledge about how residents perceive them \\
\hline 11 & Some tourists place less value in meeting other people (e.g. local) \\
\hline \multirow[t]{2}{*}{39} & Tourists have no prior experience driving on an unfamiliar side \\
\hline & Perception issues \\
\hline 7 & Residents' perception is fuelled and fed by media \\
\hline 6 & There is a streak of racism towards Asian tourists \\
\hline 12 & Residents do not have accurate knowledge about self-drive tourists \\
\hline
\end{tabular}




\begin{tabular}{|l|l|}
\hline 35 & Residents perceive self-drive tourism negatively \\
\hline 4 & Negative stories attract more interest from the public \\
\hline 5 & There are on-going challenges in communication between government and community \\
\hline & Media issues \\
\hline 3 & Some media stories are not based on hard evidence and facts \\
\hline 1 & There is lack of journalists in New Zealand \\
\hline 34 & The commercial media are encouraged to publish negative stories \\
\hline 2 & There is lack of time to investigate a story \\
\hline 33 & Commercial media like to report stories that attract audience's interest \\
\hline
\end{tabular}

Key: Intermediate effect $\quad$ Precondition 


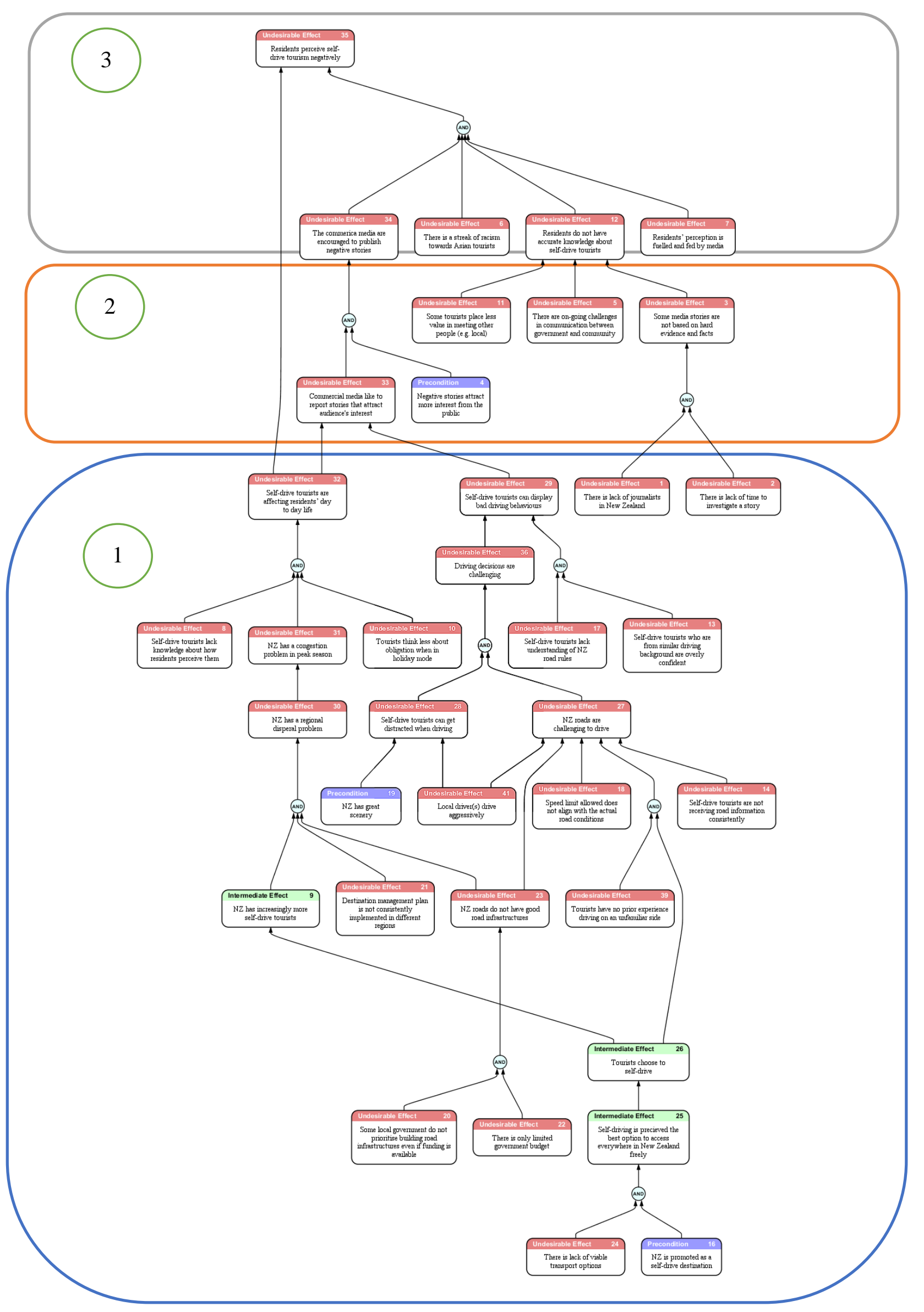

Figure 4. 5: All participants' CRT 


\subsubsection{CRT analysis}

The construction of the CRT (see Figure 4.5) starts from the top with the system's main UDE "residents' perceive self-drive tourism negatively", it is then checked whether the logic holds by reading the CRT bottom up. The researcher looked for connections with and between other UDEs until all UDEs are logically linked. When the causes can be traced down to the root causes (entities that have no additional entities leading into them), the core problems sit at the bottom.

The CRT is read from the bottom (If... then or If...and...then...), for example:

If "there is a lack of transport system" (UDE24) and "New Zealand is promoted as a self-drive destination" (Precondition16), then "Self-driving is perceived the best option to access everywhere in New Zealand freely" (Intermediate effect25).

If (Intermediate effect25), then "Tourists choose to self-drive" (Intermediate effect26), and so on...

The CRT has been divided into stages 1,2 and 3 to facilitate the exposition: stage 1 encompasses infrastructure, driving and self-drive tourism issues; stage 2 depicts media issues; and stage 3 depicts perception issues.

\section{Stage 1}

We do have a lack of transport infrastructure... You can get to main urban centres, towns but a lot of attractions and, scenery are not accessible by public transport. That I suppose is also the reason why the destination image of $\mathrm{NZ}$ is more a self-drive image... (AP1)

We just don't have the infrastructure, we don't have the public transport or transport system to give transport choices, that's why congestion is happening. (GP1)

The above quotes signal that New Zealand generally has a "transport infrastructure issue" (UDE23), which consequently leads to different effects, such as "congestion problems" (UDE31). As part of the infrastructure issue "the lack of viable transport options" (UDE24) is discovered to be one of the root causes to subsequent effects.

The lack of viable transport options (UDE24) and how "New Zealand is promoted as a selfdrive destination" (Precondition16) have influenced tourists to perceive "self-driving as the best option to explore New Zealand" (Intermediate effect25), thus "encouraging tourists to choose to self-drive" (Intermediate effect26). However, this choice made by tourists soon 
results in the discovery that "New Zealand roads are challenging to drive" (UDE27), especially for the tourists who have had no prior experience driving on unfamiliar roads.

It is apparent that before tourists embark on their self-drive journey in New Zealand, few tourists have a strong knowledge of New Zealand roads; this is exacerbated when rental car operators "do not provide road information to every tourist" (UDE14). It was found that when Western tourist participants engaged with rental car operators, they received little road information and were not questioned about their driving experience.

In contrast, Asian tourist participants were given road information and questioned on whether they have enough road knowledge to drive in New Zealand. This suggests that rental car operators may have a perception that Asian tourists need more education, whereas Western tourists are "fine" to drive:

They asked if I have driven before, if I know any road rules in NZ and I replied I did my research prior to and on arrival in NZ. (Chinese tourist, TP6)

They only told me that I am not supposed to drive off road, that's it. (Western tourist, TP1)

Another finding is that Western tourist participants did not conduct very much research before driving in New Zealand, whereas the Chinese tourist participants were more cautious about their driving in an unfamiliar country (New Zealand):

I thought it would be difficult to drive on the left-hand side, but expected most of the road rules are similar, except driving on the other side. (Western tourist, TP2)

I read the road code questions and tested myself, and took screenshots where I found useful and important. (Chinese tourist, TP7)

Why the Western tourists feel more "experienced" about the roads was explained by the tourism academic participant; tourists who have a similar driving culture think that New Zealand roads are similar to their home country:

You are not necessarily aware of the massive difference and how driving and transport works.

So, that might contribute to Western tourists, maybe not thinking critically enough or being aware of the potential risk coming with that. (AP1)

While self-driving in New Zealand tourists have experienced many challenges. One of the most mentioned UDEs is the "allowable speed limit which does not seem to align with the actual road conditions" (UDE18). Some comments include: 
The speed limit was $100 \mathrm{kmph}$, but I cannot drive to the full speed as there are corners and hills. (TP3)

Road signs here say you can drive $100 \mathrm{kmph}$, but you can't because of the road conditions. (TP4)

Government expert participants also acknowledge this problem, one commenting:

We label our road $100 \mathrm{~km}$ an hour, but we can't do that speed limit on the road, it is difficult to stick to those limits. (GP1)

Self-drive tourist participants have also complained that resident drivers are driving aggressively, which "places unnecessary pressure on them and can distract their driving" (UDE 41, 26):

Locals coming the opposite direction is like twice the speed you are doing. (TP2)

I feel stressed, as local drivers drive very fast. (TP7)

However, one of the most significant problems is that "New Zealand does not have a strong road infrastructure" (UDE23), illustrated in earlier quotes by AP1 and GP1. The insufficient road infrastructure was said to be due to "limited funding" (UDE22) and "lack of resource allocation by local government" (UDE20). These causes lie at the base of the CRT and are thus deemed to be the core problems:

NZTA only has a limited budget, it can be difficult to get the funding, funding is an issue. (GP4)

If we have more money, we can make roads a lot safer. The question is have we got enough money to treat our main routes? (GP2)

As an effect of these causes (UDE23, 18 \& 14), "self-drive tourists found it is challenging to drive on New Zealand roads" (UDE27) and thus "driving decisions can be challenging" (UDE36).

However, "the lack of viable transport options" (UDE24), together with "New Zealand being promoted as a self-drive destination" (Precondition16), New Zealand has encouraged tourists to self-drive. "The increase of self-drive tourists" (Intermediate effect9) combined with UDE23 and UDE21, results in ineffective regional dispersal, causing congestion issues in New Zealand, especially in the peak season: 
Congestion, because we have got increasing visitors who want to come here... the capacity for self-drive tourists is limited, we can't make any more capacity in some of these locations (e.g. Queenstown). You always will have the congestion problem. (GP3)

We haven't been able to disperse people as well, yep that is congestions. (GP1)

The congestion problem is further exacerbated by how "tourists think less about their obligations when on holiday" (UDE10), as AP1 highlighted:

You are on holiday, you don't really think the way you do at home... on holiday, you are free and you remove all the social norms and obligations which is also one reason why people often behave terribly. You are not aware of what is acceptable in this country (NZ), because people think we are on holiday and we just do whatever. (AP1)

In combination, these UDEs negatively impact residents' day-to-day life, which contributes to residents' perceptions:

If people [residents] can't carry on their day-to-day life and visitors play some impact, they are going to get frustrated....it is impacting their perception towards visitors. (GP5)

\section{Stage 2}

The outcomes in stage 1 have contributed to two main effects, "Self-drive tourists are affecting residents' day-to-day life" (UDE32) and "Self-drive tourists can display bad driving behaviours" (UDE29). The issues in stage 1 have attracted commercial media's attention (UDE33) and negative news related to these issues is reported because "it can attract more interest from the public" (Precondition4):

I think there is a wider issue with media, because of the way things are for media with commercial interest...they monitor what type of stories go really well... stories about a tourist driver who has their key ripped off by a local, go "gang-busters" on the website and are extremely popular with readers or listeners... (AP2)

Commercial media has been producing new stories that are profitable from "clicks" (e.g. advertising revenue), and such "stories are criticised for not being based on hard evidence and facts" (UDE3), thus providing "inaccurate knowledge about self-drive tourism” (UDE12). Nevertheless, "the lack of journalists" (UDE1) and "time to investigate a story" (UDE2) are the main reasons causing such criticism: 
Time is the main one, because there are less journalists compared to what used to be. Journalists are just rushed off their feet and working constantly, and if you can get a story out that can get huge amount of clicks very quickly, then they will do it. (JP1)

It is very uncommon for somebody to have the time to actually research something properly, it is the difficulties in the modern media landscape [commercial media]. (JP1)

Additionally, journalists who work for commercial media need to meet the interest of shareholders, constraining them from reporting news that is important:

I know a journalist who reported being pestered by his editor (commercial media) to do a report on Kim Kardashian, just because she is a celebrity and she is on the news, even though the journalist had said "Wait a min, that is not news, it is not important, I want to report political news, that is important". (AP2)

\section{Stage 3}

With the exposure of negative media stories about self-drive tourism, residents' perceptions to a certain extent are influenced by such stories. However, it is found that residents also bear preexisting biases towards tourists, especially tourists from Asian countries (e.g. China):

I think there is a streak of racism in it... what we usually hear from the locals is that is our Asian international visitors. I guess they are a little bit more identifiable, because they are in a rental van and they look different, which is not in line with our data as Australians are our biggest international visitors in NZ. But we don't focus on them crashing as much. There is some really fundamental problem at the bottom of that. (GP3)

There was a car that parked behind us, a Kiwi lady about 60 got out and asked us why we drove so slowly... I felt she was angry because I drive too slowly and affect her speed and mood. (Chinese tourist, TP7)

The above quotes indicate residents' prejudice against self-drive tourists and the reasons for such prejudice may due to stereotyping and/or negative media stories: 
I think one big problem is the local perceptions which are in some ways fed by the media, making something out of nothing and not based on data. (GP3)

Some of the locals perception is fuelled by the media who like a good story. The visiting driver is like that 3-4 years ago, any crashes involving rental vehicles, are all over the media. (GP3)

From an academic viewpoint, such prejudice by residents is a combination of media exposure and actual experience. It is also noted, that when "residents' daily life is affected by tourism activities" (UDE32), it tends to directly influence residents' perceptions:

We are talking about a combination of experience here... You didn't know about the 10 tourists who drove past and didn't cause a problem, you nearly had an accident with a rental car, and you got home and think: "Jesus, that crazy tourist nearly killed me". You remember that one...your bad experience with a tourist driver seems to confirm the media representation as correct and accurate, which reinforces your impression that tourists are dangerous drivers... (AP2)

Therefore, the UDEs in stage 1 and 2 have led to the final undesirable effect "Residents perceive self-drive tourism negatively" (UDE35). In other words, this perception issue is "built up" by various UDEs derived in stages 1,2 and 3 .

\subsubsection{CRT summary}

In essence, the fundamental problems in stage 1, such as lack of "Viable transport options" (UDE24), has caused subsequent effects, leading to UDEs such as "Self-drive tourists display bad driving behaviour" (UDE29), and "Tourists adversely affect residents' daily life" (UDE32). These UDEs are then captured by the media as commercial interests and reported to the public, as illustrated in stage 2 , where media, to some extent, exacerbate these issues. In stage 3 , such negative media stories influence residents' perception of self-drive tourism, especially when residents encounter negative experiences with tourists (e.g. on the road), triggering and reinforcing the negativity reported in the news stories, thus contributing to the main UDE: "Residents perceive self-drive tourism negatively" (UDE35). 


\subsubsection{EC analysis}

From the CRT analysis of how residents' negative perceptions are formed, root causes and core problems were discovered.

Moore and Mabin (2014) highlighted that "often the core problem is a result of an unresolved underlying conflict" (p.29). The question now becomes how to remove the core problems, transitioning to the fourth research sub-objective:

4. To identify and propose strategies to mitigate residents' negative perceptions of selfdrive tourism.

Evaporating Clouds (ECs) are constructed to depict the conflicts and/or dilemmas, to surface the underpinning assumptions, and to create injections (ideas) to resolve the conflict, moving the two sides into a win-win situation (Mabin et al., 2020).

Participants were asked to describe the conflicts and/or dilemmas they have experienced or know of in their system and five conflicts relating to the core problems in the CRT were identified (see Table 4.16). For better understanding, Table 4.17 lists the core problems and the accompanying conflicts related to these problems (coloured orange) 
Table 4. 16: Participants' described conflicts

\begin{tabular}{|l|l|l|l|}
\hline Participant & Conflict described & Related problems & Influence level \\
\hline $\begin{array}{l}\text { Government experts } \\
\text { (Figure 4.6) }\end{array}$ & $\begin{array}{l}\text { Continue promoting NZ as a } \\
\text { self-drive destination or stop } \\
\text { promoting NZ as a self-drive } \\
\text { destination }\end{array}$ & $\begin{array}{l}\text { Precondition16, } \\
\text { UDE 24 }\end{array}$ & High \\
\hline $\begin{array}{l}\text { Government experts } \\
\text { (Figure 4.7) }\end{array}$ & $\begin{array}{l}\text { Invest in road infrastructure or } \\
\text { Invest in other projects (not } \\
\text { infrastructure) }\end{array}$ & UDE20, 22, 24 & High \\
\hline $\begin{array}{l}\text { Media sector } \\
\text { (Figure 4.8) }\end{array}$ & $\begin{array}{l}\text { Report news that are negative } \\
\text { but attract public's interest or } \\
\text { report news that are important } \\
\text { but not interesting }\end{array}$ & UDE4 & Medium to high \\
\hline $\begin{array}{l}\text { Tourism academic } \\
\text { (Figure 4.9) }\end{array}$ & $\begin{array}{l}\text { Conflict of interest between self- } \\
\text { drive tourists (enjoying the } \\
\text { journey) and residents (wanting } \\
\text { to get to their destination } \\
\text { quickly) }\end{array}$ & UDE10 & Medium to high \\
\hline $\begin{array}{l}\text { Self-drive tourists } \\
\text { (Figure 4.10) }\end{array}$ & $\begin{array}{l}\text { Drive faster or not to drive faster } \\
\text { UDE18, 14 }\end{array}$ & Low \\
\hline
\end{tabular}

These ECs portray conflicts from different levels. For example, the first EC for government expert participants is concerned about promoting New Zealand as a self-drive tourism destination or not. Such conflict is at a macro level; therefore, potential injections will be more difficult but will have a stronger impact on the system. In contrast, the EC for self-drive tourists is at a much lower level, that is, concerning personal dilemmas, and such injections would have a more localised impact (see Table 4.16). 
Table 4. 17: Core problems from the CRT

\begin{tabular}{|l|l|l|}
\hline Core problems (Stage 1) & Related theme & UDE \# \\
\hline NZ is promoted as a self-drive destination & Self-drive tourism & Precon16 \\
\hline There is lack of viable transport options & Infrastructure & 24 \\
\hline $\begin{array}{l}\text { Some local government do not prioritise building road } \\
\text { infrastructure even if funding is available }\end{array}$ & Infrastructure & 20 \\
\hline There is only limited government budget & Infrastructure & 22 \\
\hline $\begin{array}{l}\text { Destination management plan is not consistently implemented in } \\
\text { different regions }\end{array}$ & Infrastructure & 21 \\
\hline Tourists have no prior experience driving on the left-hand side & Self-drive tourism & 39 \\
\hline Speed limit allowed does not align with the actual road conditions & Driving & 18 \\
\hline Self-drive tourists are not receiving road information consistently & Driving & 14 \\
\hline Self-drive tourists who are from similar driving backgrounds are & Self-drive tourism & 13 \\
\hline overly confident & & 17 \\
\hline Self-drive tourists lack understanding of NZ road rules & Self-drive tourism & 17 \\
\hline Tourists think less about obligations when in holiday mode & Self-drive tourism & 10 \\
\hline $\begin{array}{l}\text { Self-drive tourists lack knowledge about how residents perceive } \\
\text { them }\end{array}$ & Self-drive tourism & 8 \\
\hline Core problems (Stage 2) & & \\
\hline There is lack of journalists in New Zealand & Pedia & 1 \\
\hline Journalists do not have enough time to investigate a story properly & Media & 2 \\
\hline Negative stories attract more interest from the public & Perception & 4 \\
\hline Some tourists place less value in meeting other people (e.g. local) & Self-drive tourism & 11 \\
\hline $\begin{array}{l}\text { There are on-going challenges in communication between } \\
\text { government and community }\end{array}$ & Perception & 5 \\
\hline Core problems (Stage 3) & Perception & 6 \\
\hline Residents' perception is fuelled and fed by media & \\
\hline There is a streak of racism towards Asian tourists & & \\
\hline
\end{tabular}


The first EC (see Figure 4.6) explores the Government's situation "NZ is promoted as a selfdrive destination" as described in stage 1 of the CRT (see Figure 4.5). This can be framed as a dilemma: does New Zealand continue to promote itself as a self-drive destination or not? As tourism is one of the most important industries for New Zealand in generating economic and social benefits, a continued promotion of New Zealand as a self-drive destination could introduce a risk of over-tourism. Yeoman (2019) defines over-tourism as "the impact of tourism on a destination, or parts thereof, which excessively influences perceived quality of life of citizens and/or quality of visitors' experiences in a negative way”' (p.1).

New Zealand has poor infrastructure even for its own residents. Allowing tourists in the ridiculous numbers they are coming only exacerbates already existing problems. (Kantar, 2020, p.19)

Figure 4.6 represents this dilemma of whether to continue to promote New Zealand as a selfdrive destination or not, using the format of an EC which can be read from left to right using necessity logic (In order to... I must) as follows:

In order to achieve A: New Zealand prosperity, we must achieve B: Exploit benefits from tourism (e.g. economic gain), and In order to achieve B, we must D: Continue promoting New Zealand tourism as a self-drive destination.

On the other hand, In order to achieve A, we must also achieve C: Minimise risk of over-tourism, and In order to achieve C, we must D': Stop promoting New Zealand tourism as a self-drive destination.

But we cannot continue to promote and stop promoting at the same time, hence the dilemma.

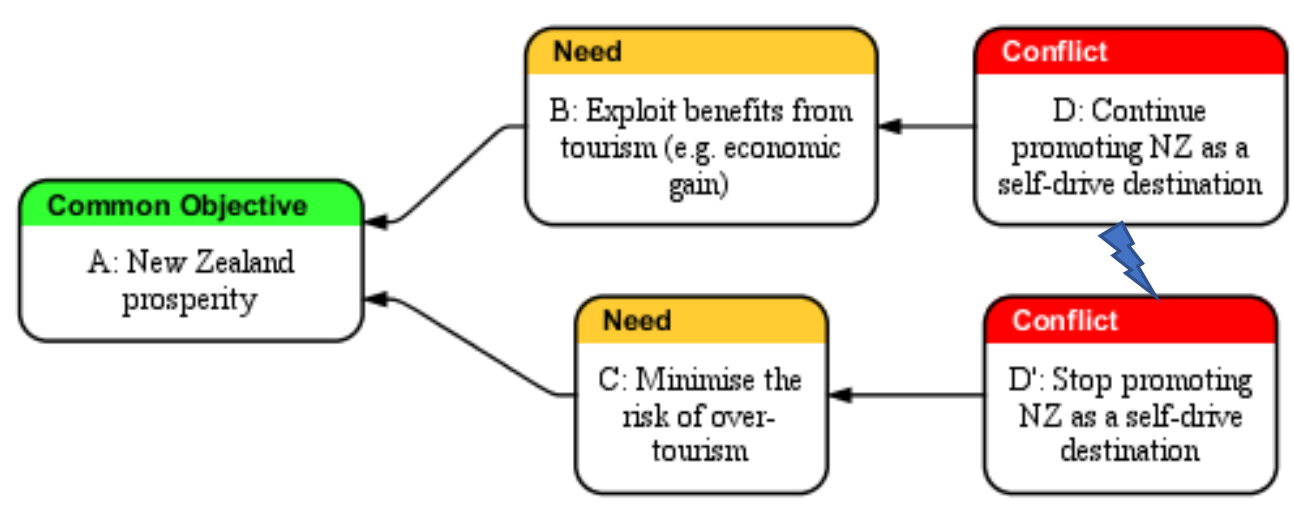

Figure 4. 6: Government's EC 
The second EC (see Figure 4.7), explores the local government dilemma of whether to spend their allocated budget investing in road infrastructures or not. They need to improve road safety and features, yet some local governments do not see this important enough for them to prioritise. With limited budget, local governments need to decide how to use allocated funds appropriately, in order to exploit the maximum value of both road infrastructures and other projects:

There are some local roads that would benefit from more guardrails and central markings or something like that. Even when we had that 8 million dollar fund for local government, there was a poor uptake. It was not important enough for them to prioritise. (GP2)

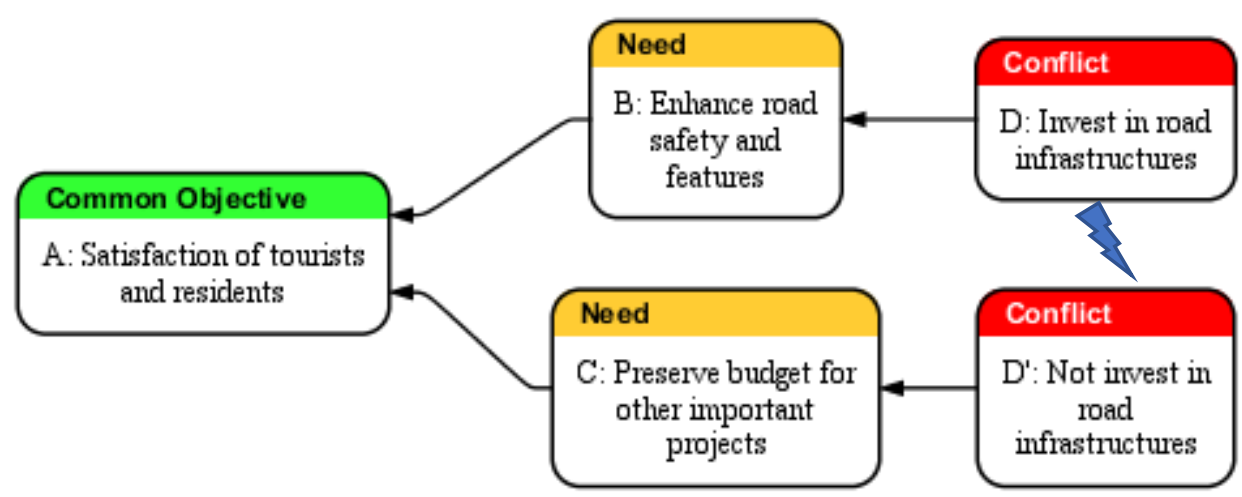

Figure 4. 7: Local government's EC 
The third EC (see Figure 4.8), explores the media companies. They have conflict over whether to report news that is less important but interesting or vice versa. This conflict tends to occur in the commercial media business, where journalists want to report stories that are important but are constrained by stakeholders' interests (e.g. profit), as highlighted in the CRT analysis, stage 2:

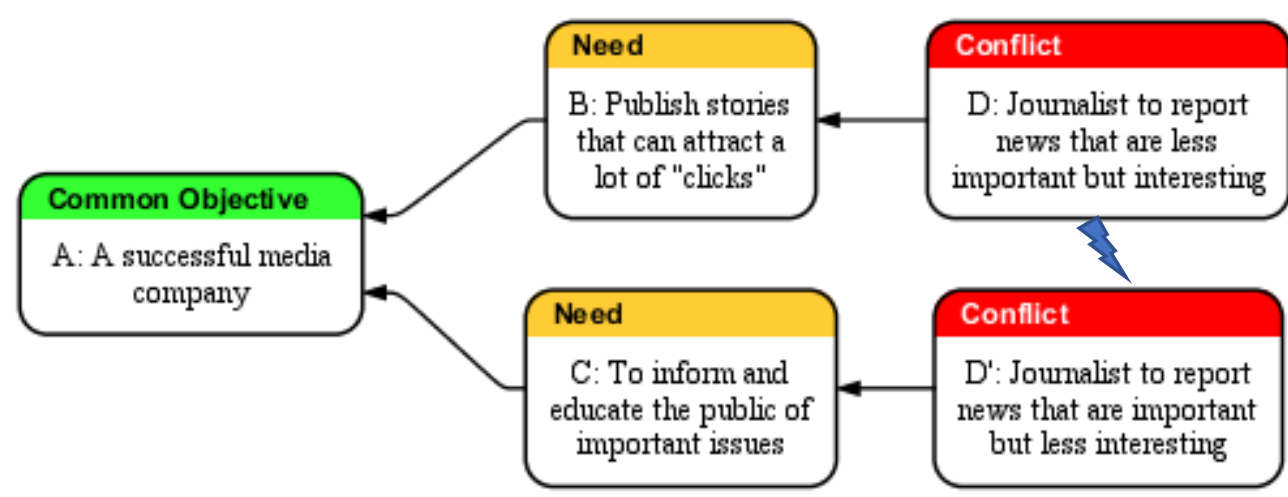

Figure 4. 8: Media participants' EC 
The fourth EC (see Figure 4.9) captures the conflict described by the tourism academic between self-drive tourists and residents. While self-drive tourists want to gain as much travel experience as possible, by cruising at a lower speed for photo-taking or enjoying the scenery, residents generally want to reach their destination fast for work or personal errands and such like. Consequently, this result in direct conflict between the two parties:

You have got people with different purposes travelling at different speeds using the same infrastructure with different levels of capability.

If they are unhappy with visitors on a road, when they pull over, the local might have a go at them, take their key, or say something unpleasant and absolutely unnecessary. (GP3)

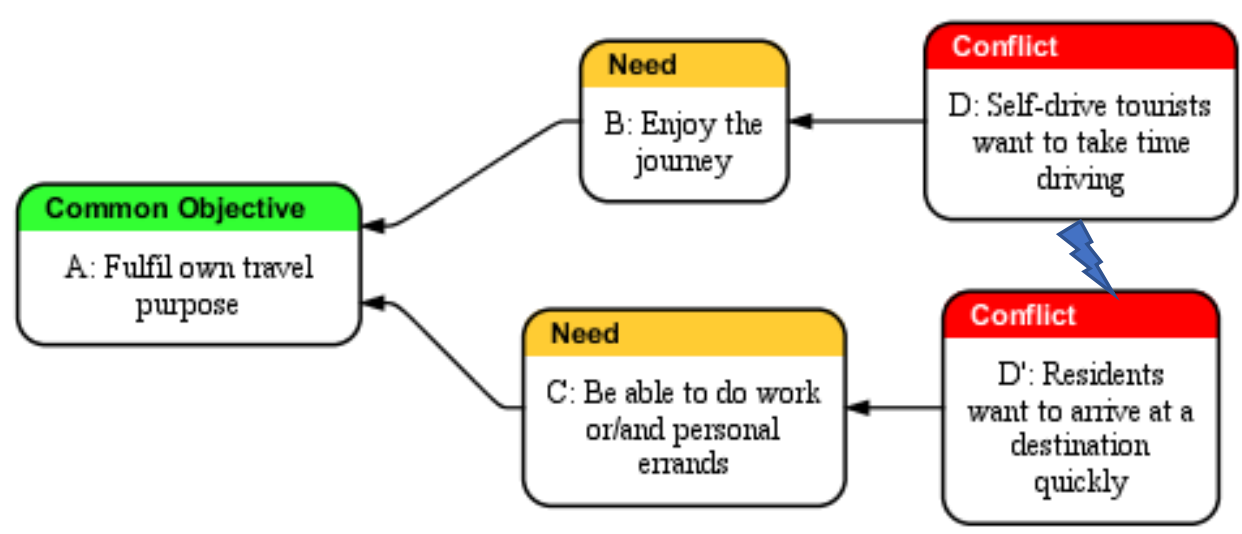

Figure 4. 9: Tourism academic participant's described EC 
The final EC (see Figure 4.10) looks at the dilemma facing self-drive tourist participants: do they drive faster or not? They want to drive at a lower speed as this assists them in maintaining low cognitive stress levels and to enjoy the journey. However, they are prompted by local drivers to drive faster to match the "speed flow" of the road. It is often a real challenge for selfdrive tourists to find a balance to achieve both conditions, especially for tourists who are not well prepared and/or have not driven in New Zealand before:

The locals believe I should be driving faster as I am driving too slow for them... a bit stressful because I always had to speed up. (TP1)

Tourists do not care about how long it is going to take from A and B, unlike the typical New Zealanders, who wants to get to a place quite quickly. International tourists as part of their whole travel experience [want to include] stops, walks and viewpoints and photographs. (GP1)

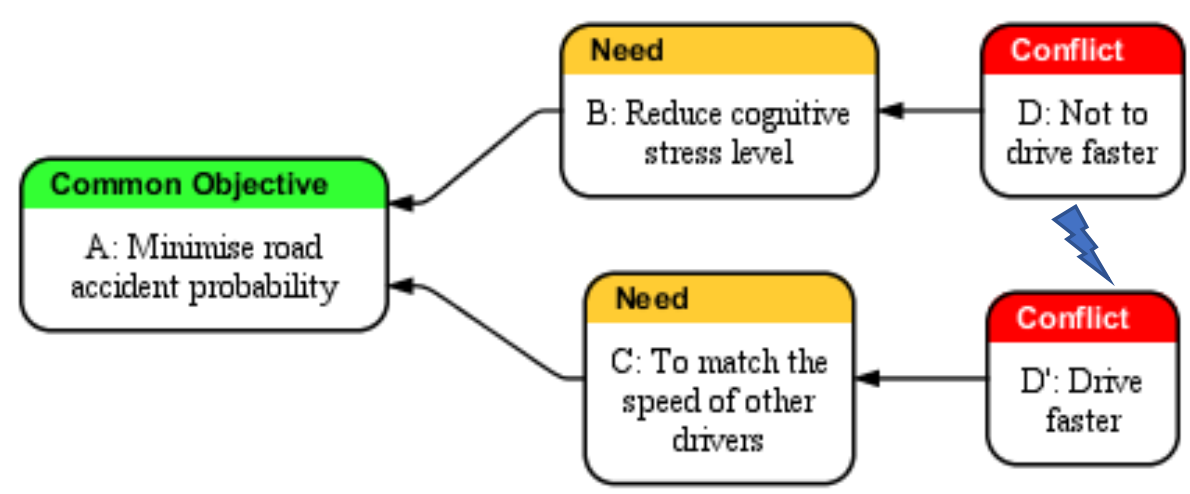

Figure 4. 10: Self-drive tourist participant's described EC 


\subsubsection{EC assumptions and injections}

For each of the EC's described, there are assumptions underpinning each of the arrows used to explain why we believe that relationship exists. The next step in the EC process is to surface these assumptions by reading the arrow and then adding 'because ...."

For instance, In order to achieve B, we must achieve D, because "Tourism is NZ's number one export industry"

Injections are then created by "breaking" the assumptions.

To demonstrate, "Focus on other sectors to replace tourism over time" would be an injection (idea) to "break" "We have already invested a lot in the tourism sector". (see Assumptions and injections BD for Figure 4.6)

It is important to note that at this stage, it is not necessary to check that injections are sensible or feasible. Indeed, an injection might well be an idea that seems impossible to implement initially (Cox et al., 2012, p.66). They are starting ideas that may lead to a workable and novel solution. 


\section{Assumptions and injections for Figure 4.6, government's EC}

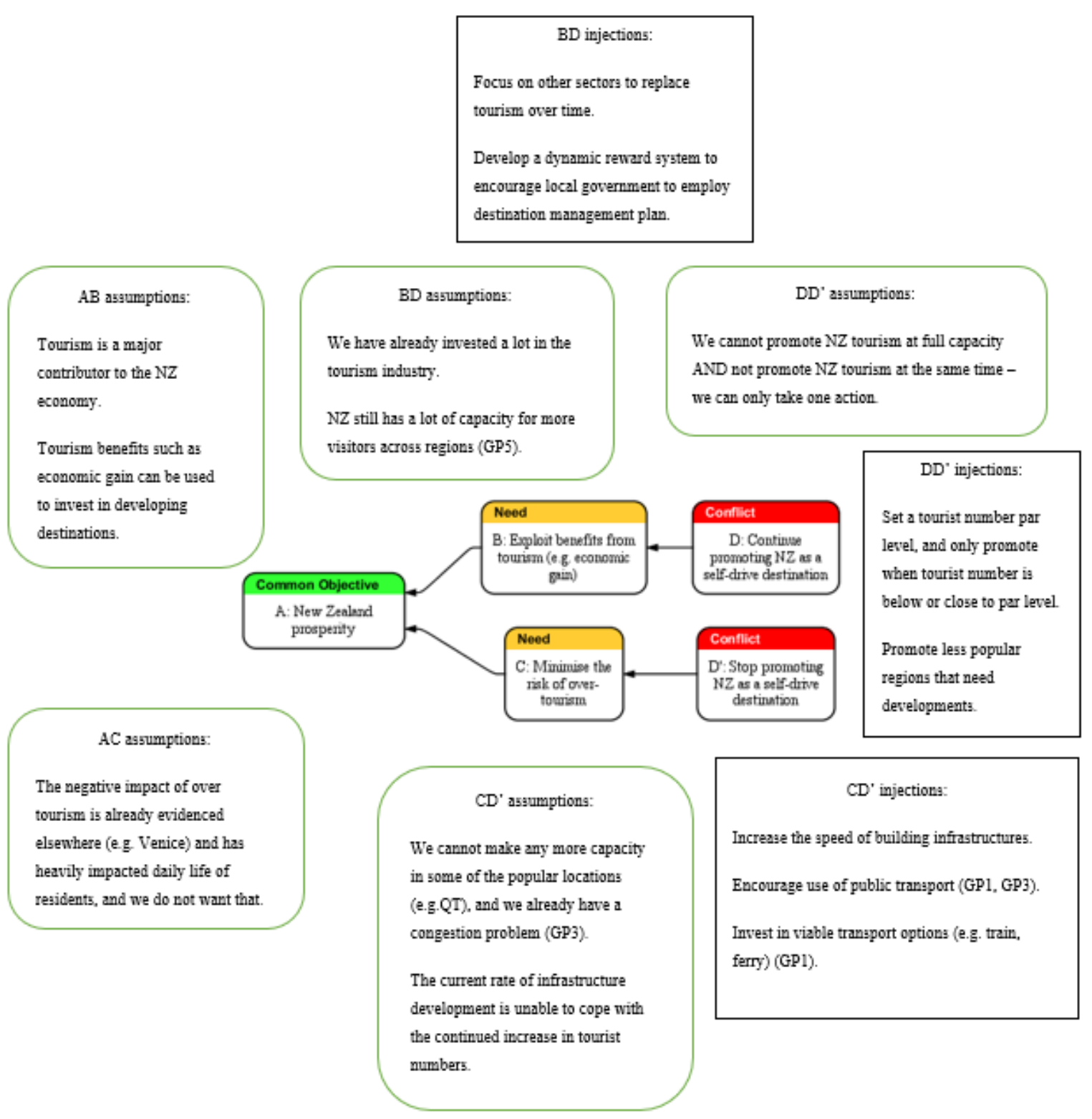




\section{Assumptions and injections for Figure 4.7, local government's EC}

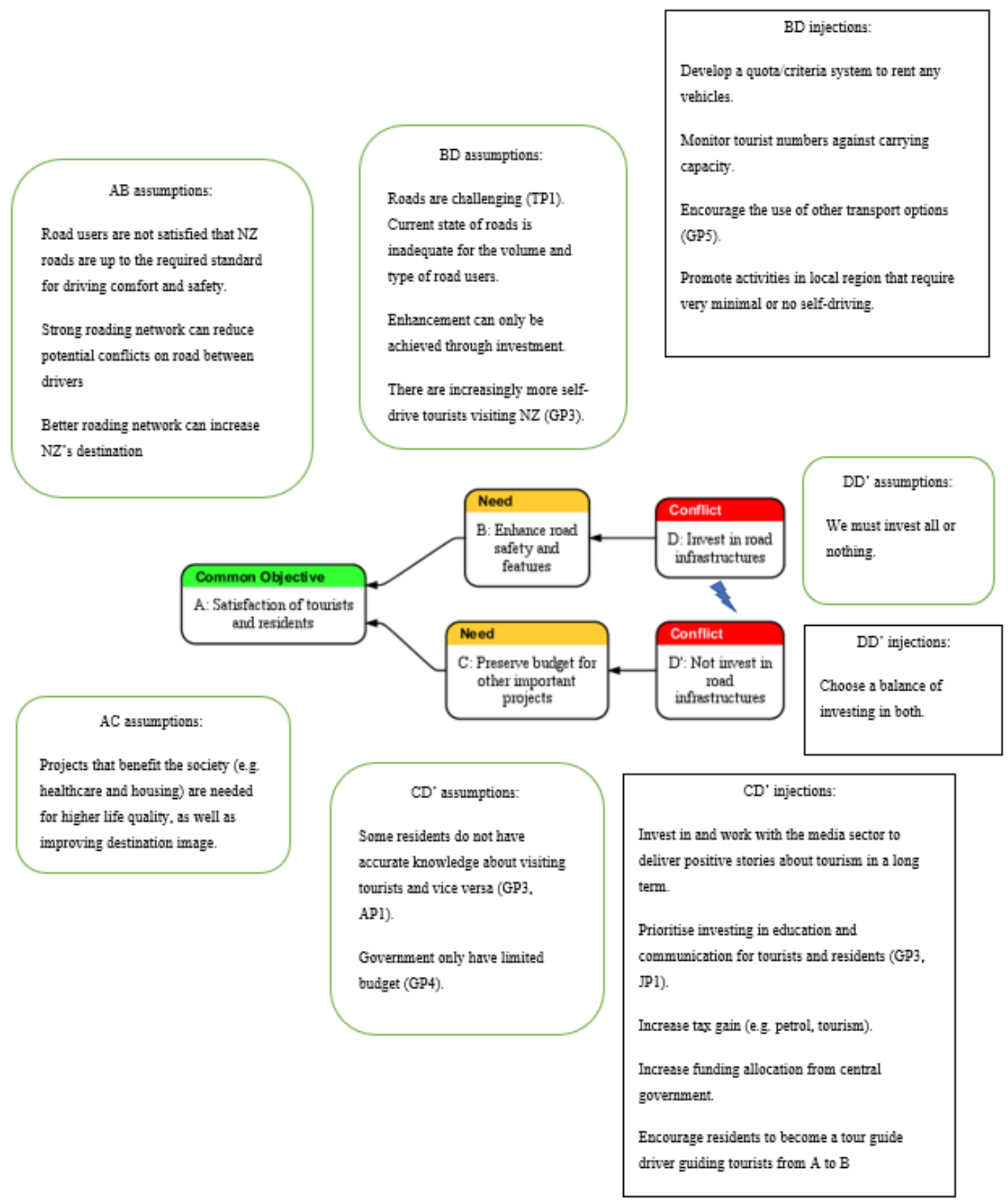




\section{Assumptions and injections for Figure 4.8, media participants' EC}

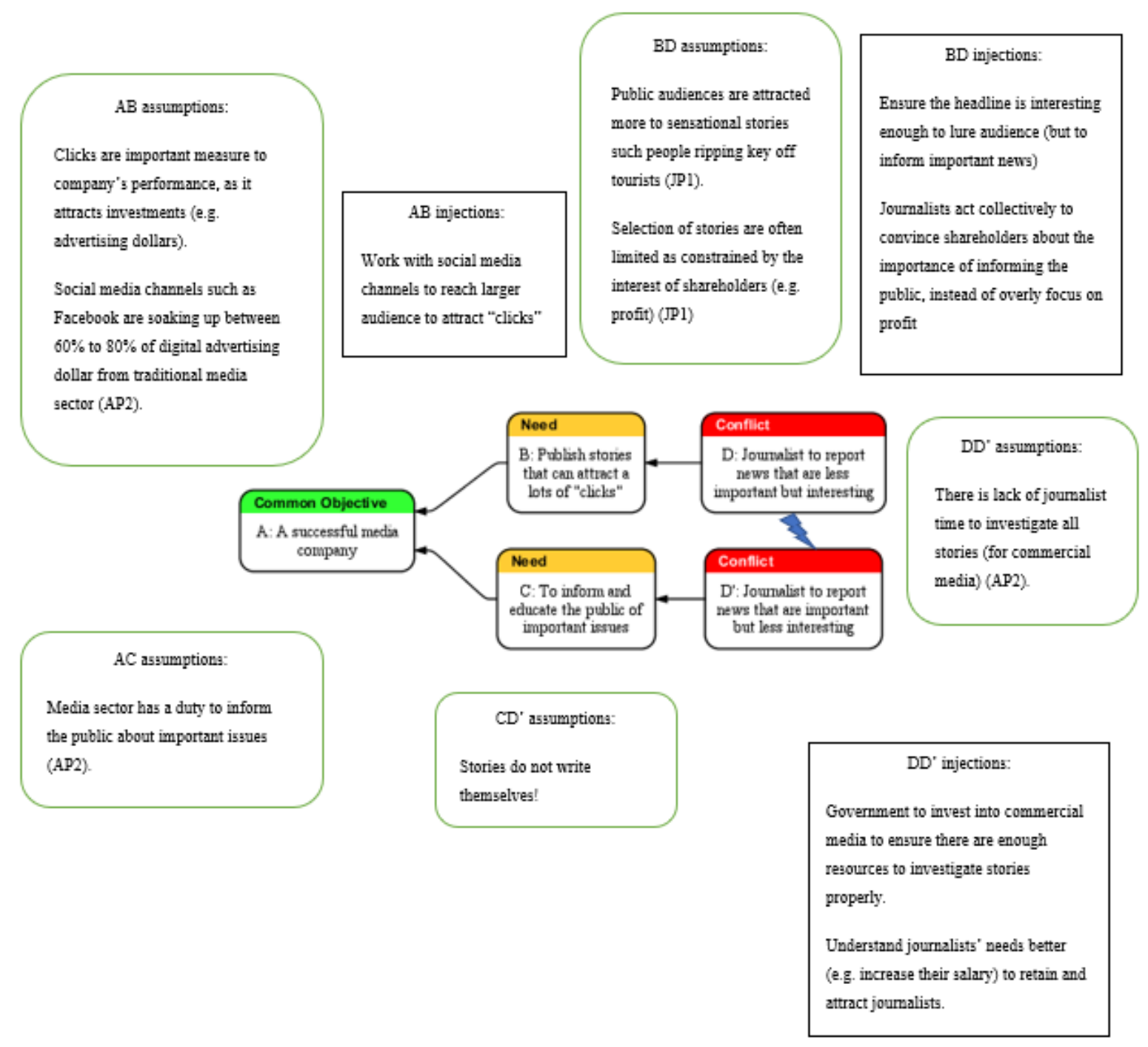




\section{Assumptions and injections for Figure 4.9, tourism academic participant's described EC}

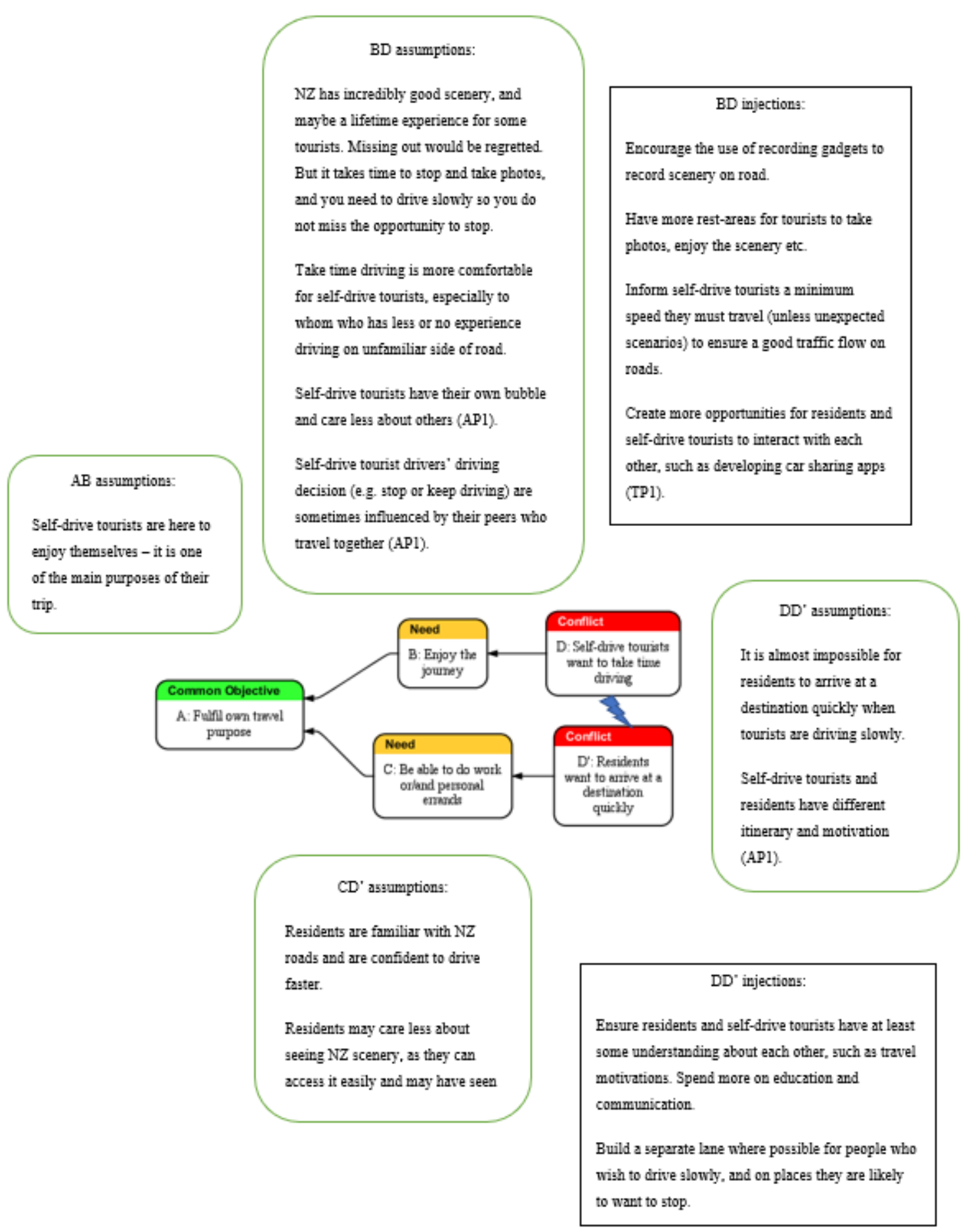




\section{Assumptions and injections for Figure 4.10, self-drive tourist participants' described EC}

\begin{tabular}{|l|}
\hline \multicolumn{1}{|c|}{ AB injections: } \\
Invest in road infrastructures to \\
build a strong roeding netvork (e.g. \\
Wrikato expressway). \\
\hline
\end{tabular}

\section{AB assumptions}

$\mathrm{NZ}$ roads are challenging to drive, and cognitive stress levels are currently high

Recucing cognitive streas levels is required for self-divive tourists to think more clearly and nake sensible decisions uben driving.

\section{BD assumptions:}

It takes time for self-divive tourists to get used to driving on an unfamiliar side of rosd.

Regulations and driving norms in NZ can be quite different to other courtries (eg. China)

Some rental car compary do not explain well on car features, it can take some tine for selfdrive touriats to operate on an unfamiliar vehicle (TP2).

Rosd siges for tuming or attractions are not "in time", self-irive tourists often need to pay more attention to these signs (TP1, TP3).

\section{BD injections:}

Work with $A$ A and rental car companies to irrest and promote driving gimulation software to selfdrive tourists prior actual driving (GP2).

Have clear road signs (e.g. attraction ahead, ready to slow down) placed early enough to allow more reaction time.

Drive with a co-pilot to instruct remind on navigation, road conditions etc.

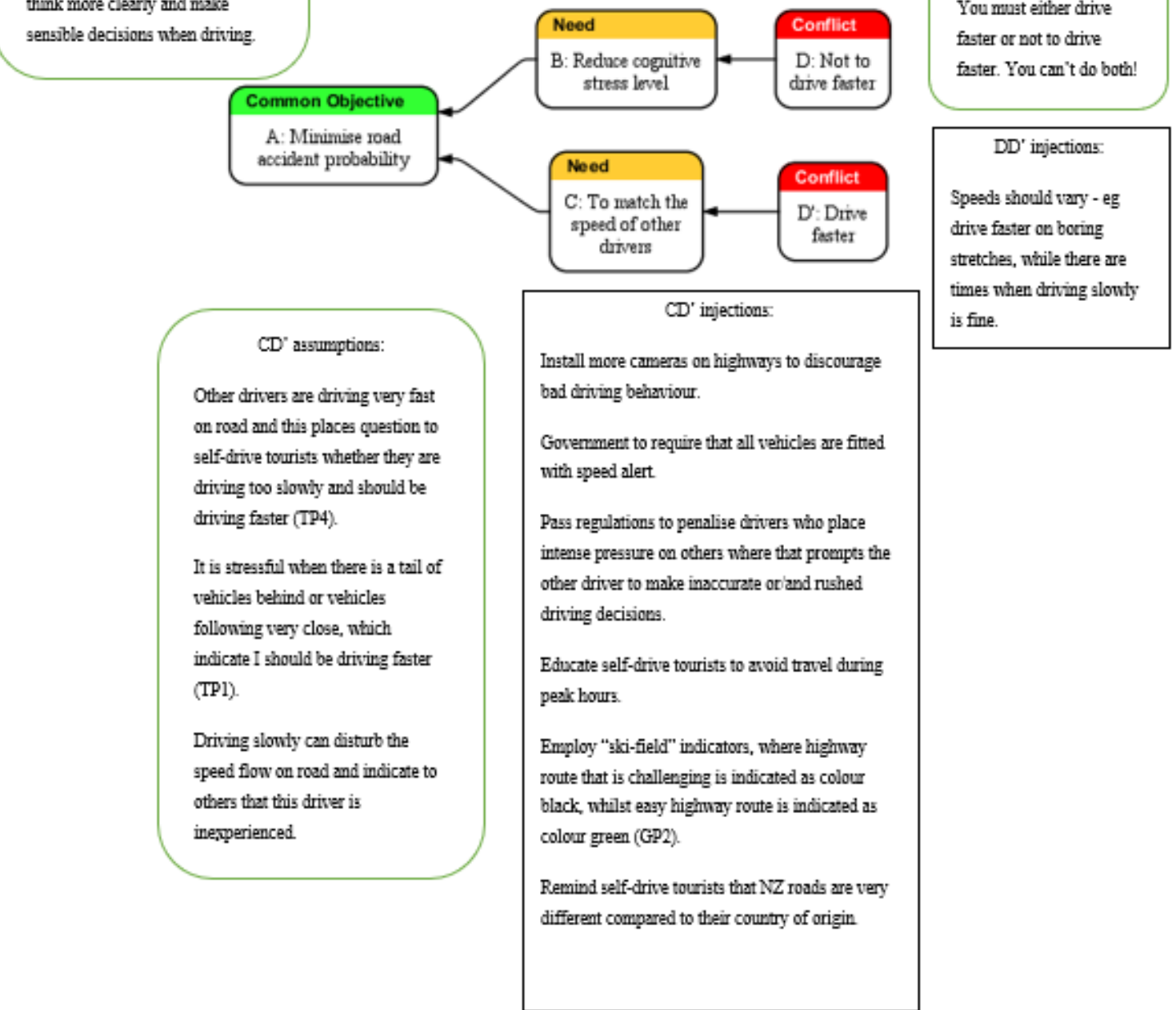




\section{Possible EC injections}

The assumptions surfaced in the above ECs generated injections (ideas) that can be employed in the FRT, to mitigate residents' negative perceptions of self-drive tourism. Table 4.18 summarises the assumptions and respective injections.

Please note that the assumptions and injections with no participant codes (e.g. GP1) are the author's own contributions.

Table 4. 18: Summary of assumptions and injections

\begin{tabular}{|c|c|c|}
\hline Figure\# & Assumptions & Injections \\
\hline \multirow[t]{7}{*}{4.6} & $\begin{array}{l}\text { BD: We have already invested a lot in } \\
\text { the tourism industry. }\end{array}$ & $\begin{array}{l}\text { BD: Focus on other sectors to replace tourism } \\
\text { over time. }\end{array}$ \\
\hline & $\begin{array}{l}\text { BD: } N Z \text { still has a lot of capacity for } \\
\text { more visitors across regions (GP5). }\end{array}$ & $\begin{array}{l}\text { BD: Develop a dynamic reward system to } \\
\text { encourage local government to employ } \\
\text { destination management plan. }\end{array}$ \\
\hline & $\begin{array}{l}\text { CD': The current rate of } \\
\text { infrastructure development is unable } \\
\text { to cope with the continue increase } \\
\text { tourist number. }\end{array}$ & $\begin{array}{l}\text { CD': Increase the speed of building } \\
\text { infrastructure. }\end{array}$ \\
\hline & $\begin{array}{l}\text { CD': We cannot make any more } \\
\text { capacity in some of the popular } \\
\text { locations (e.g.QT), and we already } \\
\text { have a congestion problem (GP3). }\end{array}$ & $\begin{array}{l}\text { CD': Encourage use of public transport (GP1, } \\
\text { GP3). }\end{array}$ \\
\hline & & $\begin{array}{l}\text { CD': Invest in viable transport options (e.g. } \\
\text { train, ferry) (GP1). }\end{array}$ \\
\hline & \multirow[t]{2}{*}{$\begin{array}{l}\text { DD': We cannot promote NZ } \\
\text { tourism at full capacity AND not } \\
\text { promote NZ tourism at the same time } \\
\text { - we can only take one action. }\end{array}$} & $\begin{array}{l}\text { DD': Set a tourist number par level, and only } \\
\text { promote when tourist number is below or close } \\
\text { to par level. }\end{array}$ \\
\hline & & $\begin{array}{l}\text { DD': Promote less popular regions that need } \\
\text { developments. }\end{array}$ \\
\hline
\end{tabular}




\begin{tabular}{|c|c|c|}
\hline \multirow[t]{10}{*}{4.7} & $\begin{array}{l}\text { BD: Current state of roads is } \\
\text { inadequate for the volume and type } \\
\text { of road users. }\end{array}$ & $\begin{array}{l}\text { BD: Develop a quota/criteria system to rent any } \\
\text { vehicles. }\end{array}$ \\
\hline & $\begin{array}{l}\text { BD: There are increasingly more } \\
\text { self-drive tourists visiting NZ (GP3). }\end{array}$ & $\begin{array}{l}\text { BD: Monitor tourist numbers against carrying } \\
\text { capacity. }\end{array}$ \\
\hline & \multirow{2}{*}{$\begin{array}{l}\text { BD: Self-drive tourism is putting } \\
\text { increased pressure on infrastructure } \\
\text { (Kantar, 2018). }\end{array}$} & $\begin{array}{l}\text { BD: Encourage the use of other transport } \\
\text { options (GP5). }\end{array}$ \\
\hline & & \multirow{2}{*}{$\begin{array}{l}\text { BD: Promote activities in local region that } \\
\text { require very minimal or no self-driving. }\end{array}$} \\
\hline & $\begin{array}{l}\text { BD: Enhancement can only be } \\
\text { achieved through investment. }\end{array}$ & \\
\hline & \multirow[t]{3}{*}{$\begin{array}{l}\text { CD': Some residents do not have } \\
\text { accurate knowledge about visiting } \\
\text { tourists and vice versa (GP3, AP1). }\end{array}$} & $\begin{array}{l}\text { CD': Invest in and work with the media sector } \\
\text { to deliver positive stories about tourism in a } \\
\text { long term. }\end{array}$ \\
\hline & & $\begin{array}{l}\text { CD': Encourage residents to become a tour } \\
\text { guide driver guiding tourists from A to B. }\end{array}$ \\
\hline & & $\begin{array}{l}\text { CD': Develop and promote car-sharing app or } \\
\text { other social interaction software. }\end{array}$ \\
\hline & \multirow[t]{2}{*}{$\begin{array}{l}\text { CD': Government only have limited } \\
\text { budget (GP4). }\end{array}$} & $\begin{array}{l}\text { CD': Prioritise investing in education and } \\
\text { communication for residents (GP3, JP1). }\end{array}$ \\
\hline & & $\begin{array}{l}\text { CD': Increase tax gain (e.g. petrol, tourism) } \\
\text { (GP4). } \\
\text { CD': Increase funding allocation from central } \\
\text { government (GP3). }\end{array}$ \\
\hline & DD': We must invest all or nothing. & DD': Choose a balance of investing in both. \\
\hline
\end{tabular}




\begin{tabular}{|c|c|c|}
\hline \multirow[t]{5}{*}{4.8} & $\begin{array}{l}\text { AB: Clicks are important measure to } \\
\text { company's performance, as it attracts } \\
\text { investments (e.g. advertising dollars). } \\
\text { AB: Social media channels such as } \\
\text { Facebook are soaking up between } \\
60 \% \text { to } 80 \% \text { of digital advertising } \\
\text { dollar from traditional media sector } \\
\text { (AP2). }\end{array}$ & $\begin{array}{l}\text { AB: Work with social media channels to reach } \\
\text { larger audience to attract "clicks" }\end{array}$ \\
\hline & $\begin{array}{l}\text { BD: Public audiences are attracted } \\
\text { more to sensational stories such } \\
\text { people ripping key off tourists (JP1). }\end{array}$ & $\begin{array}{l}\text { BD: Ensure the headline is interesting enough } \\
\text { to lure audience (but to inform important news) }\end{array}$ \\
\hline & $\begin{array}{l}\text { BD: Selection of stories are often } \\
\text { limited as constrained by the interest } \\
\text { of shareholders (e.g. profit) (JP1) }\end{array}$ & $\begin{array}{l}\text { BD: Journalists act collectively to convince } \\
\text { shareholders about the importance of informing } \\
\text { the public, instead of overly focus on profit }\end{array}$ \\
\hline & $\begin{array}{l}\text { DD': There is lack of journalist time } \\
\text { to investigate all stories (for } \\
\text { commercial media) (AP2). }\end{array}$ & $\begin{array}{l}\text { DD': Understand journalists' needs better (e.g. } \\
\text { increase their salary) to retain and attract } \\
\text { journalists. }\end{array}$ \\
\hline & & $\begin{array}{l}\text { DD': Government to invest into commercial } \\
\text { media to ensure there are enough resources to } \\
\text { investigate stories properly. }\end{array}$ \\
\hline
\end{tabular}




\begin{tabular}{|c|c|c|}
\hline \multirow[t]{6}{*}{4.9} & $\begin{array}{l}\text { BD: NZ has incredibly good scenery, } \\
\text { and maybe a lifetime experience for } \\
\text { some tourists. Missing out would be } \\
\text { regretted. But it takes time to stop } \\
\text { and take photos, and you need to } \\
\text { drive slowly so you do not miss the } \\
\text { opportunity to stop. }\end{array}$ & $\begin{array}{l}\text { BD: Encourage the use of recording gadgets to } \\
\text { record scenery on road. }\end{array}$ \\
\hline & $\begin{array}{l}\text { BD: Take time driving is more } \\
\text { comfortable for self-drive tourists, } \\
\text { especially to whom who has less or } \\
\text { no experience driving on unfamiliar } \\
\text { side of road. }\end{array}$ & $\begin{array}{l}\text { BD: Have more rest-areas for people to exploit } \\
\text { the opportunities to take photos, enjoy the } \\
\text { scenery etc. }\end{array}$ \\
\hline & $\begin{array}{l}\text { BD: Self-drive tourists have their } \\
\text { own bubble and care less about } \\
\text { others (AP1). }\end{array}$ & $\begin{array}{l}\text { BD: Inform self-drive tourists a minimum speed } \\
\text { they must travel (unless unexpected scenarios) } \\
\text { to ensure a good traffic flow on roads. }\end{array}$ \\
\hline & $\begin{array}{l}\text { BD: Self-drive tourist drivers' } \\
\text { driving decision (e.g. stop or keep } \\
\text { driving) are sometimes influenced by } \\
\text { their peers who travel together } \\
\text { (AP1). }\end{array}$ & $\begin{array}{l}\text { BD: Create more opportunities for residents and } \\
\text { self-drive tourists to interact with each other, } \\
\text { such as developing car sharing apps (TP1). }\end{array}$ \\
\hline & $\begin{array}{l}\text { DD': It is almost impossible for } \\
\text { residents to arrive at a destination } \\
\text { quickly when tourists are driving } \\
\text { slowly. }\end{array}$ & $\begin{array}{l}\text { DD': Ensure residents and self-drive tourists } \\
\text { have at least some understanding about each } \\
\text { other, such as travel motivations. Spend more } \\
\text { on education and communication. }\end{array}$ \\
\hline & $\begin{array}{l}\text { DD': Self-drive tourists and residents } \\
\text { have different itinerary and } \\
\text { motivation (AP1). }\end{array}$ & $\begin{array}{l}\text { DD': Build a separate lane where possible for } \\
\text { people who wish to drive slowly, and on places } \\
\text { they are likely to want to stop. }\end{array}$ \\
\hline
\end{tabular}




\begin{tabular}{|c|c|c|}
\hline \multirow[t]{8}{*}{4.10} & $\begin{array}{l}\text { AB: Reducing cognitive stress levels } \\
\text { is required for self-drive tourists to } \\
\text { think more clearly and make sensible } \\
\text { decisions when driving. }\end{array}$ & \multirow[t]{2}{*}{$\begin{array}{l}\text { AB: Invest in road infrastructure to build a } \\
\text { strong roading network (e.g. Waikato } \\
\text { expressway). }\end{array}$} \\
\hline & $\begin{array}{l}\text { AB: NZ roads are challenging to } \\
\text { drive, and cognitive stress levels are } \\
\text { currently high. }\end{array}$ & \\
\hline & $\begin{array}{l}\text { BD: It takes time for self-drive } \\
\text { tourists to get used to driving on an } \\
\text { unfamiliar side of road. }\end{array}$ & $\begin{array}{l}\text { BD: Government and rental car companies to } \\
\text { promote driving simulation software to self- } \\
\text { drive tourists prior actual driving (GP2). }\end{array}$ \\
\hline & $\begin{array}{l}\text { BD: Regulations and driving norms } \\
\text { in NZ can be quite different to other } \\
\text { countries (e.g. China) }\end{array}$ & $\begin{array}{l}\text { BD: Have clear road signs (e.g. attraction } \\
\text { ahead, ready to slow down) placed early enough } \\
\text { to allow more reaction time (TP1). }\end{array}$ \\
\hline & $\begin{array}{l}\text { BD: Some rental car company do not } \\
\text { explain well on car features, it can } \\
\text { take some time for self-drive tourists } \\
\text { to operate on an unfamiliar vehicle } \\
\text { (TP2). }\end{array}$ & $\begin{array}{l}\text { BD: Drive with a co-pilot to instruct/remind on } \\
\text { navigation, road conditions etc. }\end{array}$ \\
\hline & $\begin{array}{l}\text { BD: Road signs for turning or } \\
\text { attractions are not "in time", self- } \\
\text { drive tourists often need to pay more } \\
\text { attention to these signs (TP1, TP3). }\end{array}$ & \\
\hline & $\begin{array}{l}\text { CD': Other drivers are driving very } \\
\text { fast on road and this places question } \\
\text { to self-drive tourists whether they are } \\
\text { driving too slowly and should be } \\
\text { driving faster (TP4). }\end{array}$ & $\begin{array}{l}\text { CD': Install more cameras on highways to } \\
\text { discourage bad driving behaviour }\end{array}$ \\
\hline & $\begin{array}{l}\text { CD': It is stressful when there is a } \\
\text { tail of vehicles behind or vehicles } \\
\text { following very close, which indicate } \\
\text { I should be driving faster (TP1). }\end{array}$ & $\begin{array}{l}\text { CD': Government to require that all vehicles } \\
\text { are fitted with speed alert. }\end{array}$ \\
\hline
\end{tabular}




\begin{tabular}{|l|l|l|}
\hline $\begin{array}{l}\text { CD': Driving slowly can disturb the } \\
\text { speed flow on road and indicate to } \\
\text { others that this driver is } \\
\text { inexperienced. }\end{array}$ & $\begin{array}{l}\text { CD': Pass regulations to penalise drivers who } \\
\text { place intense pressure on others where that } \\
\text { prompts the other driver to make inaccurate } \\
\text { or/and rushed driving decisions. }\end{array}$ \\
& $\begin{array}{l}\text { CD': Educate self-drive tourists to avoid travel } \\
\text { during peak hours. }\end{array}$ \\
\cline { 2 - 2 } & $\begin{array}{l}\text { CD': Employ "ski-field" indicators, where } \\
\text { highway route that is challenging is indicated as } \\
\text { colour black, whilst easy highway route is } \\
\text { indicate as colour green (GP2). }\end{array}$ \\
& $\begin{array}{l}\text { CD': Remind self-drive tourists that NZ roads } \\
\text { are very different compared to their country of } \\
\text { origin. }\end{array}$ \\
\hline
\end{tabular}

\subsection{Summary of "What to change?"}

This section illustrated the "What to change?" by first, arranging the UDEs into a CRT. The CRT provides an analysis of how residents' negative perceptions are formed and discovered the core problems via cause-and-effect logic. Subsequently, ECs are employed to seek potential mitigating strategies for the core problems, by surfacing assumptions and then injections are employed to invalidate those assumptions. That is, the ideas that can resolve the ECs and result in win-win situations, as will be explored in the next section, "What to change to?". The EC processes frame the analysis of the second part of the research questions: "The potential strategies to mitigate residents' negative perceptions".

The EC bridges the two questions "What to change?" and "What to change to?". However, in surfacing and fully understanding the conflict, injections (ideas of mitigating strategies) naturally arise. These are strictly part of 'What to change to?' but have been included here under "What to change?" for brevity of exposition. 


\subsection{What to change to?}

In the preceding EC analyses injections were surfaced based on participants' and the author's ideas. These surfaced injections are employed to construct a Future Reality Tree (FRT) by presenting a sequence of cause-and-effect relationships that connects the proposed injections, together with any supporting injections, to eliminate the UDEs in the CRT and produce desirable effects (DEs) (Mabin et al., 2001).

In conjunction with the EC step, the FRT also addresses the fourth research sub-objective. Two FRTs (A \& B) are constructed providing different propositions to mitigate residents' negative perceptions.

Mitigating strategies in FRT A (see Figure 4.11) are more incremental/soft, aiming to encourage good behaviour. In contrast, the strategies in FRT B (see Figure 4.12) are more radical/hard, designed to regulate behaviour. Like the CRT, the FRT is read using sufficiency logic (If.... and...then...) from the bottom up. 
FRT A

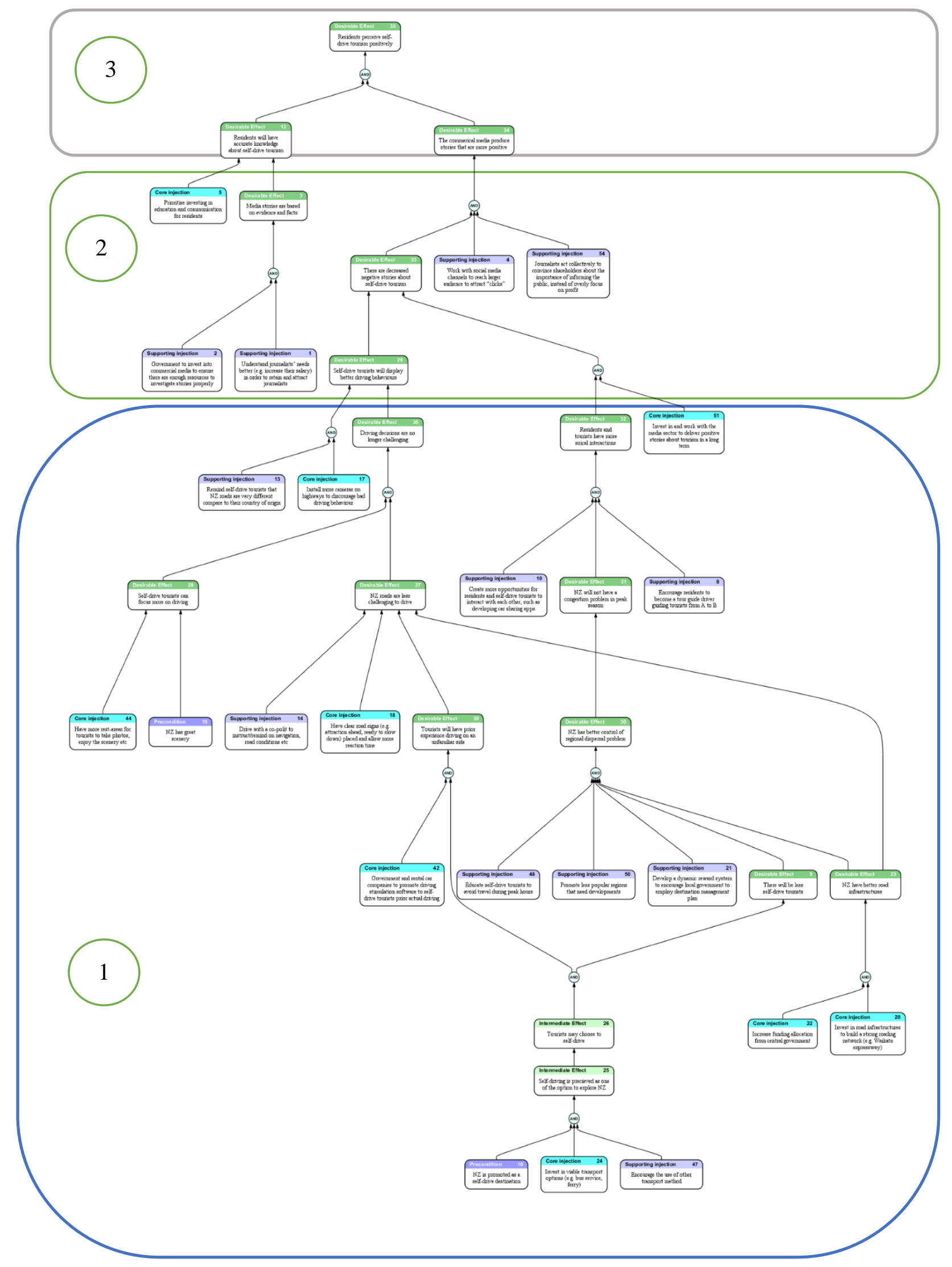

Figure 4. 11: FRT A (incremental/soft) 


\subsubsection{FRT A analysis}

In FRT A, mitigating strategies are injected into stage 1 and 2 to cause positive changes in residents' perception in stage 3. Stage 1 addresses the infrastructure, driving and self-drive tourism issues and stage 2 aims at targeting media issues.

\section{Stage 1}

Stage 1, addresses the infrastructure problem. Government expert participants have highlighted it would be good to have more budget allocations and investment on infrastructures. The enabler of these would "contribute to better infrastructures" (DE23):

If we have more money, we can make roads a lot safer. (GP2)

One of the core problems was that "self-drive tourists have no prior experience driving on the unfamiliar side of the road" (UDE39, see Figure 4.5). To mitigate this issue, one idea was proposed by a government expert; promote the use of driving simulation:

In a driving simulation, you will drive, and see and experience $\mathrm{NZ}$ outside the window including a bit of environment and you are asked to make a driving decision. To me, this has more merit than asking tourists to take a driving theory test. (GP2)

The "driving simulation idea" (Injection42) will provide "tourists with some driving experience prior to driving on the actual road" (DE39). However, relying on driving simulation solely is not strong enough to ease the driving challenges experienced by self-drive tourists in New Zealand. Thus, Injection18 was added "better road signs", to further "reduce the driving challenges" (DE27):

The signs could be a bit improved; you can put up two signs. One says leave the road for attraction, the other [earlier sign] says attraction is $500 \mathrm{~m}$ away to allow more reaction time. (TP2)

Additionally, "more rest areas could be designated to enable tourists to take photos and/or enjoy the scenery safely" (Injection44). This could "prompt self-drive tourists to focus more on driving” (DE28), rather than being distracted by New Zealand's great scenery; this injection could also promote better traffic flow. 
What I would like to see is a series of photograph stops right through the key touring routes, which is set up so it's safe to pull off to get some photographs and even look at some rest facilities. (GP2)

Residents have got their own schedules, but they get stuck behind tourists driving slowly taking pictures. (AP1)

Meanwhile, addressing the "congestion issue" (UDE31, see Figure 4.5), participants have implied potential strategies which relate to more viable transport options and to encourage regional dispersal:

Encourage public transport, making public transport a viable option and active modes, increasing the visibility of public transport and alternative means. (GP1)

The transport agency can learn more about the different needs of tourists so we can assist. For example, to avoid congestion at one place, we need to disperse tourists a bit more. (GP1)

While acknowledging that self-drive tourism plays an important role for regional dispersal and that New Zealand will continue to promote itself as a self-drive destination, core Injection24 "invest in viable transport options", and Injection47 "encourage the use of other transport modes" also need to be added to "prompt tourists to use other transport options" (DE26). This would hopefully “decrease numbers of self-drive tourists in tourism hotspots" (DE9).

In order to further address the congestion issue, supporting injections "educate self-drive tourists to avoid travel during peak hours" (48), "promote less popular regions that need development" (50), and "develop a dynamic reward system to encourage local government to employ destination management plans" (21), are also proposed.

These injections aim to influence the travel pattern of self-drive tourists and to stimulate local governments to employ destination management plans. They will also "ease driving activities in tourism hotspots" (DE9), and "help achieve successful regional dispersals" (DE30), therefore "potentially reducing congestion problems in tourist hotspots" (DE31).

If the congestion problem can be reduced this can assist to mitigate residents' negative perceptions of self-drive tourists as the cause of congestion (highlighted in the NZ residents' UDE section, see Table 4.10). Concurrently, to augment residents' knowledge of self-drive tourists' ideas, such as "encouraging residents to become a tour guide driver guiding tourists from A to B", and "develop and promote the use of car-sharing apps or other social interaction software" could be employed. This would assist in improving the social interactions between 
the two parties especially targeting Asian self-drive tourists who have less interaction with residents:

I think for us self-drive tourist, we only stay for 1-2 days in each destination. This is very limited for interacting with locals...I do not feel they have much knowledge about us at all. (Chinese tourist, TP6)

To encourage "better driving behaviours from self-drive tourists" (DE29), Injection17 "cameras should be installed on highways as a behaviour-influencing measure to discourage potential bad driving behaviours" could prove useful. These cameras could also give a "continual reminder to self-drive tourists that New Zealand roads are very different" (Injection13). As the tourism academic participant suggested:

If you like to apply the Theory of planned behaviour... if they might impact through for example, media channels, you might establish an awareness around visitors that people just like you die on NZ roads, it is happening, they are not drunk, it is just an accident and it can happen to you as well. This might influence that perceived behaviour control. (AP1)

In summary, the main objective of stage 1 is to address infrastructure, driving and self-drive tourism issues via injections, such as more budget allocation, promote less popular regions that need development, and encourage tourists to use driving simulation. These injections (mitigating strategies) aim to address the UDEs in stage 1 in the CRT (see Figure 4.5). Additionally, relationship building between residents and self-drive tourists and behaviour influencing measures were also proposed. Table 4.19 lists the injections used in stage 1. 
Table 4. 19: Stage 1 injections used in FRT A

\begin{tabular}{|l|l|}
\hline \multicolumn{2}{|l|}{ Stage l } \\
\hline Core injections \\
\hline 24 & Invest in viable transport options (e.g. bus service, ferry) \\
\hline 42 & $\begin{array}{l}\text { Government and rental car companies to promote driving simulation software to self-drive } \\
\text { tourists prior to driving }\end{array}$ \\
\hline 18 & $\begin{array}{l}\text { Have clear road signs (e.g. attraction ahead, ready to slow down, exit now) placed to allow } \\
\text { more reaction time }\end{array}$ \\
\hline 44 & Have more rest-areas for tourists to take photos, enjoy the scenery etc \\
\hline 22 & Increase funding allocation from central government \\
\hline 20 & Invest in road infrastructure to build a strong roading network (e.g. Waikato expressway) \\
\hline Supporting injections \\
\hline 47 & Encourage the use of other transport methods \\
\hline 48 & Educate self-drive tourists to avoid travel during peak hours \\
\hline 50 & Promote less popular regions as tourism destinations \\
\hline 21 & Develop a dynamic reward system to encourage local government to employ destination \\
& management plans \\
\hline 14 & Drive with a co-pilot to instruct/remind on navigation, road conditions etc \\
\hline 13 & Remind self-drive tourists that NZ roads are very different \\
\hline 17 & Install more cameras on highways to discourage bad driving behaviour \\
\hline 8 & Encourage residents to become a tour guide driver guiding tourists from A to B \\
\hline 10 & Develop and promote car-sharing app or other social interaction software \\
\hline
\end{tabular}

\section{Stage 2 and 3}

In the CRT analysis media issues were summarised. It was found that commercial media in particular tended to produce stories that are the most attractive (e.g. negative stories). In stage 2 of the FRT A, the aim is to propose strategies to influence the media sector, (commercial media); to encourage more publication of positive tourism. As a number of the driving issues have been addressed in stage 1 this should reduce the negative self-drive tourism stories available for commercial media to report; however, other negative stories could be reported, such as freedom camping or environmental impacts.

One of the drivers for commercial media favouring negative stories is profiting from advertising dollars and/or subscriptions. Yet, it has been challenging for commercial media to 
make profits as social media channels (e.g. Facebook) are squeezing the revenue gain from commercial media:

Social media (e.g. Facebook) soaked up between $60-80 \%$ of the digital advertising dollars. What we have seen is the revenue of commercial media going down at the same time as revenue of social media has gone up. (AP2)

One possible injection is: "commercial media could partner with social media channels to reach even larger audiences" (Injection4); this can reduce the financial stress for commercial media businesses. Furthermore, "to encourage the production of more positive stories" (DE34), journalists could "act collectively to convince shareholders about the importance of informing the public" (Injection54), instead of overly focusing on profit.

As other drivers to UDE3 "media stories are not based on evidence and fact," participants pointed to the lack of time and journalist employees to investigate a story properly (UDE1 \& 2, see Figure 4.5). As a possible injection, government could "set financial incentives to help commercial media to have enough resources for story investigations" (Injection2). Moreover, “commercial media companies need to understand journalists' needs better (e.g. increase their salary)" (Injection1) to attract and retain employees.

These two injections (1 and 2) will help commercial media to have "adequate resources for well researched stories" (DE3), and if combined with "government investment in residents' education and communication of tourism" (Injection5), it could result in "residents having better knowledge about self-drive tourism" (DE12); thus, contributing to the mitigation of residents' negative perceptions of self-drive tourism in stage 3.

In summary, stage 2 and 3 addressed the media issues with an aim to encourage more positive tourism stories via measures, such as financial incentives, ensuring the public receive stories that are well researched and positive in the long term, and through investment in residents' education and communication. Consequently, these proposed injections may help to mitigate residents' negative perceptions of self-drive tourism. The table below lists the injections used in these stages. 
Table 4. 20: Stage 2 and 3 injections used in FRT A

\begin{tabular}{|l|l|}
\hline \multicolumn{2}{|l|}{ Stage $\mathbf{2}$ and 3} \\
\hline Core injections \\
\hline 5 & Prioritise investing in education and communication for residents \\
\hline 2 & $\begin{array}{l}\text { Government to invest into commercial media to ensure there are enough resources to investigate } \\
\text { stories properly }\end{array}$ \\
\hline 51 & $\begin{array}{l}\text { Invest in and work with the media sector to deliver positive stories about tourism in the long } \\
\text { term }\end{array}$ \\
\hline Supporting injections \\
\hline 4 & Work with social media channels to reach larger audiences to attract "clicks" \\
\hline 54 & $\begin{array}{l}\text { Journalists act collectively to convince shareholders about the importance of informing the } \\
\text { public, instead of overly focusing on profit }\end{array}$ \\
\hline 1 & $\begin{array}{l}\text { Understand journalists' needs better (e.g. increase their salary) in order to retain and attract } \\
\text { journalists }\end{array}$ \\
\hline
\end{tabular}




\subsubsection{FRT B analysis}

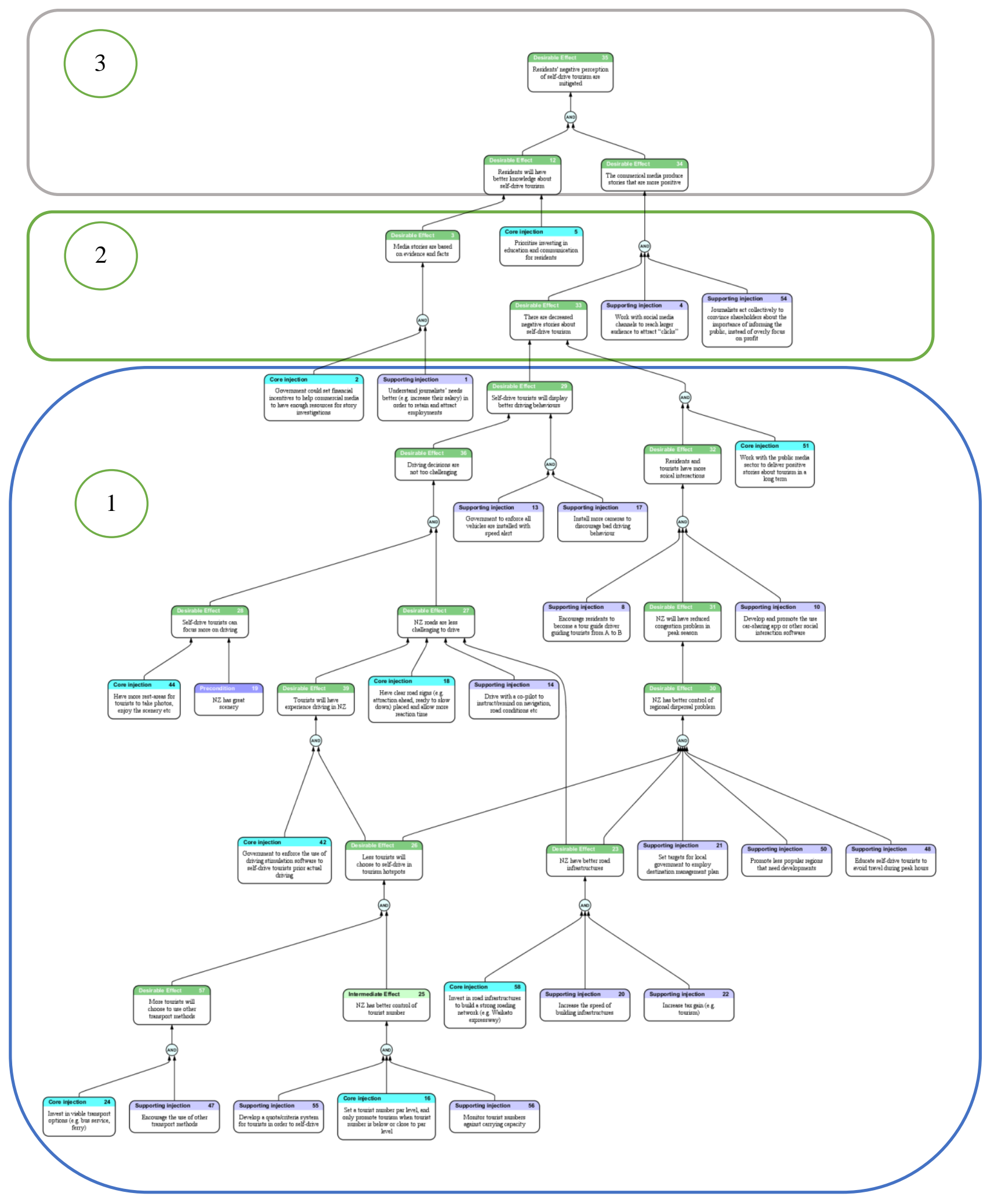

Figure 4. 12: FRT B (radical/hard) 
In FRT B (see Figure 4.12), the 3 stages format is the same as FRT A but the ideas are radical/hard aiming to turn the UDEs to DEs via enforcement and government policies.

These radical injections are not applicable in addressing the media issues. As stated by a government expert participant, Freedom of Expression cannot be interfered with:

We have to be careful from a government point of view, the media is independent, we cannot influence them. (GP5)

Therefore, injections will only be employed to address the fundamental issues in infrastructure, driving and self-drive tourism (stage 1). The media issues in stage 2 will continue to employ the same injections as depicted in FRT A.

\section{Stage 1}

Similar to FRT A, the infrastructure issues will be targeted. Central government will still have involvement in investing in developing road infrastructures, however, an increased proportion of the investment cost could come from "increased tax take (e.g. tourism)" (Injection22):

Could you charge an accommodation 'bed tax', certainly an option to explore in Queenstown to pay for visitor growth. (GP5)

Addressing the congestion issue, instead of just 'encouraging' local governments to employ destination management plans as illustrated in FRT A, "targets could be set for local governments through quarterly monitored progress to check that their destination management plan is executed consistently" (Injection 21). This could ensure the employment of the plan as, according to one participant, currently it is not being executed thoroughly by all local governments:

Having a structure approach to manage destinations to attract tourists. Some regions do it well, some don't necessarily have a strong one. (GP4)

The self-drive tourism issues could be mitigated by injections including "Set up a tourist number par level, and only promote tourism when tourist numbers are below or close to par level" (16), "Develop a quota/criteria system for tourists in order to self-drive" (55), and "Monitor tourist numbers against carrying capacity" (56). These injections in conjunction with making other transport methods more viable, aim at controlling the number of self-drive 
tourists as well as assisting to disperse them into different regions. The quote below suggested that better control of self-drive tourist numbers may reduce the pressure and potentially improve perception in some regions with smaller communities:

At certain times, tourists out number locals 3 to 1 in regions with a small community. Whenever there is a crash, it reinforces the perception that the crash is caused by tourists... (GP2)

If these can be successfully implemented, along with the destination management plan, then "New Zealand would have better regional dispersal" (DE30), subsequently "reduced congestion in peak season" (DE31).

With regard to driving issues, tourists who are eligible to self-drive in New Zealand will be required, rather than encouraged (FRT A idea) by the government, to complete a "driving simulation prior to actual driving" (Injection42). The merit of this injection is that tourists will have "simulated experience driving in New Zealand" (DE39), and consequently New Zealand roads will be less challenging for them to drive.

If "New Zealand roads are less challenging to drive" (DE27), then "driving decisions are not too challenging" (DE36). If that, and with government "requiring all vehicles to be installed with speed alert" (Injection13), as well as "installing more traffic cameras" (17), then selfdrive tourists will display better driving behaviours, and locals might too.

In summary, the aim of stage 1 is still to address the same problems as in FRT A, but via injections that are "harder" and may have stronger impacts, then move to the injections suggested in stage 2 as shown in FRT A. Table 4.21 summarises the injections used in this stage. 
Table 4. 21: Stage 1 injections used in FRT B

\begin{tabular}{|l|l|}
\hline \multicolumn{2}{|l|}{ Stage $\mathbf{l}$} \\
\hline Core injections \\
\hline 16 & $\begin{array}{l}\text { Set a tourist number par level, and only promote tourism when tourist numbers are below or } \\
\text { close to par level }\end{array}$ \\
\hline 58 & Invest in road infrastructures to build a strong roading network (e.g. Waikato expressway) \\
\hline 21 & Set targets for local government to employ destination management plans \\
\hline 24 & Invest in viable transport options (e.g. bus service, ferry) \\
\hline 42 & Government requires the use of driving simulation software by self-drive tourists prior to \\
actual driving
\end{tabular}

\subsection{Summary of "What to change to?"}

This section illustrated the TOC step of "What to change to?" via use of the FRT tool. The FRT used selected injections from the ECs to cause the UDEs in the CRT to be replaced by DEs.

Two FRTs were constructed to solve the UDEs. FRT A used a "softer" approach, emphasising education and communication throughout the stages to mitigate residents' negative perceptions. FRT B used a "harder" approach in stage 1, which focused on policy and enforcement, then continued to employ education and communication in stage 2 and 3 . The application of FRTs concluded the second research question of "potential strategies to mitigate residents' negative perceptions". 


\subsection{Summary of Chapter 4}

In this chapter, collected data is analysed by using the TOC TP method, including "Why change?", "What to change?", and "What to change to?". Within each of these steps unique TP tools were employed to analyse the data in a logical way. The results of this chapter are summarised below.

\section{Why change?}

All participants agreed that there are issues in their described system when comparing the desired with the actual state. Using GTs and lists of UDEs the problems became more visible and the issues were categorised as:

- Infrastructure

- Driving

- Self-drive tourism

- Media

- Perception

\section{What to change?}

The UDEs identified in the "Why change?" section were rearranged to construct a CRT. This logically depicted the causes and effects leading to the undesired effects. The CRT was displayed in three stages with most of the core problems discovered in stage 1: infrastructure, driving and self-drive tourism issues. These core problems fed into stage 2 causing mediarelated issues, and together these contributed to perception issues in stage 3; ultimately these were responsible for New Zealand residents' negative perceptions of self-drive tourism.

ECs were then applied to conceptualise the conflicts/dilemmas related to the core problems described by our participants. The conflicts/dilemmas ranged from high to low level, some conflicts/dilemmas are situated at a national level (e.g. to promote tourism or not), whilst others related to individuals' decisions (e.g. drive faster or not). Assumptions were surfaced and injections were proposed aiming to resolve the ECs. 


\section{What to change to?}

Selected injections from the ECs were then used when constructing the FRT, with an aim of transforming the UDEs to DEs. FRT A and B were provided to display possible ways in which negative perceptions could be mitigated, the former being "softer", and the latter "harder". The injections used in both FRTs were able to show how the core problems can be overcome by the injection of new ideas/actions, consequently resulting in desirable effects. The FRTs also have three stages, and most of the injections used in the FRTs were ideas from participants, whilst the remaining were ideas from the researcher.

The results of this chapter provided a solid understanding of the causes of residents' negative perceptions of self-drive tourism and potential ways to mitigate them. In the next chapter, the findings will be discussed in relation to the literature to support, critique and enhance understanding of the findings. 


\section{Chapter 5: Discussion of findings}

\subsection{Introduction}

This chapter discusses the findings presented in chapter 4, relative to the literature previously reviewed, as well as other relevant studies on residents' perception, and discussing how the TOC methodology can be employed to explore causes as well as mitigation ideas for addressing the research question of "What are the causes of residents' negative perceptions of self-drive tourism and potential strategies to mitigate them".

This chapter is in two sections:

1. The causes of residents' negative perceptions of self-drive tourism.

2. Mitigating strategies to prevent residents from expressing negative perceptions.

\subsection{The causes to residents' negative perceptions of self-drive tourism}

Residents' perceptions of tourism have been well researched. Numerous studies have aimed to understand the relationships between residents and tourism via frameworks, such as social exchange theory (e.g. Ap, 1992; Ward, 2011; Sharpley, 2014). However, perception studies of tourism critiqued in this study have not been able to explain "why" residents feel this way. This is argued to be a disadvantage of using quantitative research methods (Sharpley, 2014, p.42). Since many of the perception studies are quantitatively based, it has contributed to a broad, yet partial understanding of residents' perceptions towards tourism (Cordero, 2008). Thus, results of these quantitative studies have not been able to pinpoint the exact problems; instead, they generate an overview of the possible factors that may influence residents' perceptions based on, for instance, economic and/or social impact of tourism (e.g. Rasoolimanesh et al., 2015).

This study addressed these gaps by exploring the "why" via the TOC Thinking processes which do not appear to have been applied widely in the study of residents' perception or tourism.

Dettmer (2011) advocates starting the thinking processes (TP) by using a Goal Tree (GT) to provide a map of the goal(s), CSFs and NCs. By using this map, the researcher can measure how "wide" the gap is between the actual and the desired reality. This answers the first question of "Why change?" is necessary. Complemented with TOC's Current Reality Tree (CRT), the TOC methodology can assist in pinpointing the exact problem(s) that is the UDEs. Although it 
may be easier to directly ask the participants what they think are the causes of the negative perceptions, the pitfall of asking "What to change?" fails to explore the underlying problems that need to be addressed (Barnard \& Immelman, 2010). A major difference of this study, when compared with the outcomes from other studies, is its focus on understanding the negative effects of self-drive tourism from a multi-stakeholder's perspective, rather than simply focusing on "the general feelings" of resident participants on tourism. Participants are unlikely to dig deep enough to provide real solutions if not asked the right questions.

The findings in the GTs (Why change?) are consistent with what different stakeholders want to achieve in a "perfect world"; as affirmed in literatures that have studied stakeholders' interests. For instance, Prideaux and Carson (2003) and Howat et al. (2007) assert that selfdrive tourists' interests are about reducing stress, embracing individually, enjoying a sense of freedom and creating memorable experiences. And as stated by Cooper (2016), a role of government is to support tourism activities via measures, such as government policies and ensuring community wellness. A comparison was made of the GTs and the lists of UDEs from the different stakeholders; thus exposing the gaps in achieving the desired reality. The findings of this study show that infrastructure, driving, self-drive tourism, media and perception issues are the constraints preventing the entrance to the "perfect world".

Diagnosis of these gaps allows the researcher to understand where the problems exist and the complexity of such problems are then conceptualised as cause-and-effect relationships in a CRT, the next step when using TOC TP, answering "What to change?". The findings in the CRT (see Figure 4.5) revealed New Zealand residents' negative perceptions of self-drive tourism are caused by a number of issues (e.g. self-drive tourism behaviours, media), but are created gradually.

The CRT findings indicated hierarchy, "building up" to the residents' negative perceptions. The findings in stage 1 depicted fundamental issues in infrastructure, driving and self-drive tourism that are responsible for most of the subsequent UDEs, stage 2 explained media issues, leading in stage 3 to the perception issues. 


\subsubsection{Infrastructure issues}

It is found that infrastructure including roads and other infrastructure needed by both tourists and residents, has been a persistent issue in New Zealand. To address this, a $\$ 13.9$ billion land transport investment programme was carried out between 2015 and 2018, and other government initiatives, such as the "Thirty-year NZ infrastructure plan" in 2015 and the "Safer Journey 2010-2020" have aimed to improve infrastructure and road safety. Positive changes have been seen, for example a better roading network (Brodie, 2014; New Zealand Government, 2015).

However, in the same period, tourist numbers were increasing, a 35\% growth was seen between 2015 and 2019 (MBIE \& DOC, 2019). This questions whether the current rates of infrastructure improvements are keeping up with the increase in tourist numbers (considering this from a preCOVID scenario). According to the findings, it appears that even with the infrastructure plans and improvements, participants interviewed still expressed strong concerns about the infrastructure. An industry report by the Ministry for the Environment (MFE) also identified potential problems that affect infrastructure projects such as "complex and inflexible approval process" (see MFE, 2020). Such discrepancy between tourist growth and infrastructure upgrades has caused a decline in support for tourism, with more New Zealanders expressing concern about international visitors putting too much pressure on New Zealand (Kantar, 2019).

Additionally, it is found that because some local governments have not implemented a "destination management plan", which has contributed to ineffective regional dispersal. Also, the local governments that do have a good "destination management plan" still experience pressures that could be eased if there was more regional dispersal. This lack of regional dispersal is consistent with the MBIE (2016a) report which stated that there were definite regional variations in tourism and tourists tended to cluster in tourism hotspots.

The participant comments regarding the lack of regional dispersal are also consistent with the "Regional and seasonal dispersal report" in 2016, which stated that international tourists' spending remains skewed towards four main regions: Auckland, Wellington, Christchurch and Queenstown, and tourists travelling to other regions (to spend) has remained flat over the past several years (MBIE, 2016b). This suggests the tourism hotspots are still clustered with tourism activities, which places pressure on infrastructures and amplifies negative impacts (e.g. congestion). Consequently, the negative perception that "tourists are everywhere" is developed. 


\subsubsection{Driving issues}

The issues in infrastructure have relevance on driving issues, as poor infrastructure, especially roads, can lead to increased cognitive stress when driving ( $\mathrm{Wu}, 2015 ; \mathrm{Li}, 2020)$. Drivers' confidence when driving in an unfamiliar country, road and/or vehicle will increase if they are prepared ( $\mathrm{Wu}, 2015 ; \mathrm{Li}, 2020)$. Interestingly, this research revealed previously unreported differences between Asian and Western self-drive tourists in regards to their driving preparedness and behaviours.

Moreover, the findings of this study in contrast with Carr and Shaheer (2019) who stated that self-drive tourists are not well prepared and have an inadequate understanding of New Zealand rules and regulations. Carr and Shaheer's respondents are skewed to Western self-drive tourists (see Figure 5.1), hence this may not be enough to conclude that all self-drive tourists are unprepared.

\begin{tabular}{lcll}
\hline \multicolumn{1}{c}{ Nationality } & n & \multicolumn{1}{c}{ Nationality } & $\mathbf{n}$ \\
\hline Germany & 49 & South Africa & 3 \\
United Kingdom & 26 & Switzerland & 3 \\
France & $\mathbf{1 8}$ & Czech Republic & 2 \\
Canada & $\mathbf{1 6}$ & Italy & 2 \\
\hline United States of America & $\mathbf{1 6}$ & Sweden & 2 \\
\hline Australia & $\mathbf{1 6}$ & Taiwan & 2 \\
The Netherlands & $\mathbf{1 1}$ & Argentina & $\mathbf{1}$ \\
Brazil & 6 & Finland & 1 \\
Denmark & 6 & Ghana & 1 \\
\hline Japan & 6 & Greece & 1 \\
Chile & 5 & Indonesia & 1 \\
\hline Israel & 5 & Malaysia & 1 \\
Norway & 5 & Philippines & 1 \\
\hline Austria & 4 & Romania & 1 \\
Belgium & 4 & Slovakia & 1 \\
\hline China & 3 & South Korea & 1 \\
India & 3 & Spain & 1 \\
\hline
\end{tabular}

Figure 5. 1: Distribution of nationalities (Source: Carr and Shaheer, 2019)

This study revealed differences in road knowledge between Western and Asian self-drive tourists. Western self-drive tourists felt well equipped, hence more confident, through driving similarity factors, when driving on New Zealand roads, in comparison to Asian self-drive tourists. Also, Western self-drive tourists tend to neglect road research prior to driving on New Zealand roads, implying a trait of overconfidence, as found in the analysis of the tourism academic's UDEs (see Table 4.6). In contrast, because of less driving similarity, Asian selfdrive tourists are found to be better prepared for self-driving in an unfamiliar country. 
Gregersen (1996) argued that extra training on specific driving skills might improve confidence, especially amongst novice drivers; in this case, the Asian self-drive tourists driving for the first time in New Zealand. In contrast, overconfidence can lead to a high level of risk acceptance and constitutes a real risk factor in traffic (Ozkan et al., 2006).

Interestingly, a driving simulator study conducted in Munich, Germany, involving German local drivers and Chinese drivers (who had lived less than six months in Germany and with no driving experience in the country), suggested that Chinese visiting drivers are less vigilant under critical situations (e.g. a boar appeared at a speed of 1.5m/s) (Wang et al., 2019, p.488). While this appears contrary to the findings that Asian self-drive tourists are better prepared in an unfamiliar country, in Germany the driving orientation is the same as in China (driving on the right) and is under simulation conditions; hence, implying the overconfidence trait in the Chinese drivers when they were participating in the simulation. This is similar to the earlier discussion, that Western self-drive tourists are more prone to traffic risks due to overconfidence from driving similarity.

NZTA (2017a) statistics show the top three countries, in terms of the numbers of overseas drivers, involved in crashes were Australia, Germany and China. This suggests, as does the above analysis, that there should be more questions regarding Western self-drive tourists' driving abilities. Yet, participant data showed contradicting results whereby Asian self-drive tourists were provided with additional driving material and were questioned more by the rental car company compared to Western self-drive tourists. This suggested that there are other underlying issues to such misconceptions, as our government expert participant has stated:

I guess they [Asian tourists] are a little bit more identifiable, because they are in a rental or van and they look different, which is not in line with our data as Australians are our biggest international visitors in NZ. But we don't focus on them crashing as much. There is some fundamental problem at the bottom of that. (GP3) 


\subsubsection{Self-drive tourism issues}

The driving issues above illustrated how the effects of driving similarity and overconfidence can have an impact on one's driving preparedness. While this suggests that Western self-drive tourists should be "targeted" more, this is not the case.

Further investigation into the above issues showed that Western tourists have more social interactions with New Zealand residents while Asian tourists have less interaction. Also, Western tourist participants expressed a satisfactory level of rapport with New Zealand residents and had no issues, but Asian tourist participants, due to time constraints, were unable to interact with New Zealand residents in the same way, and negative interactions were found. Reisinger and Turner (2002) and Nyaupane et al. (2015) stated that as Asian tourists travel for a relatively short time and have limited contact with local people, such shallow contacts between two culturally different parties may introduce negative effects, such as communication difficulties and prejudice. Consequently, the cultural differences between Asian self-drive tourists and New Zealand residents created a gap in understanding, as government experts and media participants have highlighted. Indeed, cultural similarity can lead to mutual understanding, eliminating bias, stereotypes, and augmented intergroup relations, and positive relationship is found between cultural similarity and socialisation (Reisinger \& Turner, 2002). In contrast, cultural dissimilarity can lead to communication difficulties, increased stereotypes, and bias, as well as ineffective social contact (Reisinger \& Turner, 2002).

Social interaction is an important factor that can influence relationships (either positively or negatively) between tourists and residents and the level of cultural similarity can either augment or dilute such interactions. Asian self-drive tourists' lack of interaction with New Zealand residents has promoted misunderstanding, which contributes to the perception that Asian self-drive tourists need more driving education compared to Western self-drive tourists with whom New Zealand residents are more familiar. In the extreme, this study found reports of confrontations with Asian self-drive tourists on the road, with accusations about their driving behaviour despite the fact they were driving properly, as illustrated by participants' comments.

Thus far the discussions have aimed to explain why Asian self-drive tourists are more vulnerable as a target group, despite not being the main contributor to road accidents. This finding is consistent with ethnic stereotyping, that is the outgroup (Asian self-drive tourists), is being stereotyped. As Simon et al. (1990) highlighted, individuals, tend to target and apply stereotypical traits on outgroups that are homogeneous (Asian self-drive tourists), compared to 
target outgroups that are heterogeneous (Western self-drive tourists). In this case, the lack of social interactions and the tendency for Asian tourists to be more identifiable have prompted New Zealand residents to see and treat them differently, as a consequence of stereotyping (Duncan, 1976).

Further findings revealed that stereotyping by residents is not limited to ethnic stereotyping. In fact, stereotyping extended to self-drive tourism generally, witnessed in residents' comments and survey reports. One of the reasons found is that self-drive tourists focused on their own tourism experience (e.g. driving $20 \mathrm{~km} / \mathrm{hr}$ to take photos on the highway), and this causes conflict with residents who only want to get to their destination. Moreover, residents perceive that attractions and cities are "full of tourists", and self-drive tourism activities have promoted congestion issues, which have affected residents' day-to-day lives. This results in conflicting and unpleasant interactions, in which residents consider almost all outgroups (self-drive tourists) as a threat, as a negative stereotype trait in the integrated threat theory suggested by Stephan and Stephan (2000).

Tourists have been criticised as "selfish" individuals whose behaviour during a holiday are by design out of the ordinary, "through expressions of misrule rather than rule" (Buzzell, 2005, p.30). Being a tourist conveys the notion that an individual can transform to a new person with a novel identity (tourist), immersing into the "tourist culture", which allows the individual to ignore conventional standards of conduct that they would normally display (McKercher, 2015, p.372). One of the most common excuses given by tourists acting irresponsibly is "I am a tourist" (McKercher et al. 2008, p.378).

Such allegation of tourists' selfishness is consistent with the findings that self-drive tourists care less about others when in "holiday mode", thus becoming a threat to others. From this perspective, the social exchange between residents and self-drive tourists tends to be negative. As witnessed in the findings (Mood of the Nation and Views on Tourism survey reports), the negative impacts most rated by residents since 2015 relate to road use, such as congestion issues and contribute to serious road accidents. Such negative impacts are influencing residents' view on self-drive tourism at a social level, wherein residents believed tourism activities (selfdriving) have more adverse cost than benefits, as per social exchange theory, and also promote negative stereotyping (Andereck et al., 2005).

Critically, tourists as selfish individuals can equally apply to residents as domestic self-drive tourists/visitors. Resident drivers may also "have an itinerary to follow" and as such this can 
lead to fast driving, placing additional and unnecessary pressure on self-drive tourists. Participants complained that resident drivers do not often reflect on their driving behaviours despite them being the dominant group involved in road accidents. Based on accident records between 2012 and 2016, with an increase of about 38\% international visitors, the number of crashes involving overseas driver licence holders has remained relatively steady; on average only 17 fatal crashes out of 264 involved an overseas driver, a $6.2 \%$ of all fatal and injury crashes. (NZTA, 2017a; NZTA, 2017b; Field et al., 2019).

In contrast, $93.8 \%$ of fatal and injury crashes involved New Zealand driver licence holders (NZTA, 2017a). In 2016 alone, there was one fatal crash for every 145,000 overseas drivers, and one fatal crash for every 17,900 domestic drivers (Huffadine, 2018). Ironically, issues around resident drivers have not gained much attention from residents themselves nor have they been exposed by the media, as compared to self-drive tourists.

The discussions to this point have explained the main aspects of the CRT (Stage 1), and the fundamental issues that are contributing to residents' negative perception of self-drive tourism. These include but are not limited to the ethnic stereotyping of Asian self-drive tourists, the negative social exchange between residents and self-drive tourists, and the infrastructure issues. The next section will discuss how residents' negative perceptions are reinforced by the media.

\subsubsection{Media issues}

Stage 2 of the CRT (see Figure 4.5) depicts how the media sector, especially commercial media, can influence residents' perceptions by highlighting specific issues; here, issues related to selfdrive tourism. This sub-section will discuss how media hype, media effects and heuristics influence one's perception.

The relationship between media and society is via communication. Curran (2010) defined communication as "the process of sharing meaning based on information transfer" (p.3). In this study, the media participants reported that the delivery of news stories is mainly dominated by commercial media in New Zealand, and commercial media operate as a business whose goal is to maximise profit, via means such as advertising and subscriptions. At the same time, it was found that because commercial media is dictated by a profit motive, they often emphasise news quantity, without allowing adequate time or staff to ensure news quality. This resulted in a large number of "quick stories" that are not validated by evidence or data, with a luring headline 
designed to attract clicks. This finding is consistent with a survey of New Zealanders that found a concern of poor journalism, for instance, misleading headlines/clickbait and factual mistakes (Myllylathi \& Treadwell, 2020).

As Luhmann (2000) stated, whatever people know about society and the world, is through the mass media (p.1). Such quantity of "quick stories" and headline framing on self-drive tourism (e.g. tourist crash), is found to have impacted how residents see self-drive tourism. Equally, it is important to acknowledge the negativity bias - humans tend to automatically devote more attention to negative than positive information (Valkenburg et al., 2016). Indeed, New Zealand's commercial media understand what the audience likes from measuring which story received the most clicks (negative stories), subsequently feeding more of the most "popular" stories, considered as "media hype".

The problem is that repetitive coverage by the media of a specific topic makes it become important news even if the relevance and newsworthiness of the event seem to be disproportionately considered (Vasterman, 2005). In this regard, commercial media seems to have played a leading role in social construction, by magnification of one specific perspective (self-drive tourism), which has led to consequences for all stakeholders (Vasterman et al., 2005).

Media businesses themselves may not be aware of the possible consequences on society (e.g. residents, self-drive tourists), as their core focus is to make a profit. Such focus on profit by producing a large number of stories that the audience likes has actually created a threat that is not consistent with the facts relating to the self-drive tourism problem, constituting a case of media hype (Vasterman, 2005). As discussed in the earlier section, statistics show that overseas driver licence holders have been responsible for only 17 fatal crashes out of 264 between 2012 and 2016 , despite a $38 \%$ increase in international visitor numbers over the years, whilst the remaining crashes were contributed by New Zealand driver licence holders (NZTA, 2017a; NZTA, 2017b; Field et al., 2019). Such coverage on self-drive tourism creates a false impression that this is an urgent problem that requires attention, as a trait of media hype (Kepplinger \& Habermeier, 1995).

Media stories on self-drive tourism have attracted public concern with remedies being proposed by residents (e.g. driver test, learner plate) (Angus \& Associates, 2019). However, media stories alone are not significant enough to trigger negative perceptions towards self-drive tourism, despite the number of stories published. The reality is, consistent with the media effect 
and heuristics, New Zealanders are exposed to these stories (self-drive tourism), and such the stories act as mediators that trigger and confirm their assumptions or expectations of an existing condition; they also act as heuristics seeing self-drive tourism stories as cues, promoting discontinued search and reinforcing residents' perceptions about self-drive tourism (Klapper, 1960; Todd \& Gigerenzer, 2000; Severin et al., 2014). These are consistent with the findings; an explosion of negative news about self-drive tourism and tourism in general (e.g. freedom camping, congestion), then whenever residents encounter "bad driving behaviour" (e.g. driving too slowly), and because residents may have limited time, they tend to employ heuristics to ignore other information (e.g. driver looking for rest area).

Heuristics here actually play a more important role regarding Asian ethnic groups; a survey, Asia New Zealand Foundation (2018), showed New Zealanders' actual knowledge of Asia and/or Asian is even lower than their self-assessed knowledge. Given the lack of social interaction between Asian tourists and residents, residents' lack of knowledge of Asia and/or Asian makes them more accepting of negative news about Asian drivers, and they tend to be satisfied with a good enough decision, rather than understanding the full picture (e.g. whether the driver is actually an Asian tourist, or a second-generation New Zealand resident), (Gigerenzer, 2008). The effects of media seem to be more powerful when an individual has only limited knowledge, thus only able to resonate with their own experience within their scope of knowledge.

Such a phenomenon is also consistent with media framing, which is about selecting some aspects of perceived reality (self-drive tourism) and transforming that reality into communicating text in a more salient way (Entman, 1993). The negative aspect of self-drive tourism is selected and communicated to the audience. As Kumpel \& Haas (2016) highlighted, media framing has the power to influence public perceptions and political decisions, either by limiting or defining the message's meaning. In this scenario, how media stories were framed has helped influence residents' perceptions.

In addition, from a psychological perspective, such negative stories about self-drive tourism is organised as cognitive schemas, stored in human memory that operates as constraints on the interpretation and arrangement of events and situations (Fiske, 1980). As a result, as Medin (1995) suggested, people tend to believe and reinforce their pre-existing knowledge with strong tenacity and confidence. In this case, residents have believed and reinforced their knowledge gained from media about self-drive tourism, which is also consistent with Yeoman and 
McMahon (2020), that people may dismiss the details in each media story however the emotional reaction to that story can be persistent.

In essence, the current reality of the media sector, especially commercial media, is constrained by the interests of shareholders (e.g. profit-making) and such agenda dictates journalist employees to produce stories that are attractive to the audiences. Self-drive tourism as a "hot" topic is targeted and magnified by the media; however, such stories were framed in ways that are misleading and the contents were not based on evidence and facts (particularly the stories in 2015). Consequently, audiences (New Zealand residents) are influenced by these stories, media effects, heuristic and negativity bias took place acting as "hints" reinforcing residents' perception when they encounter bad tourist driving behaviour. In addition, because residents do not have adequate knowledge about Asian culture, Asian tourists are more prone to be perceived negativity, despite them being well prepared to drive on New Zealand roads.

Media acts as a communicator, delivering stories that are deemed to be important, but also plays an important role in influencing one's perception. In this case, it is found media has negatively influenced residents' perceptions on self-drive tourism, by magnifying and exposing such issues. Nevertheless, residents' personal experience with self-drive tourists is much stronger than media effects alone. Perhaps together with the fundamental issues found in stage 1 , this is enough to cause negative perceptions? 


\subsection{Mitigating strategies}

The mitigating strategies are derived from the analyses of the ECs in "What to change to?" Possible strategies were surfaced based on ideas from the participants, and also the researcher's ideas prompted by the research process. To demonstrate, the assumptions for BD in Figure 4.7is:

"There are increasingly more self-drive tourists visiting NZ (GP4)”.

A potential injection (idea of mitigating strategy) for this assumption according to our participants is:

"Encourage the use of other transport options (GP5)".

At the same time, an injection was also generated by the researcher:

"Monitor tourist numbers against carrying capacity".

One of the advantages of using EC as part of the TOC methodology in this research enables the researcher not only to discover mitigating strategies via analysing participants' data but also allow personal inputs, via a systematic manner (Cox et al., 2012). Such advantage gives researchers the flexibility to compare and evaluate mitigating strategies from a broader perspective; they are not limited by participants' inputs solely.

The findings in the ECs generated tentative mitigating strategies to address the different issues in the CRTs and these were applied to the subsequent FRTs (see Figures 4.11 and 4.12), providing logical maps showing how the system would look like if such mitigating strategies were implemented. Before the discussion of the FRTs, Table 5.1 summarises the strategies surfaced in the ECs from participants and the researcher's personal ideas, indicating the main issue(s) the strategies aim to address.

The findings in Chapter 4 revealed that government should be responsible in leading/implementing any strategies/changes. 
Table 5. 1: Summarised mitigating strategies from surfacing ECs

\begin{tabular}{|c|c|c|c|}
\hline Participants' ideas & Addressing issue(s) & Researcher's ideas & Addressing issue(s) \\
\hline $\begin{array}{l}\text { Encourage use of } \\
\text { public transport (GP1, } \\
\text { GP3) }\end{array}$ & $\begin{array}{l}\text { Infrastructure, self- } \\
\text { drive tourism }\end{array}$ & $\begin{array}{l}\text { Develop a dynamic } \\
\text { reward system to } \\
\text { encourage local } \\
\text { government to employ } \\
\text { destination management } \\
\text { plan. }\end{array}$ & $\begin{array}{l}\text { Infrastructure, self- } \\
\text { drive tourism }\end{array}$ \\
\hline $\begin{array}{l}\text { Invest in viable } \\
\text { transport options (e.g. } \\
\text { train, ferry) (GP1) }\end{array}$ & $\begin{array}{l}\text { Infrastructure, self- } \\
\text { drive tourism }\end{array}$ & $\begin{array}{l}\text { Set a tourist number par } \\
\text { level, and only promote } \\
\text { tourism when tourist } \\
\text { number is below or } \\
\text { close to par level }\end{array}$ & $\begin{array}{l}\text { Infrastructure, self- } \\
\text { drive tourism }\end{array}$ \\
\hline $\begin{array}{l}\text { Encourage the use of } \\
\text { other transport options } \\
\text { (GP5). }\end{array}$ & Infrastructure & $\begin{array}{l}\text { Increase the speed of } \\
\text { building infrastructures }\end{array}$ & Infrastructure \\
\hline $\begin{array}{l}\text { Increase funding } \\
\text { allocation from central } \\
\text { government (GP3) }\end{array}$ & Infrastructure & $\begin{array}{l}\text { Promote less popular } \\
\text { regions that need } \\
\text { developments }\end{array}$ & Infrastructure \\
\hline $\begin{array}{l}\text { Have more rest-areas } \\
\text { for people to exploit } \\
\text { the opportunities to } \\
\text { take photos, enjoy the } \\
\text { scenery etc (GP2) }\end{array}$ & Infrastructure & $\begin{array}{l}\text { Invest in road } \\
\text { infrastructures to build a } \\
\text { strong roading network } \\
\text { (e.g. Waikato } \\
\text { expressway). }\end{array}$ & Infrastructure \\
\hline $\begin{array}{l}\text { Have clear road signs } \\
\text { (e.g. attraction ahead, } \\
\text { ready to slow down) } \\
\text { placed and allow more } \\
\text { reaction time (TP1). }\end{array}$ & $\begin{array}{l}\text { Infrastructure, } \\
\text { driving }\end{array}$ & $\begin{array}{l}\text { Set targets for local } \\
\text { government to employ } \\
\text { destination management } \\
\text { plan }\end{array}$ & Infrastructure \\
\hline $\begin{array}{l}\text { Increase tax gain (e.g. } \\
\text { tourism) (GP4) }\end{array}$ & Infrastructure & $\begin{array}{l}\text { Monitor tourist numbers } \\
\text { against carrying } \\
\text { capacity }\end{array}$ & Infrastructure \\
\hline $\begin{array}{l}\text { Prioritise investing in } \\
\text { education and } \\
\text { communication for } \\
\text { residents (GP3, JP1) }\end{array}$ & $\begin{array}{l}\text { Self-drive tourism, } \\
\text { perception }\end{array}$ & $\begin{array}{l}\text { Promote less popular } \\
\text { regions that need } \\
\text { developments. }\end{array}$ & Self-drive tourism \\
\hline
\end{tabular}




\begin{tabular}{|c|c|c|c|}
\hline $\begin{array}{l}\text { Government and rental } \\
\text { car companies to } \\
\text { promote driving } \\
\text { simulation software to } \\
\text { self-drive tourists prior } \\
\text { actual driving (GP2) }\end{array}$ & Driving & $\begin{array}{l}\text { Develop a quota/criteria } \\
\text { system for tourists in } \\
\text { order to self-drive }\end{array}$ & Self-drive tourism \\
\hline \multirow[t]{6}{*}{$\begin{array}{l}\text { To employ "ski-field" } \\
\text { indicators, where } \\
\text { highway route that is } \\
\text { challenging is } \\
\text { indicated as colour } \\
\text { black, whilst easy } \\
\text { highway route is } \\
\text { indicate as colour } \\
\text { green (GP2). }\end{array}$} & Driving & $\begin{array}{l}\text { Government to enforce } \\
\text { the use of driving } \\
\text { simulation software to } \\
\text { self-drive tourists prior } \\
\text { actual driving }\end{array}$ & Driving \\
\hline & & $\begin{array}{l}\text { Drive with a co-polit to } \\
\text { instruct/remind on } \\
\text { navigation, road } \\
\text { conditions etc. }\end{array}$ & Driving \\
\hline & & $\begin{array}{l}\text { Install more cameras on } \\
\text { highways to discourage } \\
\text { bad driving behaviour }\end{array}$ & Driving \\
\hline & & $\begin{array}{l}\text { Educate self-drive } \\
\text { tourists to avoid travel } \\
\text { during peak hours }\end{array}$ & Driving \\
\hline & & $\begin{array}{l}\text { Remind self-drive } \\
\text { tourists that NZ roads } \\
\text { are very different } \\
\text { compare to their country } \\
\text { of origin. }\end{array}$ & Driving \\
\hline & & $\begin{array}{l}\text { Encourage residents to } \\
\text { become a tour guide } \\
\text { driver guiding tourists } \\
\text { from A to B }\end{array}$ & Driving \\
\hline
\end{tabular}




\begin{tabular}{|c|c|c|c|}
\hline & & $\begin{array}{l}\text { Develop and promote } \\
\text { car-sharing app or other } \\
\text { social interaction } \\
\text { software }\end{array}$ & Driving \\
\hline & & $\begin{array}{l}\text { Invest in and work with } \\
\text { the media sector to } \\
\text { deliver positive stories } \\
\text { about tourism in a long } \\
\text { term. }\end{array}$ & Media \\
\hline & & $\begin{array}{l}\text { Journalists act } \\
\text { collectively to convince } \\
\text { shareholders about the } \\
\text { importance of informing } \\
\text { the public, instead of } \\
\text { overly focus on profit }\end{array}$ & Media \\
\hline & & $\begin{array}{l}\text { Understand journalists' } \\
\text { needs better (e.g. } \\
\text { increase their salary) in } \\
\text { order to retain and } \\
\text { attract journalists. }\end{array}$ & Media \\
\hline & & $\begin{array}{l}\text { Government to invest } \\
\text { into commercial media } \\
\text { to ensure there are } \\
\text { enough resources to } \\
\text { investigate stories } \\
\text { properly. }\end{array}$ & Media \\
\hline
\end{tabular}


Based on the mitigating strategies suggested by participants and the researcher (see Table 5.1 above), the findings in the FRT A and FRT B (see Figures $4.11 \& 4.12$ ), provided two different pathways to mitigate residents' negative perceptions, following the TOC methodology.

The strategies in FRT A are more incremental/soft and FRT B is more radical/hard; their development was inspired by Dredge and Jenkins (2007). The authors explained that the level of government involvement and controls are based on policy instruments, such as the exercise of financial and/or legal powers to influence and/or enforce people's behaviour (Dredge \& Jenkins, 2007).

It is important to note that the FRTs in this research are tentative and the implementation of incremental or radical strategies can be fluid, open to change and debate, especially considering the current tourism system (COVID-19). Such discussion and debate can be well supported using the TOC discussion protocols (the Categories of Legitimate Reservation, see Table 3.1). Indeed, the current pause of the tourism industry can, to some degree, be treated as a "grace period" for policymakers to reflect on its tourism policies.

\subsubsection{Mitigating strategies for infrastructure issues}

As discussed in sub section 5.2, it was found that the speed of infrastructure improvements is not aligned with the rate of tourism growth (pre-COVID); infrastructure pressure due to the rapid growth of tourist numbers has caused a decline in the community's support of tourism (Kantar, 2019). In addition, the inconsistent use of "destination management plans", resulting in poor regional dispersal, has promoted a negative perception of "tourists are everywhere".

According to the findings, the mitigating strategies to address infrastructure issues are related to, the development of infrastructure to cope with the continuing increase of tourist number (pre-COVID), and subsequently positively influence residents' perception of tourism/selfdrive tourism. A panel's view in a tourism report concluded "A more proactive approach to the funding of, and investment in, tourism-related infrastructure should reduce the risk of a repetition of some of the pressures that emerged with the rapid growth in visitor numbers of recent years" (MBIE, 2019b, p.22). Moreover, investment in transport (road) infrastructure is larger compared to other investments made in 2019, see Figure 5.2, (MBIE, 2019a). This action by the government is aligned with the mitigating strategy "Increase funding allocation from central government" (Injection22) and is clearly an option to address the infrastructure 
issue, yet this may also be one strategy that cannot be relied upon as there are always more demands for government funding than can be met.

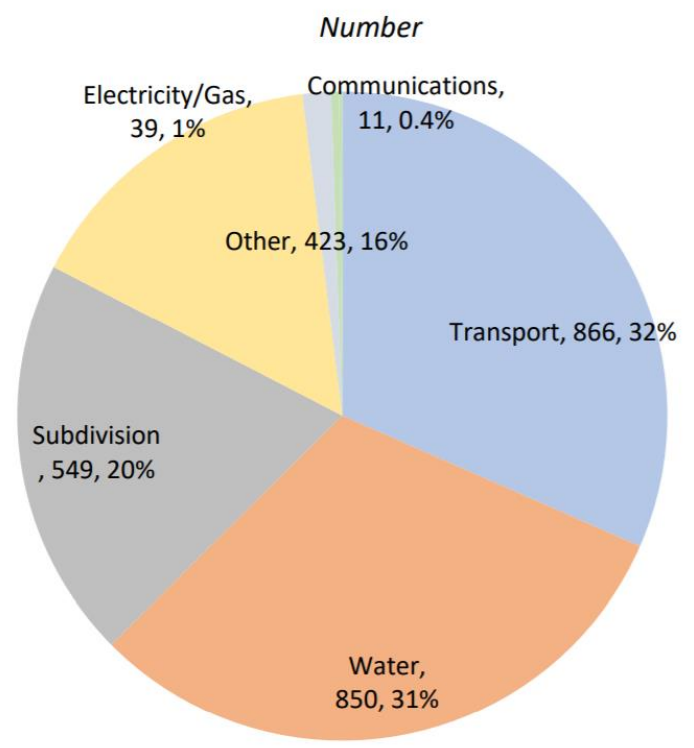

Figure 5. 2: Infrastructure project types anticipated starting in 2019 (Source: MBIE, 2019a, p.13).

Indeed, the advantage of having better road infrastructure can enhance the visitor experience, reduce road pressure and benefit the local community (MBIE, 2016). However, focusing on building more road infrastructure is not always the best strategy to mitigate residents' negative perceptions, as studies have found that more road infrastructure can lead to more road users, therefore, more traffic congestion (Duranton et al., 2011; Elias, 2012).

Applying Elias (2012) modelling results on the effect of Transmission Gully motorway project to this study, in the short term, building more road infrastructure will help mitigate congestion, as one of the causes of negative perceptions. However, over time, congestion will likely reoccur, as a consequence of increased attractiveness of driving and continuing tourism growth (preCOVID), which will then require more infrastructure developments. While, these research findings indicates that the government officials interviewed have a strong understanding of the potential threats that rapid tourism growth may bring (e.g. loss of social license), most of these government participants' areas of expertise are related to the transport sector. As such many of their mitigating strategies, as well as solutions given in published government reports (see Road 
to zero, Infrastructure construction pipeline, The Tourism New Zealand report) are mainly focused on road infrastructure (MOT, 2019b; MBIE, 2019a; MBIE, 2019b).

Whilst acknowledging that road infrastructure developments are vital for New Zealand tourism and the general community, it does not effectively solve problems such as congestions in the long term (Elias, 2012): especially when tourism growth rate exceeds building speed. Similarly, negative perceptions towards self-drive tourism may decrease in the short-term due to increased road infrastructure, but this will likely reoccur once the new infrastructure capacity is reached or exceeded.

Findings also revealed that "Invest in other viable transport options (e.g. public transport)" (Injection24) is favoured by the government experts and the tourism academic participants to reduce the impact of rapid tourism growth (pre-COVID). This strategy will address the lack of transport options raised by self-drive tourist participants, which "forced" them to choose to self-drive. The investment in viable transport options, such as public transport, is found to yield positive results such as reducing congestion, decreasing accidents and improving stakeholder relationships (improve perception) (Elias, 2012). However, counter-intuitive behaviour was found by Elias (2012), who stated that with more public transport and less private vehicle (selfdriving), the attractiveness of driving will start to increase, as people can drive their car more comfortably, in turn encouraging more traffic congestion.

Whilst investing in road infrastructure is vital, it was questioned in sub section 5.2.1 whether the current building speed has been aligned with the growth rate. In addition to this, it is now found that increasing road infrastructure (including investing in viable transport) may only be effective in the short term (Elias, 2012). Thus, potentially more radical policy instruments are required in conjunction with the infrastructure developments to manage the attractiveness of driving. Two strategies from the researcher (surfaced in the ECs) have been included in the FRT B (see Figure 4.12), "Set a tourist number par level, and only promote tourism when tourist number is below or close to par level"(Injection16) and "Set targets for local government to employ destination management planning” (Injection21), (as opposed to "encouraging" the local government in the FRT A). These strategies aim through stricter government control to:

1. To maintain a balance between tourist numbers and infrastructure building speed.

2. To dictate local governments to implement destination management plans, to attract more self-drive tourists to visit their regions, thus, better regional dispersal. 


\subsubsection{Mitigating strategies for driving issues}

The driving issues as discussed in sub section 5.2 are embedded in driving similarity and overconfidence, which also have strong correlations to driving behaviour and infrastructure conditions (Wu, 2015; Wang et al., 2019). In terms of government's mitigating strategies to support driving issues, other than the Land Transport (Road User) Rules 2004 which is a regulation that applies to all road users (see New Zealand Legislation, 2020), and infrastructure developments as discussed, it is found that many of the strategies to support self-drive tourism are based on incremental/soft instruments, such as clearer road signs or encouraging the use of driving simulation software, which have been introduced or are being implemented by the NZTA and AA (Automobile Association, 2020).

Other strategies not specifically noted in the findings, are available publicly (NZTA, 2020), such as Air New Zealand's in-flight "Driving in New Zealand" app, road safety leaflets with visitor visa issued in China and India, or working with tourism operators (e.g. rental vehicle operators, accommodation sector). These approaches work in conjunction with the mitigating strategies mentioned in the infrastructure and self-drive tourism issues sections, and aim to mitigate the causes of negative perceptions by educating self-drive tourists with consistent knowledge, and to ease driving difficulties via means, such as better road signs.

Strategies already implemented by government to address the driving issues do not seem to have been effective enough at mitigating residents' negative perceptions of tourist driving, as reflected by the opinions in the residents' perception survey (see Kantar, 2018; Kantar, 2019; Angus and Associates, 2020). The reasons for this are partly due to the combination of poor social interaction, tourist selfishness and congestion. The media issues, as discussed in sub section 5.2, appear to have the greatest influence on residents' perceptions.

The researcher's proposed strategy "Drive with a co-pilot to instruct/remind on navigation, road conditions etc" (Injection14), shown in FRT A as a behavioural instrument, could yield positive results. In a study predicting driving speed behaviour by using the "Theory of planned behaviour" (highlighted by the tourism academic), Delhomme et al. (2014) stated that descriptive norms such as an individual's beliefs about actual behaviour, is influenced by significant others (e.g. family member), and this may strongly influence young drivers' behaviour to drive faster or slower (p.132). Thus, having a co-pilot next to a self-drive tourist to assist with navigation, road conditions etc. may influence the driving speed, positively. The 
radical strategy in FRT B "Government to require all rental vehicles to have speed alert installed" (Injection13) could also act as a behavioural influencer with or without a co-pilot.

With regard to the rental car companies' inconsistent distribution of road information to visitor drivers, radical strategies may need to be applied. Currently, the "Code of Practice for informing overseas drivers" contains a mandatory policy to assess the "at risk" hirers" preparedness; this includes all first time visitors but excludes those driving on Australian and UK licences (TIA \& Rental Vehicle Association NZ, 2018, p.4). While this policy is useful to ensure self-drive tourists are ready to drive, it also contains flaws. To demonstrate; a self-drive tourist may lie about their preparedness level, Western tourists may indicate they are prepared due to driving similarity but in fact they have not conducted adequate research, and the notion of excluding Australian and UK licence holders does not hold true, as these two countries are listed in the top five countries in terms of their involvement in crashes, Australia ranked $1^{\text {st }}$ and UK ranked $5^{\text {th }}$, (NZTA, 2017a).

Therefore, rather than rental car companies "asking" the tourists if they are prepared enough to drive, the mitigating strategy "government to enforce the use of driving simulation software prior to self-driving” (Injection42) in FRT B may be a better approach. This strategy could ensure that every self-drive tourist has an adequate level of road knowledge to drive in New Zealand, hence, minimising the risk of side effects (e.g. crashes). 


\subsubsection{Mitigating strategies for self-drive tourism issues}

The causes of the issues arising from residents' negative perceptions of self-drive tourism are mainly found in poor social interactions (Asian tourists) and tourist selfishness. Mitigating strategies to address these issues are presented but will be challenging to implement in the current COVID-19 situation. To demonstrate, strategies from a government participant "Develop and promote the use car-sharing app or other social interaction software" (Injection10) and the researcher's idea "Encourage residents to become a tour guide driver guiding tourists from A to B" (Injection8) are applied in both FRT A and B to address the aforementioned issues. The former aims to augment the interactions between residents and selfdrive tourists (especially Asian tourists) via technology, while the latter focuses on increasing personal interactions, with an overall aim to improve understanding, enhance tourist experiences and to reduce negative perceptions.

As discussed in sub section 5.2, Asian tourists tend to have less opportunity for social interaction with residents, this limits the understanding between New Zealand residents and Asian tourists. The impacts of mobile technologies are found to have a positive influence on individual's travel patterns and behaviour, and that tourists become more willing to engage in value co-creation with service providers (e.g. local community) if mobile technologies are used frequently (Law et al., 2018). Additionally, Valk et al. (2010) asserted that "the use of mobile technologies can facilitate increased access to education” (p.119). Thus, the application of mobile technologies could assist with mitigating some of the misunderstandings between residents and self-drive tourists. They could also be used to improve tourists' awareness and concern about other road users, via value co-creation and better access to education (e.g. road knowledge, New Zealand culture). This strategy is assumed to be able to withstand limited social distancing, under a COVID-19 scenario.

"Encouraging the residents to become tour guide drivers" (Injection8) also aims to improve social interactions. The benefit of this strategy is the increased personal interaction, which may result in better social exchange. However, it could also result in negative social exchange, as an extension of barriers such as cultural misunderstanding (Brown et al., 2010). Of course, this strategy may not be applicable to all tourists, as tourists have vastly different travel motivations or social interaction willingness (e.g. Chinese tourist versus Western tourist) (Pearce \& Lee, 2005). This strategy could prove problematic in a COVID-19 scenario, through an increased 
intolerance to close face-to-face interactions, though tourists may be happier to travel within a "bubble" with their driver.

In addressing tourist selfishness issues (e.g. driving slower to take photos), infrastructure improvements as suggested by participants "Have more rest areas for tourists to take photos, enjoy the scenery etc"(Injection44), and a behavioural strategy from the researcher "Install more cameras to discourage bad driving behaviour" (Injection17), are proposed in FRT A. It was found that self-drive tourist participants complained about the lack of rest areas. While increasing the number of rest areas would mitigate this issue, it may not be effective enough to alter self-drive tourists' behaviours or their intention to drive slower. Combining the development of rest areas and installing more speed cameras, as a behavioural control mechanism, could have positive effects on consistent road speed. It has been validated that the application of speed cameras can result in better driving behaviour and more consistent speeds (Delaney et al., 2005).

It is important to note that the unfamiliarity of New Zealand, such as driving rules, roads and vehicles, are also factors contributing to self-drive tourists driving slower and are consistent with $\mathrm{Wu}(2015)$ and $\mathrm{Li}$ (2020)'s studies, but if the infrastructure developments and educational instruments (mobile technologies), can improve the self-drive tourists' driving confidence, this would allow them to make better driving decisions in a foreign country (New Zealand). 


\subsubsection{Mitigating strategies for media issues}

While the mitigating strategies proffered to address the fundamental issues can certainly improve self-drive tourism, none of these mitigating strategies directly addresses the media sector, found to play a significant role influencing residents' perceptions. To a certain extent, protected by the Freedom of Expression, media have the autonomy to decide what and how a story is presented (Law Commission, 2011, p.9), in terms of its contents and/or headline. Due to this, government expert participants were unable or unwilling, to provide mitigating strategies concerning the media sector, which is reflected by their absence in the summary of mitigating strategies from surfacing ECs (see Table 5.1).

The findings did discover that government is acting actively to build positive relationships with the commercial media, "feeding" them with positive and consistent information, accurate evidence and data, as a means to encourage more balanced stories. In spite of these efforts, difficulties were found as government officials had to constantly rebuild relationships with the journalists due to the high turnover rate of media employees. The employment environment in commercial media has remained unchanged since 2007; a journalism survey in 2007 concluded that more time and journalist staff allocation were needed to pursue an investigation, as well as better pay to attract and retain experienced journalists and to mentor new employees (Hollings et al., 2007). This is consistent with the findings in the media's UDE list (see Table 4.13.1) and comments from the media participants.

Arguably, as a potential outcome of the media's high staff turnover, the relationship-building strategy between government and media sector can be fragile. In a democracy enshrining freedom of expression, mitigating strategies for the media sector cannot be overly radical, but they still need to be strong enough to address the current media issues (e.g. lack of staff, time to write an accurate story and better pay). Therefore, the mitigating strategy "Government could set financial incentives to help commercial media to have enough resources for story investigations" and a strategy focused towards the commercial media business "Understand journalists' needs better (e.g. increase their salary) in order to retain and attract employments", are proposed by the researcher and included in FRT A and B.

Meanwhile, government could exploit the advantage of publicly-owned media (e.g. RNZ), which is found to have better resources compared to commercial media. In this case, the strategy "Work with the public media sector to deliver positive stories about tourism in the long term" (Injection51) may be feasible to further influence the public about the benefits of 
tourism/self-drive tourism. Daily Encourager as a non-for-profit media is a good example of how positive stories can be delivered (see Daily Encourager, 2020).

However, these mitigating strategies for the media sector will not be effective unless the fundamental issues (infrastructure, driving and self-drive tourism), are also addressed. As commercial media rely on stories that are the most lucrative, then without mitigation of the fundamental issues, incidents are likely to occur which will, no doubt, be reported by the commercial media, perhaps in a negative light.

Therefore, to improve residents' negative perceptions of self-drive tourism, it is not feasible to rely on only one mitigating strategy or focus on only one cause (e.g. infrastructure). It requires a collaboration of different strategies logically addressing causes at different levels. The CRTs and FRTs show how a proposed core injection, along with supporting injection(s), can transform the undesirable effects in the CRTs to desirable effects in the FRTs, eventually reversing residents' negative perceptions of self-drive tourism. 


\subsection{Analytical framework}

Figure 5.3 portrays an analytical framework aimed to conceptualise this study's results; it contains three main elements.

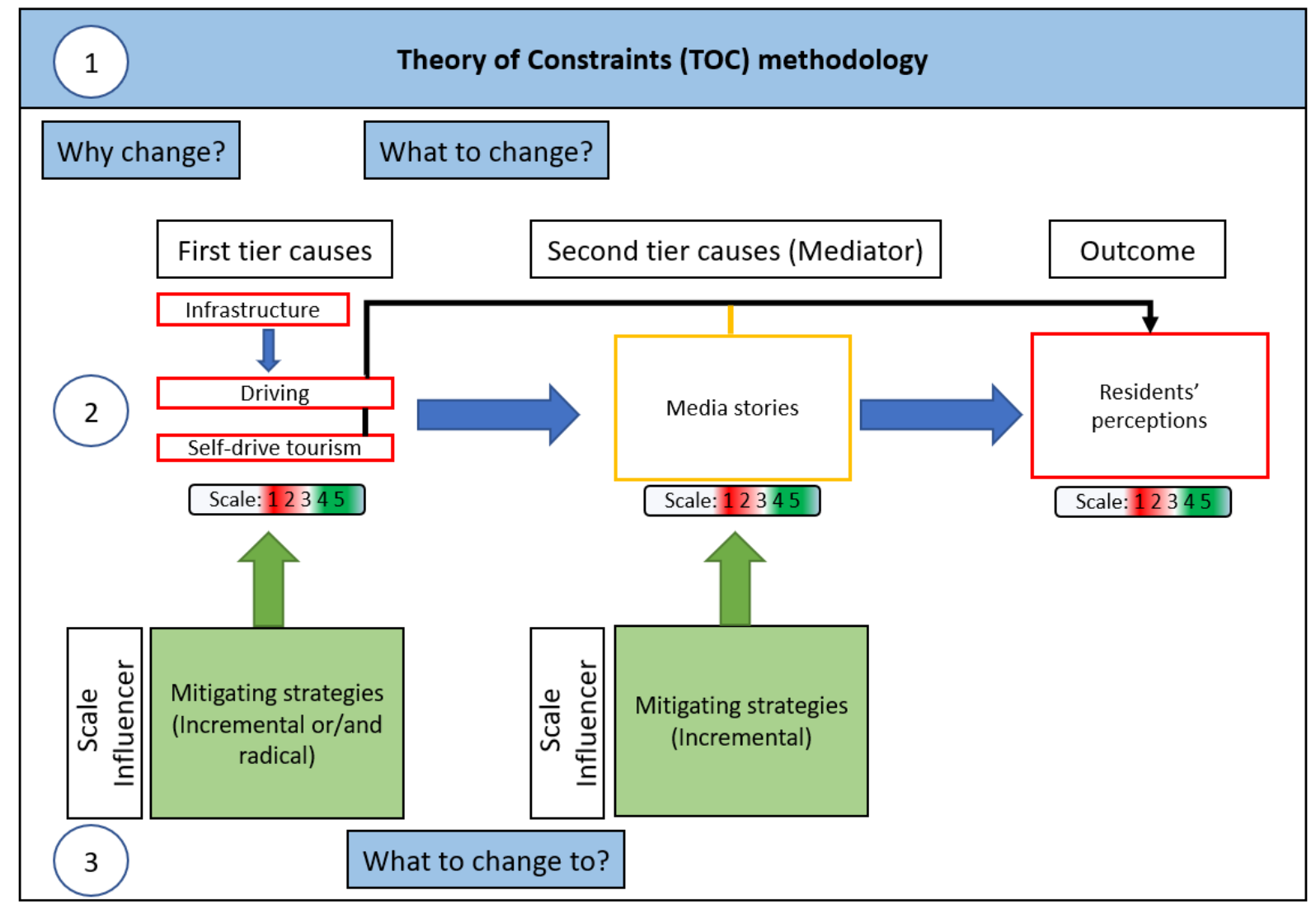

Figure 5. 3: Analytical framework of this study's results

\section{Element 1}

Coloured in blue, element 1 outlines that this study is guided by the TOC methodology, with "Why Change?", "What to change?" and "What to change to?" throughout the study.

\section{Element 2}

The scales, 1 being very bad, 5 being very good and 3 neutral, show the current level of each tier.

For example, according to this study's findings, infrastructure has a current score of 2 (bad), as there are still too many complaints. Media has a current score of 3 (neutral), as they are reporting more balanced stories. Subsequently, the residents' perceptions are currently scored 
2, as their perceptions are not only influenced by media but also driving and self-drive tourism issues directly.

Element 2 outlines the different contributors to residents' perceptions, with the first tier showing the fundamental contributors including infrastructure, driving (an arrow is between infrastructure and driving to show the former has impact on the latter), and self-drive tourism. The second tier portrays the contributor media. Media is defined also as a mediator as it converts information from the first tier and this can then influence the residents' perception outcomes.

There are also direct contributor factors between driving and self-drive tourism, through the media contributor, to the residents' perception outcomes. That is, residents' perceptions can be directly influenced by the two contributors, and media may subsequently reinforce or dilute the magnitude of such contributors (depending on what type of stories they report).

\section{Element 3}

The scale explained above is dynamic and can be affected by mitigating strategies. The strategies strength can have differing effects on the scores.

To illustrate, incremental/soft strategies would have a lesser and slower impact on improving the score, whilst radical/hard strategies would have a stronger and faster impact. That said, as discussed in previous sections, media, by law cannot be "enforced", thus only incremental/soft strategies can be employed here, but both incremental and radical strategies could be employed for the fundamental issues. Hence, implementation of both incremental and radical strategies would affect the score on residents' perceptions; ideally a shift from 2 (bad) to 4 (good).

\subsection{Summary of Chapter 5}

A summary of this chapter will be included in the Conclusion. 


\section{Chapter 6: Conclusion and recommendations}

\subsection{Introduction}

The purpose of this study is to investigate the causes of residents' negative perceptions of selfdrive tourism and to develop strategies to mitigate the negative perceptions, via the Theory of Constraints (TOC) methodology.

This chapter will:

1. Revisit the research objectives.

2. Reflect on the application of the TOC methodology in tourism.

3. Highlight the theoretical and practical implications of this study.

4. Highlight the studies limitations.

5. Provide future research direction.

\subsection{Research objectives revisited}

Research sub-objective one: To identify the self-drive tourism system's goal(s), then to identify the critical success factors and necessary conditions to achieve the goal(s).

Research sub-objective two: To identify the self-drive tourism system's undesirable effects and examine if there are any gaps preventing the system's goal(s) from being achieved.

Research sub-objective three: To identify the causes of residents' negative perceptions of self-drive tourism via cause-and-effect logic.

The first and second sub-objectives addressed "Why change?" by following the TP of "Goal Trees" (GTs) and "Undesirable effects" (UDEs). The third objective addressed "What to change?" through construction of the "Current Reality Tree" (CRT) (Cox et al., 2012). 
In the "Why change?" section (4.2), the researcher compared the GTs with the lists of UDEs. The results established that the "perfect world" does not currently exist as many issues (gaps) were discovered, these are:

- Infrastructure

- Driving

- Self-drive tourism

- Media

- Perception

Advancing to the "What to change?" section (4.4) CRT was applied to organise the different issues via cause-and-effect logic. The main findings are:

1. Infrastructure developments in New Zealand are progressively improving, with strong investments in transport/road infrastructure aiming to strengthen New Zealand's road safety and user experience. Unfortunately, the speed of developing the infrastructure is unable to keep up with the rapid tourism growth; hence, infrastructure remains an issue in New Zealand. Also, local government inconsistency in implementing a destination management plan contributes to ineffective regional dispersal, thus resulting in congestion problems in tourism hotspots.

2. Road infrastructure has correlations with self-drive tourists' cognitive stress levels while driving and drivers' preparedness level can either reduce or increase cognitive stress. It is found that Western self-drive tourists are less prepared due to driving similarity and overconfidence compared to Asian self-drive tourists. Nonetheless, Asian self-drive tourists are "better" taken care of by rental car operators, with more questions being asked of them in regards to their driving abilities and preparedness, compared to Western self-drive tourists.

3. The level of social interactions between self-drive tourists and residents can influence residents' understanding of self-drive tourists. It is found that New Zealand residents tend to understand Western tourists more, but appear to be less knowledgeable of Asian tourists because there is less opportunity to interact. This could also explain why Asian self-drive tourists are treated differently by rental car operators. Residents' lack of understanding of Asian tourists introduces ethical stereotyping and negative social exchange. 
4. Self-drive tourists and residents have different motivations when driving on New Zealand roads. Self-drive tourists want to explore New Zealand by driving slower, taking photos and such like, whilst residents may only want to get to a destination as fast as possible. This introduces conflict between the two parties, contributing to negative stereotyping towards self-drive tourism.

5. Commercial media's media hype about self-drive tourism has played a leading role in social construction, giving the impression that self-drive tourism is problematic. This is compounded by a lack of adequate resources and journalists; hence, stories are under investigated and poorly reported. When residents encounter bad driving behaviour this triggers and reinforces such an impression, as traits of media effect, heuristics and negativity bias.

Summarising the three research objectives, the causes of residents' negative perceptions are progressive in stages; with infrastructure, driving and self-drive tourism issues at stage 1 of the CRT (see Figure 4.5), producing undesirable effects that are constraining positive relationships with the residents. These undesirable effects are magnified and exposed to the public by commercial media in stage 2 of the CRT (see Figure 4.5), driven by their profit agenda. Together these act to promote residents' negative perceptions of self-drive tourism in stage 3 (see Figure 4.5).

Research sub-objective four: To identify and propose strategies to mitigate residents' negative perception of self-drive tourism.

Situated in "What to change?" and "What to change to?" (section 4.6) of the TOC methodology, the EC processes were used to surface assumptions and then injections (ideas of mitigating strategies) were developed to invalidate the surfaced assumptions (Cox et al., 2012). During the EC processes, participants' data and the researcher's ideas were used to create the best possible strategies for each assumption; these strategies can be incremental (soft) or radical (hard). FRTs were created to show how the strategies can be implemented.

Participants stated that government should be responsible for any changes needed. The government experts presented mitigating strategies that focused on addressing infrastructure and driving issues, which were more incremental, compared to the more radical ideas of the researcher. 
1. The COVID-19 pandemic has paused New Zealand's tourism industry, providing a "grace period" for stakeholders to revisit related policies and to make changes where needed.

2. Infrastructure related mitigating strategies are found to be useful in addressing congestion in tourism hotspots in the short term, but not effective in the long term; especially with rapid tourism growth, as seen pre-COVID-19. Thus, radical strategies maybe required by government, such as controlling tourist numbers.

3. Government strategies to address the driving issues emphasise education and communication with the self-drive tourists, such as providing driving leaflets. However, these do not appear to be highly effective in mitigating negative perceptions. The researcher proposes ideas to influence driving behaviour such as a co-pilot and driving simulation; to improve driving confidence.

4. Mitigating strategies to address self-drive tourism issues, such as social interaction, are the development of a car-sharing app or other social interaction software, as well as encouraging residents to be tour guides. These aim to create more opportunities for selfdrive tourists and residents to interact.

5. Other suggestions include more rest areas for self-drive tourists to take photos and to enjoy the scenery will help to reduce the conflict between self-drive tourists and residents, and more traffic cameras to encourage drivers to follow New Zealand road rules.

6. Media issues are less controllable as the government cannot interfere with freedom of expression; the mitigating strategies to address these issues are mainly via continuous relationship building with commercial media. Other possible strategies such as financial incentives to ensure commercial media has adequate resources were proposed.

7. Infrastructure, driving and self-drive tourism issues in stage 1 of the CRT should be mitigated as much as possible first, before advancing to media issues in stage 2 of the CRT. The perception issues in stage 3 of the CRT can be mitigated only once stage 1 and 2 are "under control".

Thus, regarding the research objectives, many mitigating strategies were found to change the UDEs into DEs (from CRT to FRT). Residents' negative perceptions are able to be mitigated using incremental and/or radical strategies. 


\subsection{Application of the TOC methodology in tourism}

This section addresses:

Research sub-objective five: To explore the use of the TOC methodology in tourism academic studies.

Although the Theory of Constraints (TOC) has been applied in the hotel sector (see Dalci and Kosan, 2012), and used in teaching (Mabin et al., 2020) and webinars (Kimes, 2020) to illustrate how it can be applied to address tourism issues, this research appears to be the first in-depth tourism study integrating the TOC methodology particularly the Thinking Processes (TP).

While using TOC, the researcher found that the methodology fosters "co-creation". For example, while surfacing the mitigating strategies, the researcher worked with data collected from participants, but TOC fosters researcher input. In addition, the "co-creation" strength can extend to readers of this study. That is, any new ideas surfaced by readers can be integrated and used to amend and/or strengthen the robustness of a TP map (e.g. FRT). This "co-creation" approach can be useful to address chronic tourism issues; by first building a basic logic tree to address the main problem and over time new entities could be added or an existing entity or entities maybe replaced.

Overall, the application of TOC methodology in this study introduced a "new" methodology to the tourism discipline. While it may be debated whether TOC is adequate to fully explain tourism as a complex and dynamic phenomenon, the researcher found that the TOC methodology is effective in addressing not only self-drive tourism, but many other tourism topics, such as capacity management and tourist satisfaction. 


\subsection{Theoretical contributions}

The theoretical contributions of this thesis to the literature on perceptions, tourism and TOC is threefold. This research contributes:

1. To the understanding of how negative perceptions are formed, using a system based qualitative methods.

2. To the understanding of how negative perceptions can be mitigated via TOC methodology.

3. To integrate TOC methodology with the studies of tourism.

First, this research provides empirical evidence for the causes of negative perceptions. To date, there is a lack of literature that investigates the in-depth feelings of residents/hosts perceptions towards tourists (Sharpley, 2014), or the causes of those ill-feelings. This research contributes to filling this gap by using a system based qualitative methods, and the findings contribute to previous residents-tourists perception literature, by providing an explanation of "why" residents have negative feelings. Additionally, it appears that many of the studies on self-drive tourism are primarily focused on the tourists' perceptions (e.g. see Mmopelwa \& Kgathi, 2007; Coghlan \& Prideaux, 2009; Meng \& Hudson, 2016). This research also contributes to the selfdrive tourism literature by investigating self-drive tourism from the residents' perspectives.

Second, this research discovered mitigating strategies through adopting a more flexible approach, tailoring strategies based on analyses of causes of negative perception using the TOC methodology, rather than solely using existing literature. As a system based method, this research seeks fundamental solutions (mitigating strategies) to root causes holistically, rather than a piecemeal approach dealing with a few symptoms at a time.

Third, as highlighted in sub section 6.2, this research contributed to the integration between TOC and tourism studies. It also showcased and reinforced how TOC methodology can be applied in academic study, in response to Ronen's (2005) call for more studies to utilise TOC's analytic capabilities.

Overall, the findings in this research are highly consistent with the literature, which explained how stereotyping, negative social exchange, media hype, media effects, heuristics and negatively bias can influence one's perception. Meanwhile, driving similarity, cultural differences, overconfidence, and tourist selfishness are extended from the literature, providing a more in-depth understanding of the causes of negative perceptions. The mitigating strategies 
developed from the analysis were correlated with the literature to collect evidence that they can mitigate negative perceptions.

\subsubsection{Practical contributions}

The results from this research reveal several practical contributions worthy of consideration by the stakeholders. First, the causes of residents' negative perceptions are clustered in infrastructure, driving and self-drive tourism issues, and governments' responses to these issues have tended to rely on "softer" policies. This research suggests that government needs to implement "harder" policies to work in conjunction with existing strategies and/or policies.

Although it is found that the media sector cannot be "controlled" due to the freedom of expression, current relationship building between government and media sectors on self-drive tourism/ tourism reporting show signs of positive changes, amid challenges in high journalist turnover. It is recommended that government target the media sector by other means, and that the media sector itself seeks to understand journalist employees' needs, to retain and attract them.

This research provided logic maps depicting the causes of negative perceptions, and development of mitigating strategies. The researcher encourages readers to input personal/professional ideas to strengthen the maps, using the TOC methods, as a means of "cocreation".

More importantly, the findings of this research are not only theoretical, but are also actionable to mitigate and improve residents' negative perceptions of self-drive tourism and tourism in general. 


\subsection{Limitations of this study}

This study has three main limitations, namely self-drive tourist sampling, implementation and testability.

The first limitation, self-drive tourist sampling, relates to sample size, location and sampling design. Although only eight participants were recruited, they all matched the sampling requirements, as described in section 3.7. As the researcher was constrained by time and resources additional participants could not be recruited. This research would have benefited from having more participants from other countries such as India and/or Japan.

The selected location (a holiday park) used to recruit participants, during December and January, was populated mainly by German and Chinese tourists. Other locations (e.g. airports, popular tourist attractions) may have given the opportunity to select tourists from different countries, but the researcher was unable to get approval for access. Even if access had been granted it would be difficult to distinguish who is a self-drive tourist and able to participate in an interview (30-45minutes) when their intention is either to travel to another destination or to enter an attraction. Nevertheless, including more locations such as hotels, I-sites and camping grounds would have increased the sampling representation.

Excluding residents as participants in the sampling design may have under-represented their in-depth feelings about self-drive tourism. Including residents in the sample design would have required a large sample size to ensure good representation. Surveys in this case provided the best solution and had already been conducted by industry experts. However, it is acknowledged that these surveys would not have fully captured the residents' feelings in realtime.

The second limitation relates to the implementation of the proposed strategies to mitigate negative perceptions. This study was unable to check whether the implementations of such strategies could cause the desired changes without creating other undesirable side effect(s) due to time constraints. In a full TP analysis, the TP tool "Negative Branch Reservation" would be employed rigorously to test if implementing a proposed injection led to other new undesirable effects (Cox et al., 2012). Moreover, the last two stages of the TOC TP "How to cause the change?" and "How to sustain the change?" need further input from stakeholders in order to check if any obstacles are preventing the proposed strategies being implemented, or to manage the transformation from its current reality to a future reality. 
The third limitation relates to the testability of the research results. Due to resource constraints, the researcher was unable to confirm with the participants if the constructed trees (GTs, CRTs) reflected their views, or to discuss the mitigating strategies (ECs) and the proposed changes (FRTs). However, the GTs and CRTs were based fully on participants' input, although they did rely on the researcher's interpretation. Furthermore, the researcher has sent a summary of the interview transcriptions to those who requested them; however, no one responded with comments. As the ECs and FRTs were constructed using both the participants' and the researcher's ideas, they are only illustrative.

\subsection{Future research}

As implied in previous sections, future research could include a more comprehensive research method (e.g. mixed methods) to study the perceptions of self-drive tourism. Also, there are further opportunities where TOC could be used in tourism studies, through utilising different stages of the TOC methodology, and/or the "original" Five Focusing Steps used to continually improve a system's ability (see Cox et al., 2012, p.57; Kimes, 2020).

With regard to the study of residents' perceptions, further research could include residents in the sampling design, to gain a deeper understanding of their feelings in a real-time setting. Whilst this research only included self-drive tourists who are from countries that drive on the right-hand side, future research could also include self-drive tourists who drive on the same side as New Zealand (e.g. Australia, UK) to compare if there are any significant perception changes when driving with an unfamiliar vehicle in an unfamiliar country.

In addition, the impact of the COVID-19 pandemic on self-drive tourism activities would be a fertile area for research. The researcher sought to obtain data to compare the proportion of crashes caused by self-drive tourists and residents pre and during COVID, but data was not yet available. Future research could also compare the perceptions of self-drive tourism pre-COVID and post-COVID once tourism resumes, to test if negative perceptions have changed during the border restrictions.

Finally, regarding mitigating strategies, future research could test if the proposed strategies can effectively address the different issues, eventuating in an improvement in residents' perceptions of self-drive tourism. Methods such as System Dynamics could be employed to simulate the behaviour over time (for an example, see Elias, 2012). Finally, the last two steps 
of the TOC TP "How to cause the change?" and "How to sustain the change?" could be implemented.

\subsection{Concluding remarks}

This research focused on examining the causes of residents' negative perceptions of self-drive tourism and the development of strategies to mitigate those negative perceptions.

Through the application of the TOC methodology, the goals and lists of undesirable effects were compared, gaps that constrained achievement of the goals were discovered, and causes of residents' negative perceptions were traced by connecting the undesirable effects using causeand-effect logic. This research portrayed pathways of how to mitigate negative perceptions, showing a future reality if the proposed incremental and/or radical mitigating strategies were implemented.

More specifically, this research identified infrastructure, driving, self-drive tourism and media issues as the main contributors to promoting residents' negative perceptions, and it provided the causal linkages of these main contributors to the perception issues. Mitigating strategies were created to specifically target the identified issues.

From a theoretical perspective, this research has responded to the call by Sharpley (2014) that more qualitative studies are required to examine "why" residents feel certain ways towards tourist/tourism. This research also showed how TOC methodology can be applied in tourism studies and encourages future use of TOC methodology to address other tourism issues. It also prompts readers to "co-create" personal and/or professional ideas using the TP tools in practice. Despite limitations, such as sample size, the resulting analysis offered future research opportunities, including future research from a "COVID" perspective.

Reflecting on the process of writing the thesis, the researcher has gained a broader understanding of self-drive tourism. While the researcher is happy that this thesis has answered the research objectives and addressed the research gaps, a more detailed investigation, including a simulation model testing of the efficacy of the strategies, was not possible within the Master thesis constraints. Nevertheless, this more detailed investigation could come to fruition when the researcher embarks on the next academic journey; to pursue a $\mathrm{PhD}$ degree. 


\section{References}

Aberson, C. L. (2015). Positive intergroup contact, negative intergroup contact, and threat as predictors of cognitive and affective dimensions of prejudice. Group Processes \& Intergroup Relations, 18(6), 743-760.

Amaratunga, D., Baldry, D., Sarshar, M., \& Newton, R. (2002). Quantitative and qualitative research in the built environment: Application of "mixed" research approach. Work Study, 5l(1), 17-31. Retrieved from https://search.proquest.com/docview/218383317?accountid=14782

Almeida-García, F., Peláez-Fernández, M. Á., Balbuena-Vázquez, A., \& Cortés-Macias, R. (2016). Residents' perceptions of tourism development in Benalmádena (Spain). Tourism Management, 54, 259-274.

Andereck, K. L., Valentine, K. M., Knopf, R. C., \& Vogt, C. A. (2005). Residents' perceptions of community tourism impacts. Annals of tourism research, 32(4), 1056-1076.

Angus and Associates (2019). Views on Tourism. Unpublished report.

Angus and Associates (2020). Views on Tourism. Unpublished report.

Ap, J. (1992). Residents' perceptions on tourism impacts. Annals of tourism Research, 19(4), $665-690$.

Asia New Zealand Foundation. (2018). New Zealanders' Perceptions of Asia and Asian Peoples. Retrieved from https://www.asianz.org.nz/assets/reports/1179_POA_2018_FA_WEB.pdf

Automobile Association AA. (2020). The simulated practical driving test. Retrieved from https://www.aa.co.nz/drivers/learn-to-drive-the-aa-way/simulated-driving-test/

Baran, S. J., \& Davis, D. K. (2009). Mass communication theory: Foundations, ferment and future (5th ed.). Boston, MA: Wadsworth Cengage Learning.

Barnard, A., \& Immelman, R. (2010). Holistic TOC implementation case studies: Lessons learned from the public and private sector. JF Cox \& JG Schleier (Eds.), 455-498.

Bhowmik, C., Gangwar, S., \& Ray, A. (2018). Integrating Six-Sigma and theory of constraint for manufacturing process: a case study. In Soft computing: theories and applications (pp.607-617). Springer, Singapore.

Bimonte, S., \& Punzo, L. F. (2016). Tourist development and host-guest interaction: An economic exchange theory. Annals of Tourism Research, 58, 128-139.

Bleach-Wood, S., Goddard, K., Harding, D., Kildare, C., \& Messenger, S. (2005, December). Maximising Manufacturing Performance with TOC. [Paper presentation]. Victoria University of Wellington $40^{\text {th }}$ Annual Conference, Wellington, NZ.

Borah, P. (2016). Media Effects Theory. https://doi.org/10.1002/9781118541555.wbiepc156 
Braun, W. (2002). The System Archetypes. System, 2002.

Brown, K. G., Cave, J., Moyle, B., Croy, G., \& Weiler, B. (2010). Tourism interaction on islands: the community and visitor social exchange. International Journal of Culture, Tourism and Hospitality Research.

Brodie, C. (2014). Safer Journeys: New Zealand's Road Safety Strategy 2010-20. Retrieved from https://www.itf-oecd.org/sites/default/files/docs/brodieoct2014 $0 . p d f$

Buzzell, T. (2005). Holiday revelry and legal control of fireworks: A study of neutralisation in two normative contexts. Western Criminology Review 6: 30-42.

Carr, N. \& Shaheer, I. (2019). International Self-drive Visitors' Awareness of Road Safety in $N Z$. (Transport Research \& Education Trust). University of Otago.

Coghlan, A., \& Prideaux, B. (2009). 4WD Desert tourism-an examination of attitudes, motivations and perceptions. Alice Springs: Desert Knowledge Australia.

Cooper, C. (2016). Essentials of tourism. Pearson.

Cordero, M., \& Carlos, J. (2008). Residents perception of tourism: a critical theoretical and methodological review. CIENCIA ergo-sum, Revista Cientifica Multidisciplinaria de Prospectiva, 15(1), 35-44.

Cox, J. F., Blackstone, J. \& Schleier, J. S. (2003). Managing Operations: A Focus on Excellence. North River Press, Great Barrington, $M A$.

Cox, J. F., Boyd, L. H., Sullivan, T.T., Reid, R.A., \& Cartier, B. (2012). The theory of constraints international certification organization dictionary.

Retrieved from https://cdn.ymaws.com/www.tocico.org/resource/resmgr/dictionary/tocico dictionary 2nd editio.pdf

Cox, J.F., \& Spencer, M.S. (1998). The Constraints Management Handbook. Lucie Press, Boca Raton, FL.

Cox, J. F., Mabin, V. J., \& Davies, J. (2005). A case of personal productivity: Illustrating methodological developments in TOC. Human Systems Management, 24(1), 39-65.

Creswell, J.W. (2007). Qualitative inquiry \& research design: Choosing among five approaches (2nd ed.). Lincoln: Sage Publications Inc.

Creswell, J.W., \& Clark, V.L. (2011). Choosing a mixed methods design. Designing and conducting mixed methods research. ( $2^{\text {nd }} \mathrm{ed}$.). Sage publications.

Creswell, J.W., \& Poth, C.N. (2016). Qualitative inquiry and research design: Choosing among five approaches. Sage publications.

Curran, J. (2010). Media and society. Bloomsbury Publishing. 
Daily Encourager. (2020). About daily encourager trust, News that build people up.

Retrieved from

https://dailyencourager.co.nz/about/

Dalci, I., \& Kosan, L. (2012). Theory of constraints thinking-process tools facilitate goal achievement for hotel management: A case study of improving customer satisfaction. Journal of Hospitality Marketing \& Management, 21(5), 541-568.

Davies, J., Mabin, V. J., \& Balderstone, S. J. (2005). The theory of constraints: a methodology apart?-a comparison with selected OR/MS methodologies. Omega, 33(6), 506-524.

Deery, M., Jago, L., \& Fredline, L. (2012). Rethinking social impacts of tourism research: A new research agenda. Tourism management, 33(1), 64-73.

Delhomme, P., Cristea, M., \& Paran, F. (2014). Implementation of automatic speed enforcement: Covariation with young drivers' reported speeding behaviour and motivations. European review of applied psychology, 64(3), 131-139.

Delaney, A., Ward, H., Cameron, M., \& Williams, A. F. (2005). Controversies and speed cameras: lessons learnt internationally. Journal of public health policy, 26(4), 404-415.

Dettmer, H. W. (1995). Quality and the theory of constraints. Quality Progress, 28(4), 77.

Dettmer, H. W. (2007). The logical thinking process: A systems approach to complex problem solving. ASQ Quality Press.

Dettmer, H. W. (2011). Our goal is... What is our goal?. Goal Systems International.

Dredge, D., \& Jenkins, J.M. (2007). Tourism planning and policy. John Wiley and Sons.

Duhé, S. F., \& Zoch, L. M. (1994). Framing the media's agenda during a crisis. Public Relations Quarterly, 34(4), 42-45.

Duncan, B. L. (1976). Differential social perception and attribution of intergroup violence: Testing the lower limits of stereotyping of Blacks. Journal of Personality and Social Psychology, 34, 590-598.

Durfee, J. L. (2006). "Social change" and "status quo" framing effects on risk perception: An exploratory experiment. Science Communication, 27(4), 459-495.

Duranton, G., \& Turner, M.A. (2011). The fundamental law of road congestion: Evidence from US cities. American Economic Review, 101(6), 2616-52.

Elias, A. A. (2012). A System Dynamics Model for Stakeholder Analysis in Environmental Conflicts. Journal of Environmental Planning and Management 54 (8): 1125-1147.

Entman, R. M. (1993). Framing: Toward clarification of a fractured paradigm. Journal of Communication, 43, 51-58. 
Etikan, I., Musa, S.A., \& Alkassim, R. S. (2016). Comparison of convenience sampling and purposive sampling. American journal of theoretical and applied statistics, 5(1), 1-4.

Evans-Pritchard, D. (1989). How "The? See "Us": Native American Images of Tourist. Annals of Tourism Research 16(1):89-105.

Fan, D. X., Zhang, H. Q., Jenkins, C .L., \& Tavitiyaman, P. (2017). Tourist typology in social contact: An addition to existing theories. Tourism Management, 60, 357-366.

Field, A., McKegg, K., \& Schiff, A. (2019). Signature Programme Evaluation: Visitor Drivers Project. Retrieved from https://nzta.govt.nz/assets/Safety/docs/safer-journeys/signature-programmeevaluation-visiting-drivers-project-may-2019.pdf

Fiske, S. T. (1993). Social cognition and social perception. Annual review of psychology, 44(1), 155-194.

Flick, U. (2013). The SAGE handbook of qualitative data analysis. Sage publications.

Galvez, J., Guzman, E., Conejo, R., \& Millan, E. (2009). Student Knowledge Diagnosis Using Item Response Theory and Constraint-Based Modelling. AIED, 291-298.

Gigerenzer, G. (2008). Why heuristics work. Perspectives on psychological science, 3(1), 20 29.

Goldratt, E. M., \& Cox, J. F. (1984). The Goal: Excellence in Manufacturing. Croton-onHudson, NY: North River Press.

Goldratt, E. M. (1994). It's Not Luck. Massachusetts: North River Press.

Goldkuhl, G. (2012). Pragmatism vs interpretivism in qualitative information systems research. European Journal of Information Systems, 21, 135-146.

Google. (2020). Perception studies. Retrieved from https://scholar.google.com/scholar?hl=en\&as $\mathrm{sdt}=0 \% 2 \mathrm{C} 5 \& \mathrm{q}=$ perception+studies + in +tourism\&btnG=\&oq=percept

Gregersen, N. P. (1996). Young drivers' overestimation of their own skill-An experiment on the relation between training strategy and skill. Accident Analysis and Prevention, $28(2), 243-250$.

Griffiths, I., \& Sharpley, R. (2012). Influences of nationalism on tourist-host relationships. Annals of Tourism Research, 39(4), 2051-2072.

Guba, E. G., \& Lincoln, Y. S. (1982). Epistemological and methodological bases of naturalistic inquiry. ECTJ, 30(4), 233-252.

Gursoy, D., Chi, C. G., \& Dyer, P. (2009). An examination of locals' attitudes. Annals of Tourism Research, 36(4), 723-726. 
Hadinejad, A., Moyle, B., Scott, N., Kralj, A., \& Nunkoo, R. (2019). Residents' attitudes to tourism: a review. Tourism Review, 74(2), 150-165.

Hallahan, K. (1999). Seven models of framing: Implications for public relations. Journal of public relations research, $11(3), 205-242$.

Hohmann, C. (2014). What is a Goal Tree. Retrieved from https:/hohmannchris.wordpress.com/2014/03/07/what-is-a-goal-tree/

Hollings, J., Samson, A., Tilley, E., \& Lealand, G. (2007). The big NZ journalism survey: underpaid, under-trained, under-resourced, unsure about the future-but still idealistic. Pacific journalism review, 13(2), 175.

Houston, D. (2007). TQM and higher education: A critical systems perspective on fitness for purpose. Quality in Higher Education, 13(1), 3-17.

Howat, G., Brown, G., \& March, H. (2007). Self-drive tourism: Travellers to South Australia's Limestone Coast region. Gold Coast Sustainable Tourism CRC.

Hsu, C. H., \& Chen, N. (2019). Resident Attribution and Tourist Stereotypes. Journal of Hospitality \& Tourism Research, 43(4), 489-516.

Huffadine, L. (2018). How bad are tourist drivers really? Retrieved from https://www.stuff.co.nz/national/101732029/how-bad-are-foreign-drivers

Ikeziri, L. M., Souza, F. B. D., Gupta, M. C., \& de Camargo Fiorini, P.(2019). Theory of constraints: review and bibliometric analysis. International Journal of Production Research, 57(15-16), 5068-5102.

Inman, R. A., Martha, L. S., \& Green, Kenneth, W. (2009). Analysis of the relationships among TOC use, TOC outcomes, and organizational performance. International Journal of Operations \& Production Management, 29(4), 341-356.

Kallio, H., Pietilä, A. M., Johnson, M., \& Kangasniemi, M. (2016). Systematic methodological review: Developing a framework for a qualitative semi-structured interview guide. Journal of advanced nursing, 72(12), 2954-2965.

Kantar. (2020). Mood of the Nation. Retrieved from https://tia.org.nz/resources-and-tools/insight/mood-of-the-nation/

Kantar. (2019). Mood of the Nation. Retrieved from https://tia.org.nz/assets/c4197debe8/Mood-of-the-Nation-2019-FINAL-v2.pdf

Kantar. (2018). Mood of the Nation. Retrieved from https://tia.org.nz/assets/Uploads/4b12568910/Mood-of-the-Nation-InfographicMarch-2018.pdf

Kantar. (2017). Mood of the Nation. Retrieved from https://tia.org.nz/assets/Uploads/9a613c63fe/Mood-of-the-Nation-Nov-17.pdf 
Kantar. (2016). Mood of the Nation. Retrieved from https://tia.org.nz/assets/Uploads/67ad038249/Mood-of-the-Nation-November2016.pdf

Kantar. (2015). Mood of the Nation Retrieved from https://tia.org.nz/assets/Uploads/346b4a8016/Mood-of-the-Nation-Dec-15.pdf

Kaushik, V., \& Walsh, C. A. (2019). Pragmatism as a Research Paradigm and Its Implications for Social Work Research. Social Sciences, 8(9), 255.

Kepplinger, H. M., \& Habermeier, J. (1995). The impact of key events on the presentation of reality. European journal of communication, 10(3), 371-390.

Kim, S., Mabin, V. J., \& Davies, J. (2008). The theory of constraints thinking processes: retrospect and prospect. International Journal of Operations \& Production Management, 28(2), 155-194.

Kimani, S. W. (2015). Exploring Quality of Learning and Teaching Experiences in Higher Education using the Theory of Constraints: Kenya and New Zealand. Retrieved from http://researcharchive.vuw.ac.nz/handle/10063/4878

Kimes, S. (2020, July 21). Value-based pricing and revenue Management in a Post COVID19 world. [Video]. YouTube. https://www.youtube.com/watch?v=ie2oxZosbbE\&ab channel=TeHerengaWaka $\% E 2$ $\% 80 \% 94$ VictoriaUniversityofWellington

Kitchin, T., \& Guildford, J. (2020). Tourists charged after Queenstown woman killed in crash. Retrieved from https://www.stuff.co.nz/national/118799041/tourist-charged-after-elderlyqueenstown-woman-killed-in-crash

Klapper, J. T. (1960). The effects of mass communications. Glencoe, IL: Free Press.

Krefting, L. (1991). Rigor in qualitative research: The assessment of trustworthiness. American journal of occupational therapy, 45(3), 214-222.

Kümpel, A.S., \& Haas, A. (2016). Framing gaming: The effects of media frames on perceptions of game (r) s. Games and Culture, 11(7-8), 720-744.

Lankford, S.V., \& Howard, D.R. (1994). Developing a tourism impact attitude scale. Annals of tourism research, 2I(1), 121-139.

Law, R., Chan, I. C. C., \& Wang, L. (2018). A comprehensive review of mobile technology use in hospitality and tourism. Journal of Hospitality Marketing \& Management, 27(6), 626-648

Law Commission. (2011). The News Media Meets 'New Media', Right, Responsibilities and Regulation in the digital age. Retrieved from

https://www.lawcom.govt.nz/sites/default/files/projectAvailableFormats/NZLC\%20IP 27.pdf 
Leech, B. L. (2002). Asking questions: Techniques for semi-structured interviews. Political Science \& Politics, 35(4), 665-668.

Li, C. (2020). Exploring the attitude of Chinese self-drive tourists towards driving safety in New Zealand (Master dissertation, Auckland University of Technology).

Lincoln, Y. S, \& Guba, E. A. (1985). Naturalistic Inquiry. Sage publications.

Lin, P. M., Fan, D. X., Zhang, H. Q., \& Lau, C. (2019). Spend less and experience more: Understanding tourists' social contact in the Airbnb context. International Journal of Hospitality Management, 83, 65-73.

Lin, Z., Chen, Y., \& Filieri, R. (2017). Resident-tourist value co-creation: The role of residents' perceived tourism impacts and life satisfaction. Tourism Management, 61, 436-442.

Lindsay, P., \& D, Norman. (1977). Human information processing; An introduction to psychology. (2 $2^{\text {nd }} \mathrm{Ed}$.). Academic press.

Litvin, S.W., Smith, W.W., \& McEwen, W.R. (2019). Not in my backyard: Personal politics and resident attitudes toward tourism. Journal of Travel Research, 59(4), 674-685.

Luhmann, N. (2000). The reality of the mass media. Stanford, CA: Stanford University Press.

Mabin, V. J. (1999). Goldratt's" Theory of Constraints" thinking processes: A systems methodology linking soft with hard. Victoria University of Wellington.

Mabin, V. J. (2019, July). The Thinking Processes (TP) Basics Workshop. [Paper presentation]. 2019 TOCICO International Conference, The Productivity Journey, Chicago, IL, USA.

Mabin, V. J., \& Balderstone, S. J. (2003). The performance of the theory of constraints methodology. International Journal of Operations \& Production Management, 23(6), 568-595.

Mabin, V. J., Daniell, E. J., \& Hislop, L. J. (2020). A practical guide to the theory of constraints. (8th ed.). Victoria University of Wellington.

Mabin, V. J., \& Davies, J. (2010). The TOC Thinking Process: Their nature and use-reflections and consolidation. Theory of constraints handbook. New York, The Unites States of America: McGraw Hill.

Mabin, V. J., Forgeson, S., \& Green L. (2001). Harnessing Resistance: Using the Theory of Constraints to Assist Change Management', Journal of European Industrial Training, 25. 168-191.

MacCannell, D. (1984). Reconstructed ethnicity tourism and cultural identity in third world communities. Annals of tourism research, 11(3), 375-391.

McNamara Research Group. (2018). NZTA Visiting Drivers Report, September-December 2017. McNamara Research Group, Wellington. 
Mahadevan, R. (2014). Understanding senior self-drive tourism in Australia using a contingency behavior model. Journal of Travel Research, 53(2), 252-259.

Marsh, B. (2002). Heuristics as social tools. New Ideas in Psychology, 20(1), 49-57.

MBIE Ministry of Business, Innovation and Employment. (2016a). Road infrastructure. Retrieved from https://www.mbie.govt.nz/assets/8fafb5e 9 a2/tourism-and-tourism-infrastructure-innew-zealand.pdf

MBIE Ministry of Business, Innovation and Employment. (2016b). Regional and seasonal dispersal of international tourists. Retrieved from https://www.mbie.govt.nz/assets/1f4279cc57/regional-and-seasonal-dispersalreport.pdf

MBIE Ministry of Business, Innovation and Employment., \& DOC Department of Conservation. (2019). New Zealand-Aotearoa Government Tourism Strategy. Retrieved from https://www.mbie.govt.nz/dmsdocument/5482-2019-new-zealand-aotearoagovernment-tourism-strategy-pdf

MBIE Ministry of Business, Innovation and Employment. (2019a). National Construction Pipeline Report. Retrieved from https://www.mbie.govt.nz/assets/national-construction-pipeline-report-2019.pdf

MBIE Ministry of Business, Innovation and Employment. (2019b). The tourism New Zealand report. Retrieved from https://www.mbie.govt.nz/dmsdocument/6974-the-tourism-new-zealand-report

McKercher, B. (2015). Tourism: The quest for the selfish. Challenges in tourism research, 8796.

McKercher, B., Weber, K., \& Du Cros, H. (2008). Rationalising inappropriate behaviour at contested sites. Journal of Sustainable Tourism, 16(4), 369-385.

McNally, W. (2020). Thinking with Flying Logic. Retrieved from http://flyinglogic.com/docs/Thinking $\% 20$ with\%20Flying\%20Logic.pdf

McLennan, C. L. J., Becken, S., \& Moyle, B. D. (2017). Framing in a contested space: Media reporting on tourism and mining in Australia. Current Issues in Tourism, 20(9), 960 980 .

$\mathrm{McNab}, \mathrm{H}$. (2015). Vigilante locals fed up with tourists' dangerous driving are snatching keys from hire cars in desperate bid to make road safer. Retrieved from https://www.dailymail.co.uk/news/article-2989714/Vigilante-locals-fed-touristsdangerous-driving-snatching-keys-hire-cars-desperate-bid-make-roads-safer.htm1

Medin, D. L., Busemeyer, J., \& Hastie, R. (1995). Decision Making from a Cognitive Perspective: Advances in Research and Theory (Vol. 32). Academic Press. 
Meng, F., \& Hudson, S. (2016). Drive Tourism in Rural Destination Development: Dual Perspectives from Industry Stakeholders and Potential Visitors. Travel and Tourism Research Association: Advancing Tourism Research Globally, 48.

MFE Ministry for the Environment. (2020). Problems with infrastructure project development. Retrieved from https://www.mfe.govt.nz/publications/rma/building-competitive-cities-reform-urbanand-infrastructure-planning-system-5/

Mkansi, M., \& Acheampong, E. A. (2012). Research philosophy debates and classifications: students' dilemma. Electronic Journal of Business Research Methods, 10(2), 132-140.

Mmopelwa, G., Kgathi, D. L., \& Molefhe, L. (2007). Tourists' perceptions and their willingness to pay for park fees: A case study of self-drive tourists and clients for mobile tour operators in Moremi Game Reserve, Botswana. Tourism management, 28(4), 1044-1056.

Monterrubio, C. (2016). The impact of spring break behaviour: An integrated threat theory analysis of residents' prejudice. Tourism Management, 54, 418-427.

Monterrubio, C. (2018). Tourist stereotypes and servers' attitudes: a combined theoretical approach. Journal of Tourism and Cultural Change, 16(1), 57-74.

Moore, R. M., \& Mabin, V. J. (2014). Reaching Community Consensus on Reforms for More Sustainable Urban Water Management Systems: The Case of Kāpiti, NZ. International Journal of Systems and Society (IJSS), 1(2), 22-38.

MOT Ministry of Transport. (2017). Overseas driver crashes. Retrieved from https://www.transport.govt.nz/assets/Uploads/Research/Documents/4ae59905fo/Over seas-drivers2017-Sep17.pdf

MOT Ministry of Transport. (2019a). Road safety questions and answers. Retrieved from https://www.transport.govt.nz/multi-modal/keystrategiesandplans/road-safetystrategy/questions-and-answers/

MOT Ministry of Transport. (2019b). Road to Zero road safety strategy. Retrieved from https://www.transport.govt.nz/assets/Import/Uploads/OurWork/Documents/e97c3b3d0d/Road-to-Zero-consultation-document-July2019.pdf

Motwani, J., Klein, D., \& Harowitz, R. (1996). The theory of constraints in services: part 1-the basics. Managing Service Quality, 6, 53-56.

Muresan, I., Oroian, C., Harun, R., Arion, F., Porutiu, A., Chiciudean, G., Todea, A., \& Lile, R. (2016). Local residents" attitude toward sustainable rural tourism development. Sustainability, 8(1), 100. 
Myllylathi, M. \& Treadwell, G. (2020). Trust in news in NZ. AUT research centre for Journalism, Media and Democracy (JMAD). Retrieved from Auckland University of Technology http:/openrepository.aut.ac.nz/bitstream/handle/10292/13356/Trust $\% 20 \mathrm{in} \% 20 \mathrm{News}$ $\% 20$ in $\% 20 \mathrm{NZ} \% 20$ report.pdf?sequence $=2 \&$ is Allowed $=\mathrm{y}$

Naor, M., Bernardes, E. S., \& Coman, A. (2013). Theory of Constraints: Is it a Theory and a Good one? International Journal of Production Research, 51 (2), 542-554.

Neuman, W. R., \& Guggenheim, L. (2011). The evolution of media effects theory: A six-stage model of cumulative research. Communication Theory, 2l(2), 169-196.

Newfield, B. (2015). Tourist drivers are 'terrifying'.

Retrieved from

http://www.stuff.co.nz/stuff-nation/12874031/Tourist-drivers-are-terrifying

New Zealand Government. (2015). The thirty year New Zealand infrastructure plan. Retrieved from

https://www.treasury.govt.nz/sites/default/files/2018-03/nip-aug15.pdf

New Zealand Legislation. (2020). Land transport (road user) rule 2004. Retrieved from http://www.legislation.govt.nz/regulation/public/2004/0427/1atest/DLM302188.htm1

Noy, C. (2008). Sampling knowledge: The hermeneutics of snowball sampling in qualitative research. International Journal of social research methodology, 11(4), 327-344.

Nyaupane, G.P., Timothy, D.J., \& Poudel, S. (2015). Understanding tourists in religious destinations: A social distance perspective. Tourism Management, 48, 343-353.

NZTA New Zealand Transport Agency. (2016). Safer Journeys Action Plan 2016-2020. Retrieved from

https://www.saferjourneys.govt.nz/assets/Safer-journeys-files/Safer-Journey-Action$\underline{\text { Plan-2016-2020.pdf }}$

NZTA New Zealand Transport Agency. (2017a). Overseas driver crash statistics: questions and answers. Retrieved from

https://www.nzta.govt.nz/assets/Uploads/15-239-Safer-Journeys-visiting-drivertoolkit-resource-QAs-v2.pdf

NZTA New Zealand Transport Agency. (2017b). Visitor drivers project data insights- 2016. Retrieved from https://nzta.govt.nz/assets/Safety/docs/safer-journeys/visiting-drivers-project-datainsights-2016.pdf

NZTA New Zealand Transport Agency. (2020). Initiatives. Retrieved from https://www.nzta.govt.nz/safety/nz-road-safety-strategy/visiting-driverspartnership/initiatives/ 
OCED. (2002). Glossary of statistical terms- Tourism.

Retrieved from

https://stats.oecd.org/glossary/detail.asp?ID=2725\#: :text=Tourism\%20is\%20defined $\% 20$ as $\% 20$ the,from $\% 20$ within $\% 20$ the $\% 20$ place $\% 20$ visited.

Olshewsky, T. M. (1983). Peirce's pragmatic maxim. Transactions of the Charles S. Peirce Society, $19(2), 199-210$.

Otara, A. (2011). Perception: A guide for managers and leaders. Journal of management and strategy, 2(3), 21-24.

Özkan, T., Lajunen, T., Chliaoutakis, J. E., Parker, D., \& Summala, H. (2006). Cross-cultural differences in driving skills: A comparison of six countries. Accident Analysis \& Prevention, 38(5), 1011-1018.

Pearce, P. L., \& Lee, U. I. (2005). Developing the travel career approach to tourist motivation. Journal of travel research, 43(3), 226-237.

Pearce, P. L., Moscardo, G., \& Ross, G. F. (1996). Tourism community relationships. Oxford: Pergamon.

Pearce, P. L., \& Stringer, P. F. (1991). Psychology and tourism. Annals of tourism Research, 18(1), 136-154.

Peterson, T. (2016). Could T-plates for tourists make a difference?

Retrieved from

http://www.stuff.co.nz/stuff-nation/14754653/Could-T-plates-for-tourists-make-adifference

Pickens, J. (2005). Attitudes and perceptions. Organizational behaviour in health care, 43-76.

Prideaux, B., \& Carson, D. (2003). A framework for increasing understanding of self-drive tourism markets. Journal of vacation marketing, 9(4), 307-313.

Prideaux, B., \& Carson, D. (2010). Drive tourism: Trends and emerging markets. Routledge.

Ratliff, K. A., \& Nosek, B.A. (2011). Negativity and Outgroup Biases in Attitude Formation and Transfer. Personality and Social Psychology Bulletin, 37(12), 1692-1703.

Rahman, S. U. (1998). Theory of constraints. International Journal of Operations \& Production Management, 18(4), 336-355.

Rahman, S. U. (2002). The theory of constraints' thinking process approach to developing strategies in supply chains. International Journal of Physical Distribution \& Logistics Management, 32(10), 809-828.

Rasoolimanesh, S. M., Jaafar, M., Kock, N., \& Ramayah, T. (2015). A revised framework of social exchange theory to investigate the factors influencing residents' perceptions. Tourism Management Perspectives, 16, 335-345. 
Reisinger, Y., \& Turner, L.W. (2002). Cultural differences between Asian tourist markets and Australian hosts, Part 1. Journal of travel Research, 40(3), 295-315.

Ronen, B. (2005). Special Issue on the theory of constraints-practice and research. Human Systems Management, 24(1), 1-2.

Rothman, R. A. (1978). Residents and transients: Community reaction to seasonal visitors. Journal of Travel Research, 16(3), 8-13.

Scheinkopf, L. (1999). Thinking for a change. Boca Raton, FL: CRC Press LLC.

Schragenheim, E. (1999). Management Dilemmas: The Theory of Constraints Approach to Problem Identification and Solutions, Boca Raton, FL: St.

Severin, W. J \& Tankard, J. W. (2014). Communication theories: Origins, methods, and uses in the mass media. Addison Wesley Longman.

Sharpley, R. (2014). Host perceptions of tourism: A review of the research. Tourism Management, 42, 37-49.

Sharpley, R. (2018). Tourism, tourists and society. Routledge.

Shone, M. C., Simmons, D. G., \& Fairweather, J. R. (2003). Community perceptions of tourism in Christchurch and Akaroa. Tourism Recreation Research and Education Centre. Lincoln University.

Simon, B., Mlicki, P., Johnston, L., \& Caetano, A. (1990). The effects of ingroup and outgroup homogeneity on ingroup favoritism, stereotyping, and overestimation of relative ingroup size. European Journal of Social Psychology, 20, 519-523.

Şimşit, Z. T., Günay, N.S., \& Vayvay, Ö. (2014). Theory of constraints: A literature review. Procedia-Social and Behavioral Sciences, 150, 930-936.

Sinclair-Maragh, G., Gursoy, D., \& Vieregge, M. (2015). Residents' perceptions toward tourism development: A factor-cluster approach. Journal of Destination Marketing \& Management, 4(1), 36-45.

Stats NZ. (2020). International Visitor Survey: Transport. Retrieved from http://nzdotstat.stats.govt.nz/wbos/Index.aspx?DataSetCode=TABLECODE7575\#

Stephan, W. G., \& Stephan, C.W. (2000). An integrated threat theory of prejudice. Reducing prejudice and discrimination, 23-45.

Teddlie, C., \& Tashakkori, A. (2009). Foundations of mixed methods research: Integrating quantitative and qualitative approaches in the social and behavioral sciences. Sage publication.

Thompson, C., \& Sabik, M. (2018). Allocation of attention in familiar and unfamiliar traffic scenarios. Transportation research part $F$ : traffic psychology and behaviour, 55, 188198. 
Thomason, P., Crompton, J. L., \& Dan Kamp, B. (1979). A study of the attitudes of impacted groups within a host community toward prolonged stay tourist visitors. Journal of travel research, $17(3), 2-6$.

TIA Tourism Industry Aotearoa., \& Rental Vehicle Association NZ. (2018). Rental Vehicle Operators, Code of practice for informing overseas drivers. Retrieved from http://www.drivesafe.org.nz/assets/Uploads/9ff844daf0/Rental-Operators-Code-ofPractice-v1.3.2-Sept2018.pdf

Todd, P. M., \& Gigerenzer, G. (2000). Précis of" Simple heuristics that make us smart". Behavioral and brain sciences, 23(5), 727-741.

TNZ Tourism New Zealand. (2017). Mood of the Nation Retrieved from https://www.tourismnewzealand.com/markets-stats/research/infographics/mood-ofthe-nation/

TNZ Tourism New Zealand. (2020). Self-drive Tours. Retrieved from https://www.newzealand.com/nz/feature/self-drive-tours/

Tripadvisor. (2019a). Don't drive if you not competent.

Retrieved from https://www.tripadvisor.co.nz/ShowTopic-g255104-i125-k13099059Dont drive if you not competent-New Zealand.html

Tripadvisor. (2019b). Help with plan change for Dec/Jan trip. Retrieved from https://www.tripadvisor.co.nz/ShowTopic-g255104-i125-k13080693Help With Plan Change for Dec Jan trip-New Zealand.html

Tsfati, Y., \& Cohen, J. (2012). Perceptions of media and media effects: The third person effect, trust in media and hostile media perceptions. Blackwell Publishing Ltd.

Tulasi, C. L., \& Rao, A. R. (2012). Review on theory of constraints. International Journal of Advances in Engineering \& Technology, 3(1), 334.

Tung, V.W.S., King, B.E.M., \& Tse, S. (2019). The Tourist Stereotype Model: Positive and Negative Dimensions. Journal of Travel Research, 59(1), 37-51.

Valk, J. H., Rashid, A. T., \& Elder, L. (2010). Using mobile phones to improve educational outcomes: An analysis of evidence from Asia. International Review of Research in Open and Distributed Learning, 11(1), 117-140.

Valkenburg, P. M., Peter, J., \& Walther, J. B. (2016). Media effects: Theory and research. Annual review of psychology, 67, 315-338.

Van Manen, M. (1977). Linking ways of knowing with ways of being practical. Curriculum inquiry, 6(3), 205-228. 
van Veelen, R., Otten, S., Cadinu, M., \& Hansen, N. (2016). An integrative model of social identification: Self-stereotyping and self-anchoring as two cognitive pathways. Personality and social psychology review, 20(1), 3-26.

Vasterman, P. L. (2005). Media-hype: Self-reinforcing news waves, journalistic standards and the construction of social problems. European Journal of Communication, 20(4), 508530 .

Vasterman, P. L., Yzermans, C. J., \& Dirkzwager, A. J. (2005). The role of the media and media hypes in the aftermath of disasters. Epidemiologic reviews, 27(1), 107-114.

Wahyuni, D. (2012). The research design maze: Understanding paradigms, cases, methods and methodologies. Journal of applied management accounting research, 10(1), 69-80.

Wang, W., Cheng, Q., Li, C., André, D., \& Jiang, X. (2019). A cross-cultural analysis of driving behavior under critical situations: A driving simulator study. Transportation research part F: traffic psychology and behaviour, 62, 483-493.

Ward, C., \& Berno, T. (2011). Beyond social exchange theory: Attitudes toward tourists. Annals of tourism research, 38(4), 1556-1569.

Watson, K. J., Blackstone, J. H., \& Gardiner, S. C. (2007). The evolution of a management philosophy: The theory of constraints. Journal of operations Management, 25(2), 387402.

Weaver, A. (2018). Statistics, publicity and industry intervention: Changing depictions of the Chinese outbound travel market in New Zealand newspapers. Tourism and Hospitality Research, 18(3), 367-377.

Woosnam, K. M. (2012). Using emotional solidarity to explain residents' attitudes about tourism and tourism development. Journal of Travel Research, 51(3), 315-327.

Wu, M. Y. (2015). Driving an unfamiliar vehicle in an unfamiliar country: Exploring Chinese recreational vehicle tourists' safety concerns and coping techniques in Australia. Journal of Travel Research, 54(6), 801-813.

Wu, M.Y., Pearce, P. L., \& Li, Q. (2018). Chinese behind the wheel: Factors affecting their satisfaction with international self-drive holidays. Journal of Destination Marketing \& Management, 9, 12-19.

Yeoman, I. (2019). Does New Zealand have too much tourism? Retrieved from https://www.wgtn.ac.nz/news/2019/05/does-new-zealand-have-too-much-tourism

Yeoman, I., \& McMahon-Beattie, U. (2020). Getting over Overtourism! Overtourism Debate. Emerald Publishing Limited.

Yilmaz, K. (2013). Comparison of quantitative and qualitative research traditions: Epistemological, theoretical, and methodological differences. European journal of education, 48(2), 311-325. 
Zhang, Y \& Kim, H. C. (2017, March 29-31). Road safety study in New Zealand: Road Crashes involving overseas Drivers. IPENZ Transportation Group Conference, Hamilton, New Zealand. 


\section{Appendices}

\section{Appendix 1: Interview guidelines}

\section{General questions}

1. Could you please tell me how long have you been in New Zealand and for what purposes?

2. Do you have much experience driving back home?

.... How often and how long would you drive on a daily and weekly basis?

a. .... When did you get your driving license?

3. Prior to arriving in New Zealand, have you had any experiences driving on an unfamiliar road or driving in another country?

4. What made you want to choose self-driving in New Zealand, rather than other travel methods?

5. Did you rent or purchase the vehicle? What type of vehicle is it? What was the procedure like?

\section{Why change}

1. Where have you self-drive travelled in NZ and for how long? In three words, how did it feel like?

2. In an ideal world, what should self-drive tourism be like in New Zealand? What did you expect prior to arrival?

3. How does the ideal self-drive tourism compare with your actual self-drive tourism experience here in New Zealand?

4. What is your goal as a self-drive tourist in New Zealand? ... What do you want to get out of your self-drive trip?

5. What do you consider to be the most important factors necessary for achieving that goal?

6. What are the conditions needed in order to achieve (....)?

7. What do you see are the obstacles that are preventing you from achieving your goal?

8. Do you have any thoughts on how we can overcome these obstacles? Do you know of any current or future plans to overcome these obstacles? 


\section{What to change?}

1. What are some specific problems (issues) you have encountered in New Zealand about self-drive tourism?

2. Can you highlight two or three most important/critical problems/undesirable issues?

3. Why do you identify the issue(s) as being undesirable or bad? How do these UDE's affect you?

4. What do you feel are really causing the problem or undesirable issues?

5. Are these problems or undesirable issues affecting your ability to achieve your goal? If yes: How do they affect your ability to achieve your goal?

6. Why do you think these problems or undesirable issues still exist? (ie why haven't they been resolved?)

7. Have you experienced any conflicts or dilemmas because of these undesirable issues or problems?

Please can you describe the conflicts or dilemmas.

Thank you very much for your time and for sharing your thoughts on this topic! 


\section{Government experts}

\section{Why change?}

1. How do you define self-drive tourism in New Zealand?

2. In an ideal world, what should self-drive tourism be like in New Zealand? Do you think we are achieving it?

3. What do you think is the goal for New Zealand/tourism industry in terms of self-drive tourism?

4. What do you consider to be the most important factors necessary for achieving that goal you just identified?

5. What are the conditions needed to achieve the factors you just described?

6. (How does the actual self-drive tourism compare with the ideal self-drive tourism in New Zealand?) How are we performing as far as meeting these conditions?

\section{What to change?}

1. What are any specific problems (issues) you have encountered or seen reported in New Zealand and/or region about self-drive tourism?

2. Can you highlight 2 or 3 most important/critical problems/undesirable issues?

3. Why do you identify the issue(s) as being undesirable or bad? In what ways? Why do you put up with it?

4. What do you feel really causes the problem or undesirable issues?

5. How do these problems or undesirable effects affect the government's ability to achieve the goal? (identified in Q3)

6. Why does these problems or undesirable issues still exist?

7. What are some potential solutions to fix these issues?

8. What is stopping you from fixing the issues?

9. What are some conflicts or dilemmas as a result of these undesirable issues or problems?

10. Please describe the conflicts or dilemmas? What is needed?

11. Are there any obstacles that are preventing NZ self-drive tourism to achieve the goal you just described?

12. In your opinion, how can we overcome these obstacles? Are there any current or future plans to overcome these obstacles?

Any other thoughts? 


\section{Tourism academic}

1. Why do you think tourists self-drive in New Zealand, when compared to other travelling methods?

What motivates them? ... What do you think is their most important goal?

2. What do you think are the most important factors necessary for self-drive tourists to achieve their goal?

3. What are the conditions needed to achieve the factors you just described?

4. What are some factors that may affect tourists' behaviour prior and during selfdriving on $\mathrm{NZ}$ roads?

5. What could be some undesirable effects/critical problems that result from these behaviours?

6. How do you think the media reports on tourist driving? - would you say they're neutral, positive or negative?

7. Do the media reports (e.g. news stories on 'bad tourist driving') affect self-drive tourists' behaviour. If so, how?

8. Do you think that media reports affect residents' perception and behaviour towards self-drive tourists in general?

...What about the government?

...If so, in what ways?

...What about when the locals are driving on road? Could there be a change of behaviour? (if so, why?)

9. How do locals' perceptions/behaviour affect tourists' attitude or/and behaviour to self-driving?

10. How do the government's actions (e.g. strategy plan, regulations) affect tourists" attitude or/and behaviour to self-driving?

11. Are there any potential conflicts or dilemma that might arise between tourists and locals on road while driving and in general?

12. Are there any other aspects that could affect how tourists drive? (e.g. obstacles, solutions)

.... Any other thoughts? 


\section{Media academic and journalist}

1. What is the goal that the media sector wants to achieve? ... What are their roles?

2. What do they need to do to achieve that goal?

3. In an ideal world, what should media reporting be like? ... How and what should they be reporting and communicate to people?

4. How does the ideal media reporting compare with the actual media reporting in NZ? (if there are any differences)

5. What do you think motivates journalist to author a story?

6. How would you describe the current media reporting and communication in NZ?

7. What kind of story do you think people like the most in this current era? Has there been a shift of taste? If yes, why? Do you think this is going to remain the same in the future?

8. Do you think is there a specific interest of topic or ethnicity group target by the media? If yes, why?

9. Do you think the news/stories reported by the media are reflecting the reality? (telling the truth)

10. Do you think there are any bias existing in media reporting and communication? If so, what are they? Are there any ways we could overcome them?

11. To what extent do you think that people's perception is influenced by the media stories?

12. What do you think are some immediate response and long-term effects after readers have read a new story? 


\section{Appendix 2: Information and consent form}

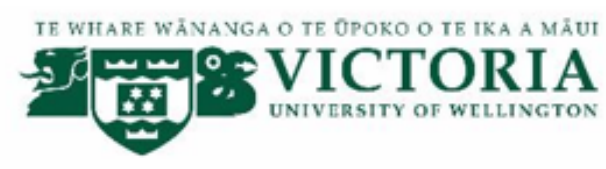

\section{Self-drive tourism study}

INFORMATION SHEET FOR PARTICIPANTS

You are invited to take part in this research. Please read this information before deciding whether or not to take part. If you decide to participate, thank you. If you decide not to participate, thank you for considering this request.

\section{Who am I?}

My name is Wing Cho Cheung (Joe) and I am a Master's student in Tourism Management at Victoria University of Wellington. This research project is work towards my Master's Thesis|

\section{What is the aim of the project?}

This project aims to investigate causes of the NZ's residents' negative perceptions of selfdrive tourism and potential mitigating strategies. Your participation will support this research by providing information and knowledge of self-drive tourism. This research has been approved by the Victoria University of Wellington Human Ethics Committee.

Application No: 0000028062

\section{How can you help?}

You have been invited to participate because of your personal experience on self-drive tourism in New Zealand. If you agree to take part I will interview you at a public space (e.g. café). I will ask you questions about your experience on self-driving in New Zealand. The interview will take approximately 45-60 minutes. I will audio record the interview with your permission and write it up later. You can choose to not answer any question or stop the interview at any time, without giving a reason. You can withdraw from the study by contacting me at any time after 24 hours of the interview. If you withdraw, the information you provided will be destroyed or returned to you.

\section{What will happen to the information you give?}

This research is confidential. This means that the researchers named below will be aware of your identity but the research data will be combined and your identity will not be revealed in any reports, presentations, or public documentation. 
Only my supervisors and I will read the notes or transcript of the interview. The interview transcripts, summaries and any recordings will be kept securely and destroyed by $31 / 7 / 2021$. What will the project produce?

The information from my research will be used in my Master's thesis and reports potentially to government bodies and/or academic publications and conference presentations.

\section{If you accept this invitation, what are your rights as a research participant?}

You do not have to accept this invitation if you don't want to. If you do decide to participate, you have the right to:

- choose not to answer any question;

- ask for the recorder to be turned off at any time during the interview

- withdraw from the study after 24 hours of the interview;

- ask any questions about the study at any time;

- receive a copy of your interview recording

- receive a copy of your interview notes

- be able to read any reports of this research by emailing the researcher to request a copy. 